\title{
Guidelines for Management of Ischaemic Stroke and Transient Ischaemic Attack 2008
}

\author{
The European Stroke Organisation (ESO) Executive Committee and the \\ ESO Writing Committee
}

\section{Key Words}

Stroke prevention - Educational measures - Stroke Unit • Imaging $\cdot$ Acute treatment $\cdot$ Rehabilitation

\begin{abstract}
This article represents the update of the European Stroke Initiative Recommendations for Stroke Management. These guidelines cover both ischaemic stroke and transient ischaemic attacks, which are now considered to be a single entity. The article covers referral and emergency management, Stroke Unit service, diagnostics, primary and secondary prevention, general stroke treatment, specific treatment including acute management, management of complications, and rehabilitation.
\end{abstract}

Copyright $\odot 2008$ S. Karger AG, Basel / Translation is only granted with permission from the publisher and ESO, please contact p.roth@karger.ch

\section{Foreword}

This article represents the update of the European Stroke Initiative (EUSI) Recommendations for Stroke Management, which were first published in this journal in 2000 [1,2], and subsequently translated into a number of languages including Spanish, Portuguese, Italian, German, Greek, Turkish, Lithuanian, Polish, Russian and Mandarin Chinese. The first update of the recommendations was published in 2003 [2]. In 2006, the EUSI decided that a larger group of authors should prepare the next update. In the meantime, a new European Stroke Society, the European Stroke Organisation (ESO), was established and took over the task of updating the guidelines. Accordingly, the new recommendations have been prepared by members of both the former EUSI Recommendations Writing Committee and the ESO (see appendix). The members of the Writing Group met in Heidelberg, Germany for 3 days in December 2007 to finalize the new
The ESO Writing Committee: Peter A. Ringleb, Heidelberg, Germany; Marie-Germaine Bousser, Paris, France; Gary Ford, Newcastle, UK; Philip Bath, Nottingham, UK; Michael Brainin, Krems, Austria; Valeria Caso, Perugia, Italy; Álvaro Cervera, Barcelona, Spain; Angel Chamorro, Barcelona, Spain; Charlotte Cordonnier, Lille, France; László Csiba, Debrecen, Hungary; Antoni Davalos, BarceIona, Spain; Hans-Christoph Diener, Essen, Germany; José Ferro, Lisbon, Portugal; Werner Hacke, Heidelberg, Germany; Michael Hennerici, Mannheim, Germany; Markku Kaste, Helsinki, Finland; Peter Langhorne, Glasgow, UK; Kennedy Lees, Glasgow, UK; Didier Leys, Lille, France; Jan Lodder, Maastricht, The Netherlands;
Hugh S. Markus, London, UK; Jean-Louis Mas, Paris, France; Heinrich P. Mattle, Bern, Switzerland; Keith Muir, Glasgow, UK; Bo Norrving, Lund, Sweden; Victor Obach, Barcelona, Spain; Stefano Paolucci, Rome, Italy; E. Bernd Ringelstein, Münster, Germany; Peter D. Schellinger, Erlangen, Germany; Juhani Sivenius, Kuopio, Finland; Veronika Skvortsova, Moscow, Russia; Katharina Stibrant Sunnerhagen, Göteborg, Sweden; Lars Thomassen, Bergen, Norway; Danilo Toni, Rome, Italy; Rüdiger von Kummer, Dresden, Germany; Nils Gunnar Wahlgren, Stockholm, Sweden; Marion F. Walker, Nottingham, UK; Joanna Wardlaw, Edinburgh, UK.

\section{KARGER}

Fax +41613061234 E-Mail karger@karger.ch www.karger.com
(C) 2008 S. Karger AG, Basel

$1015-9770 / 08 / 0255-0457 \$ 24.50 / 0$

Accessible online at:

www.karger.com/ced
Werner Hacke, MD, PhD

Department of Neurology, University of Heidelberg, Im Neuenheimer Feld 400

DE-69120 Heidelberg (Germany)

Tel. +496221568 210, Fax +496221565348

E-Mailwerner_hacke@med.uni-heidelberg.de 
Table 1. Classification of evidence for diagnostic and for therapeutic measures (from Brainin et al. [582])

Evidence classification scheme for a diagnostic measure

Class I A prospective study in a broad spectrum of persons with the suspected condition, using a 'gold standard' for case definition, where the test is applied in a blinded evaluation, and enabling the assessment of appropriate tests of diagnostic accuracy
Evidence classification scheme for a therapeutic intervention

An adequately powered, prospective, randomized, controlled clinical trial with masked outcome assessment in a representative population or an adequately powered systematic review of prospective randomized controlled clinical trials with masked outcome assessment in representative populations. The following are required:

a randomization concealment

b primary outcome(s) is/are clearly defined

c exclusion/inclusion criteria are clearly defined

d adequate accounting for dropouts and crossovers with numbers sufficiently low to have a minimal potential for bias

e relevant baseline characteristics are presented and substantially equivalent among treatment groups or there is appropriate statistical adjustment for differences

Class II A prospective study of a narrow spectrum of persons with the suspected condition, or a well-designed retrospective study of a broad spectrum of persons with an established condition (by 'gold standard') compared to a broad spectrum of controls, where test is applied in a blinded evaluation, and enabling the assessment of appropriate tests of diagnostic accuracy

Class III Evidence provided by a retrospective study where either persons with the established condition or controls are of a narrow spectrum, and where test is applied in a blinded evaluation

Prospective matched-group cohort study in a representative population with masked outcome assessment that meets a-e above or a randomized, controlled trial in a representative population that lacks one criterion a-e

All other controlled trials (including well-defined natural history controls or patients serving as own controls) in a representative population, where outcome assessment is independent of patient treatment

Class IV Evidence from uncontrolled studies, case series, case reports, or expert opinion
Evidence from uncontrolled studies, case series, case reports, or expert opinion recommendations. The members of the Writing Committee were assigned to six groups covering different topics. Each group was co-chaired by two colleagues, and included up to five further experts. In order to avoid bias or conflict of interest, none of the chairs had major involvement in clinical trials or studies discussed in their respective group.

These guidelines cover both ischaemic stroke and transient ischaemic attacks (TIAs), which are now considered to be a single entity. If recommendations differ for the two conditions, this will be explicitly mentioned; otherwise the recommendations are valid for both conditions. Separate guidelines exist or are being prepared for intracerebral haemorrhage [3] and subarachnoid haemorrhage. The classes of evidence and levels of recommendations used in these guidelines are defined according to the criteria of the European Federation of Neurological Societies (table 1,2). The article covers referral and emergency management, Stroke Unit service, diagnostics, primary and secondary prevention, general stroke treat- ment, specific treatment including acute management, management of complications, and rehabilitation.

Changes in the guidelines necessitated by new evidence will be continuously incorporated in the on-line version that can be found on the ESO website (www.esostroke.org). The reader is advised to check the online version when making important treatment decisions.

\section{Introduction}

Stroke is one of the leading causes of morbidity and mortality worldwide [4]. Large differences in incidence, prevalence and mortality have been noted between Eastern and Western Europe. This has been attributed to differences in risk factors, with higher levels of hypertension and other risk factors resulting in more severe stroke in Eastern Europe [5]. Notable regional variations have also been found within Western Europe. Stroke is the most important cause of morbidity and long-term disability in 
Europe, and demographic changes will result in an increase in both incidence and prevalence. It is also the second most common cause of dementia, the most frequent cause of epilepsy in the elderly, and a frequent cause of depression $[6,7]$.

Many guidelines and recommendations for stroke management or specific aspects of stroke care have been published during the last decade $[2,8-18]$. Most recently, the updated Helsingborg Declaration focused on standards of stroke care and research needs in Europe [19]. In the future, the global harmonization of stroke guidelines will be the focus of the World Stroke Organisation, supported by the ESO and other national and regional stroke societies.

\section{Public Awareness and Education}

Recommendations

- Educational programmes to increase awareness of stroke at the population level are recommended (Class II, Level B)

- Educational programmes to increase stroke awareness among professionals (paramedics/emergency physicians) are recommended (Class II, Level B)

The 'time is brain' concept means that treatment of stroke should be considered as an emergency. Thus, avoiding delay should be the major aim in the prehospital phase of acute stroke care. This has far-reaching implications in terms of recognition of signs and symptoms of stroke by the patient or by relatives or bystanders, the nature of first medical contact, and the means of transportation to hospital.

Delays during acute stroke management have been identified at different levels [20]:

- at the population level, due to failure to recognize the symptoms of stroke and contact emergency services

- at the level of the emergency services and emergency physicians, due to a failure to prioritize transport of stroke patients

- at the hospital level, due to delays in neuroimaging and inefficient in-hospital care.

A large amount of time is lost outside the hospital [21]: for stroke patients at a Portuguese university hospital this accounted for $82 \%$ of the delay in treatment [22]. Studies that identify demographic, social, cultural, behavioural and clinical factors associated with longer prehospital time may provide targets for educational campaigns [23, 24].

The interval from symptom onset to first call for medical help is the predominant part of prehospital delay [2528]. Major reasons for delayed contact include lack of awareness of stroke symptoms and recognition of their
Table 2. Definitions for levels of recommendation (from Brainin et al. [582])

\begin{tabular}{ll} 
Level A & $\begin{array}{l}\text { Established as useful/predictive or not useful/predic- } \\
\text { tive for a diagnostic measure or established as effec- } \\
\text { tive, ineffective or harmful for a therapeutic interven- } \\
\text { tion; requires at least one convincing Class I study or } \\
\text { at least two consistent, convincing Class II studies }\end{array}$ \\
\hline Level B & $\begin{array}{l}\text { Established as useful/predictive or not useful/predic- } \\
\text { tive for a diagnostic measure or established as effec- } \\
\text { tive, ineffective or harmful for a therapeutic inter- } \\
\text { vention; requires at least one convincing Class II } \\
\text { study or overwhelming Class III evidence }\end{array}$ \\
\hline Level C & $\begin{array}{l}\text { Established as useful/predictive or not useful/predic- } \\
\text { tive for a diagnostic measure or established as effec- } \\
\text { tive, ineffective or harmful for a therapeutic inter- } \\
\text { vention; requires at least two Class III studies }\end{array}$ \\
\hline GCP points & $\begin{array}{l}\text { Recommended best practice based on the experience } \\
\text { of the guideline development group. Usually based } \\
\text { on Class IV evidence indicating large clinical uncer- } \\
\text { tainty, such GCP points can be useful for health } \\
\text { workers }\end{array}$
\end{tabular}

severity, but also denial of the disease and the hope that symptoms would resolve. This suggests that educating the population to recognize stroke symptoms, and changing people's attitudes to acute stroke, may reduce the delay from stroke onset to emergency medical service (EMS) involvement.

Medical attention is rarely sought by the patient: in many cases contact is initially made by a family member [28-30]. Information and educational initiatives should therefore be directed both to persons at high risk of stroke and also to those around them.

Stroke awareness depends on demographic and sociocultural factors, and on personal medical knowledge. Knowledge of stroke warning signs varies considerably, depending on the symptoms, and is dependent on the way questions are asked (e.g. open-ended or multiplechoice questions [31, 32]).

While most people agree that stroke is an emergency, and that they would seek medical help immediately, in reality only up to $50 \%$ call EMS. In many cases, the first contact is with a family member or with a general practitioner; in some studies between $45 \%$ and $48 \%$ of patients were referred via a general practitioner [29, 33-36].

Most studies show that only approximately $33-50 \%$ of patients recognize their own symptoms as stroke. There are considerable discrepancies between theoretical knowledge of stroke and the reaction in case of an acute 
stroke. Some studies have shown that patients with better knowledge of stroke symptoms do not always arrive earlier at hospital.

The most frequently used sources of stroke information are mass media [37-39], and friends and relatives who have knowledge of stroke: only rarely is information derived from general practitioners or books [40-44]. The sources accessed vary with age: older people more often obtain information from health campaigns or their general practitioner, whereas younger people gain more information from TV [38-40].

Interventional studies have measured the effect of education on stroke knowledge. Eight non-randomized studies measured the impact of educational measures on prehospital time delay or thrombolysis use [45-52]. In six studies, the intervention was a combined educational programme directed at the public, paramedics and health professionals, while in two studies education was directed only to the population. Only the TLL Temple Foundation Stroke Project included a concurrent control group $[50,51]$. All studies had a pre-post design. Thrombolysis usage increased after education in the intervention group of the TLL study, but only for up to 6 months after intervention ended [51]. This suggests that public education has to be maintained to sustain stroke awareness in the population.

Education should also be directed to paramedics and emergency department (ED) staff to improve the accuracy of stroke identification and speed up transfer to the hospital [53]. Education of paramedics increases stroke knowledge, clinical and communication skills and decreases prehospital delays [54].

Educating medical students in basic stroke knowledge during their first year at medical school has been shown to be associated with a high degree of knowledge retention [55]. The value of postgraduate training is universally acknowledged, but training programmes for stroke specialists are still heterogeneous throughout Europe. To overcome such heterogeneity and to increase the number of specialists available for stroke care, some countries (e.g. France, UK) have developed and implemented national curricula. In contrast, other countries rely on training specialization within neurology training programmes. With a view towards harmonization of training, a European Masters' Programme for Stroke Medicine (http://www.donau-uni.ac.at/en/studium/strokemedicine/index.php), and annual Stroke Summer Schools (http://www.eso-stroke.org), have been established.

\section{Referral and Patient Transfer}

Recommendations

- Immediate EMS contact and priority EMS dispatch are recommended (Class II, Level B)

- Priority transport with advance notification to the receiving hospital (outside and inside hospital) is recommended (Class III, Level B)

- It is recommended that suspected stroke victims should be transported without delay to the nearest medical centre with a stroke unit that can provide ultra-early treatment (Class III, Level B)

- It is recommended that dispatchers and ambulance personnel be trained to recognise stroke using simple instruments such as the Face-Arm-Speech Test (Class IV, Good Clinical Practice - GCP)

- Immediate emergency room triage, clinical, laboratory and imaging evaluation, accurate diagnosis, therapeutic decision and administration of appropriate treatments at the receiving hospital are recommended (Class III, Level B)

- It is recommended that in remote or rural areas helicopter transfer should be considered in order to improve access to treatment (Class III, Level C)

- It is recommended that in remote or rural areas telemedicine should be considered in order to improve access to treatment (Class II, Level B)

- It is recommended that patients with suspected TIA be referred without delay to a TIA clinic or to a medical centre with a stroke unit that can provide expert evaluation and immediate treatment (Class III, Level B)

Successful care of the acute stroke victim begins with the recognition by both the public and health professionals [56] that stroke is an emergency, like acute myocardial infarction (MI) or trauma. However, in practice the majority of ischaemic stroke patients do not receive recombinant tissue plasminogen activator (rtPA) because they do not reach the hospital soon enough [22, 36, 57, 58]. Emergency care of the acute stroke victim depends on a four-step chain:

- rapid recognition of, and reaction to, stroke signs and TIAs

- immediate EMS contact and priority EMS dispatch

- priority transport with notification of the receiving hospital

- immediate emergency room triage, clinical, laboratory and imaging evaluation, accurate diagnosis, and administration of appropriate treatments at the receiving hospital.

Once stroke symptoms are suspected, patients or their proxies should call EMS. The EMS system should have an electronic validated algorithm of questions to diagnose stroke during the phone interview $[33,59]$. The ambulance dispatchers and paramedics should be able to di- 
agnose stroke using simple instruments such as the Face-Arm-Speech Test [60]. They should also be able to identify and provide appropriate help for patients who need urgent care because of early complications or comorbidities of stroke, such as impaired consciousness, seizures, vomiting, or haemodynamic instability.

Suspected stroke victims should be transported without delay to the nearest medical centre with a stroke unit that can provide ultra-early treatment. Patients with onset of stroke symptoms within $3 \mathrm{~h}$ should be given priority in evaluation and transportation [20]. In each community, a network of stroke units or, if stroke units are not yet available, a network of medical centres providing organized acute stroke care should be implemented and publicized to the general population, health professionals and the emergency transport systems [61, 62].

If a doctor receives a call or consultation from a patient with suspected stroke, he or she should recommend or arrange transportation, preferably through the EMS system, to the nearest hospital with a stroke unit providing organized acute stroke care and ultra-early treatment. Ambulance dispatchers should inform the stroke unit and describe the patient's clinical status. Proxies who can describe symptom onset or the patient's medical history should accompany the patient.

Few intervention studies have examined the impact of decreasing the delay from symptom onset to arrival at the hospital and making ultra-early treatment accessible for a larger proportion of patients. Most such studies have used a before-and-after intervention design, were neither randomized nor masked with respect to intervention or evaluation of outcome, and lacked concurrent controls $[23,53]$. The types of interventions included education and training programmes, helicopter transfer, telemedicine and reorganisation of pre-hospital and in-hospital protocols for acute stroke patients.

Direct presentation to the ED via ambulance or EMS transportation is the fastest way of referral $[28,53,63-$ 65]. Helicopter transport can reduce the time between referral and hospital arrival $[66,67]$, and also promotes access to thrombolytic therapy in remote and rural areas [68]. In mixed rural and urban areas, air and ground distances can be compared using simple rules [69]. No studies have compared air and ground transport specifically in stroke patients. In one study, predominantly in trauma patients, ground ambulances provided shorter arrival

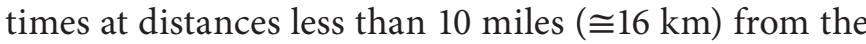
hospital; even with only short delays in despatching air transport, air was faster only for distances longer than 45 miles $(\cong 72 \mathrm{~km})[70]$. One economic study showed that helicopter transfer of patients with suspected acute ischaemic stroke for potential thrombolysis is cost-effective [71].

Telemedicine using a bidirectional video-conferencing equipment to provide health services or assist health care personnel at distant sites is a feasible, valid and reliable means of facilitating thrombolysis delivery to patients in distant or rural hospitals, where timely air or ground transportation is not feasible. The quality of treatment, complication rates, and short- and long-term outcomes are similar for acute stroke patients treated with rtPA via a telemedicine consultation at local hospitals and those treated in academic centres [72-81].

Activation of the stroke code as a special infrastructure with immediate calling of a stroke neurologist at a stroke unit and priority transfer of the patients to this centre is effective in increasing the percentage of patients treated with thrombolysis, and also in shortening prehospital delays [82, 83].

Recent community and hospital-based studies demonstrated a high risk of stroke immediately after a TIA [6, 84]. Observational studies showed that urgent evaluation at a TIA clinic and immediate initiation of treatment reduces stroke risk after TIA $[85,86]$. This underlines the need for urgent referral of TIA for expert evaluation and immediate treatment.

\section{Emergency Management}

Recommendations

- Organisation of pre-hospital and in-hospital pathways and systems for acute stroke patients is recommended (Class III, Level C)

- Ancillary tests, as outlined in table 3, are recommended (Class IV, GCP)

In-hospital delay may account for $16 \%$ of total time lost between stroke onset and computed tomography (CT) [22]. Reasons for in-hospital delays are:

- a failure to identify stroke as an emergency

- inefficient in-hospital transport

- delayed medical assessment

- delay in imaging

- uncertainty in administering thrombolysis [20, 21, 24].

Stroke care pathways may allow care to be organized more effectively, although a meta-analysis [87] did not support their routine implementation. Such pathways may reduce delays in door-to-medical department time, 
Table 3. Emergency diagnostic tests in acute stroke patients

\begin{aligned} & \hline In all patients \\ & 1 Brain imaging: CT or MRI \\ & 2 ECG \\ & 3 Laboratory tests \\ & - Complete blood count and platelet count, \\ & prothrombin time or INR, partial thromboplastin time \\ & - Serum electrolytes, blood glucose \\ & - C-reactive protein or sedimentation rate \\ & - Hepatic and renal chemical analysis \\ & \hline When indicated \\ & 4 Extracranial and transcranial Duplex/Doppler ultrasound \\ & 5 MRA or CTA \\ & 6 Diffusion and perfusion MR or perfusion CT \\ & 7 Echocardiography (transthoracic and/or transoesophageal) \\ & 8 Chest X-ray \\ & 9 Pulse oximetry and arterial blood gas analysis \\ & 10 Lumbar puncture \\ & 11 EEG \\ & 12 Toxicology screen \\ & \hline\end{aligned}

door-to-imaging time [88, 89], door-to-needle time [89] and, where appropriate, door-to-arteriography time.

Acute stroke care has to integrate EMS, ED staff and stroke care specialists. Communication and collaboration between EMS, ED staff, radiologists, clinical laboratories and neurologists are important for rapid delivery of treatment [90-92]. Integrating EMS and ED staff was found to increase the use of thrombolysis [93]. Hospitals where patients are not delivered directly to a stroke unit should implement a system allowing the ED to pre-notify the acute stroke team as soon as possible. Routinely informing ED physicians or stroke physicians during transport has been shown to be associated with reduced inhospital delay [82, 94-96], increased use of thrombolysis $[93,94]$, decreased length of hospital stay [96] and decreased in-hospital mortality [93].

A stroke recognition instrument with high diagnostic accuracy is necessary for rapid triage [97]; stroke mimics like migraine and seizure might be a problem [98, 99]. Stroke recognition instruments such as Face-Arm-Speech Test and Recognition of Stroke in the Emergency Room (ROSIER) can assist the correct recognition of stroke by ED personnel $[60,98,100]$.

A neurologist or stroke physician should be involved in the acute care of stroke patients and available in the ED [99]. Comparing neurologist care to non-neurologist care, two studies in the USA found that neurologists perform more extensive and costly testing, but that their patients had lower in-hospital and 90-day mortality rates and were less dependent on discharge [101, 102]. However, this might not be true for other countries like the UK, where most stroke physicians are not neurologists, but are still highly skilled in management of patients with TIA and stroke.

Reorganisation of stroke wards can help to avoid bottlenecks and unnecessary in-hospital transport. Brain imaging facilities should be relocated in or next to the stroke unit or the ED, and stroke patients should have priority access [90]. Neuroradiologists should be notified as early as possible [90]. In a Finnish study, in-hospital delays were decreased considerably by moving the CT scanner close to the ED and by implementing a pre-notifying system [95]. Thrombolysis should be started in the CT room or in the vicinity of the scanner. Finally, an arteriography suite should be readily accessible if endovascular treatment is required.

Written care protocols for acute stroke patients should be available; centres using such protocols were found to have higher thrombolysis rates [93]. Implementing a continuous quality improvement scheme can also diminish in-hospital delays $[81,103]$. Benchmarks should be defined and measured for individual institutions, and have recently been developed for regional networks and countries. As a minimum requirement, door-to-imaging and door-to-treatment times should be monitored.

While only a minority of stroke patients present in an immediately life-threatening condition, many have significant physiological abnormalities or comorbidities. Symptoms and signs which may predict later complications such as space-occupying infarction, bleeding, or recurrent stroke, and medical conditions such as hypertensive crisis, co-existing MI, aspiration pneumonia, or cardiac and renal failure, must be recognized early. Stroke severity should be assessed by trained staff using the National Institutes of Health Stroke Scale (NIHSS) [104].

Initial examination should include:

- observation of breathing and pulmonary function

- early signs of dysphagia, preferably with a validated assessment form [105]

- evaluation of concomitant heart disease

- assessment of blood pressure (BP) and heart rate

- determination of arterial oxygen saturation using infrared pulse oximetry if available.

Simultaneously, blood samples for clinical chemistry, glucose, coagulation and haematology studies should be drawn, and a venous line inserted. The examination should be supplemented by a medical history that includes risk factors for stroke and cardiac disease, medications, conditions that may predispose to bleeding complications, 
and markers for stroke mimics. A history of drug abuse, oral contraceptive use, infection, trauma or migraine may give important clues, particularly in young patients.

\section{Stroke Services and Stroke Units}

Recommendations

- It is recommended that all stroke patients should be treated in a stroke unit (Class I, Level A)

- It is recommended that healthcare systems ensure that acute stroke patients have access to high-technology medical and surgical stroke care when required (Class III, Level B)

- The development of clinical networks, including telemedicine, is recommended to expand access to high-technology specialist stroke care (Class II, Level B)

\section{Providing Stroke Services}

All acute stroke patients require specialist multidisciplinary care delivered in a stroke unit, and selected patients will require additional high-technology interventions. Health services need to establish the infrastructure to deliver these interventions to all patients who require them: the only reason for excluding patients from stroke units is if their condition does not warrant active management. Recent consensus documents $[11,106]$ have defined the roles of primary and comprehensive stroke centres (table 4).

Primary stroke centres are defined as centres with the necessary staffing, infrastructure, expertise and programmes to provide appropriate diagnosis and treatment for most stroke patients. Some patients with rare disorders, complex stroke, or multi-organ disease may need more specialized care and resources that are not available in primary stroke centres.

Comprehensive stroke centres are defined as centres that provide both appropriate diagnosis and treatment for most stroke patients, and also high-technology medical and surgical care (new diagnostic and rehabilitation methods, specialized tests, automatic monitoring of multiple physiological parameters, interventional radiology, vascular surgery, neurosurgery).

The organisation of clinical networks using telemedicine is recommended to facilitate treatment options not previously available at remote hospitals. Administration of rtPA during telemedicine consultations is feasible and safe [107]. Clinical networks using telemedicine systems achieve increased use of rtPA $[80,108]$ and better stroke care and clinical outcomes [80].

Guidelines for Management of Ischaemic

Stroke and TIA 2008
Table 4. Recommended requirements for centres managing acute stroke patients

\begin{tabular}{ll}
\hline Primary stroke centre & Comprehensive stroke centre \\
\hline $\begin{array}{l}\text { Availability of 24-hour CT scan- } \\
\text { ning }\end{array}$ & MRI/MRA/CTA \\
\hline $\begin{array}{l}\text { Established stroke treatment } \\
\text { guidelines and operational proce- } \\
\text { dures, including intravenous } \\
\text { rtPA protocols 24/7 }\end{array}$ & $\begin{array}{l}\text { Transoesophageal echocardi- } \\
\text { ography }\end{array}$ \\
\hline
\end{tabular}

Close co-operation of neurolo-
gists, internists and rehabilitation
experts

Specially trained nursing person- Transcranial Doppler sonogranel phy

Early multidisciplinary stroke Extracranial and intracranial unit rehabilitation including speech therapy, occupational therapy and physical therapy colour-coded duplex sonography

Neurosonological investigations Specialized neuroradiological, within $24 \mathrm{~h}$ (extracranial Doppler neurosurgical and vascular sonography) surgical consultation (including telemedicine networks)

Transthoracic echocardiography Carotid surgery

Laboratory examinations (in- Angioplasty and stenting cluding coagulation parameters)

Monitoring of blood pressure, Automated monitoring of ECG, oxygen saturation, blood pulse oximetry, blood pressure glucose, body temperature

Automated ECG monitoring at Established network of rehabedside bilitation facilities to provide a continuous process of care, including collaboration with outside rehabilitation centre

\section{Stroke Unit Care}

An updated systematic review has confirmed significant reductions in death (3\% absolute reduction), dependency (5\% increase in independent survivors) and the need for institutional care ( $2 \%$ reduction) for patients treated in a stroke unit, compared with those treated in general wards. All types of patients, irrespective of gender, age, stroke subtype and stroke severity, appear to benefit from treatment in stroke units [61, 109]. These results have been confirmed in large observational studies of routine practice [110-112]. Although stroke unit care is more costly than treatment on general neurologi-

Cerebrovasc Dis 2008;25:457-507 
cal or medical wards, it reduces post-acute inpatient care costs $[113,114]$ and is cost-effective [115-118].

A stroke unit consists of a discrete area of a hospital ward that exclusively or nearly exclusively takes care of stroke patients and is staffed by a specialist multidisciplinary team [61]. The core disciplines of the team are medicine, nursing, physiotherapy, occupational therapy (OT), speech and language therapy (SLT) and social work [119]. The multidisciplinary team should work in a coordinated way through regular meetings to plan patient care. Programmes of regular staff education and training should be provided [119]. The typical components of stroke unit care in stroke unit trials [119] were:

- medical assessment and diagnosis, including imaging (CT, magnetic resonance imaging, MRI), and early assessment of nursing and therapy needs

- early management, consisting of early mobilization, prevention of complications, and treatment of hypoxia, hyperglycaemia, pyrexia and dehydration

- ongoing rehabilitation, involving coordinated multidisciplinary team care, and early assessment of needs after discharge.

Both acute and comprehensive stroke units admit patients acutely and continue treatment for several days. Rehabilitation stroke units admit patients after 1-2 weeks and continue treatment and rehabilitation for several weeks if necessary. Most of the evidence for effectiveness comes from trials of comprehensive stroke units and rehabilitation stroke units $[61,120]$. Mobile stroke teams, which offer stroke care and treatment in a number of wards, probably do not influence important outcomes and cannot be recommended [121]. Such teams have usually been established in hospitals where stroke units were not available.

The stroke unit should be of sufficient size to provide specialist multidisciplinary care for the whole duration of hospital admission. Smaller hospitals may achieve this with a single comprehensive unit, but larger hospitals may require a pathway of care incorporating separate acute and rehabilitation units.

\section{Diagnostics}

\section{Diagnostic Imaging}

Recommendations

- In patients with suspected TIA or stroke, urgent cranial CT (Class I), or alternatively MRI (Class II), is recommended (Level A)
- If MRI is used, the inclusion of diffusion-weighted imaging (DWI) and $\mathrm{T}_{2}{ }^{*}$-weighted gradient echo sequences is recommended (Class II, Level A)

- In patients with TIA, minor stroke or early spontaneous recovery, immediate diagnostic work-up, including urgent vascular imaging (ultrasound, CT angiography, or MR angiography), is recommended (Class I, Level A)

Imaging of the brain and supplying vessels is crucial in the assessment of patients with stroke and TIA. Brain imaging distinguishes ischaemic stroke from intracranial haemorrhage and stroke mimics, and identifies the type and often also the cause of stroke; it may also help to differentiate irreversibly damaged tissue from areas that may recover, thus guiding emergency and subsequent treatment, and may help to predict outcome. Vascular imaging may identify the site and cause of arterial obstruction, and identifies patients at high risk of stroke recurrence.

\section{General Principles}

Stroke victims should have clear priority over other patients for brain imaging, because time is crucial. In patients with suspected TIA or stroke, general and neurological examination followed by diagnostic brain imaging must be performed immediately on arrival at the hospital so that treatment can be started promptly. Investigation of TIA is equally urgent because up to $10 \%$ of these patients will suffer stroke within the next $48 \mathrm{~h}$. Immediate access to imaging is facilitated by pre-hospital notification and good communication with the imaging facility: stroke services should work closely with the imaging department to plan the best use of resources.

Diagnostic imaging must be sensitive and specific in detecting stroke pathology, particularly in the early phase of stroke. It should provide reliable images, and should be technically feasible in acute stroke patients. Rapid, focused neurological assessment is helpful to determine which imaging technique should be used. Imaging tests should take into account the patient's condition [122]; for example, up to $45 \%$ of patients with severe stroke may not tolerate MR examination because of their medical condition and contraindications [123-125].

\section{Imaging in Patients with Acute Stroke}

Patients admitted within $3 \mathrm{~h}$ of stroke onset may be candidates for intravenous thrombolysis [126]; CT is usually sufficient to guide routine thrombolysis. Patients arriving later may be candidates for trials testing extended time windows for thrombolysis or other experimental reperfusion strategies. 
Plain CT is widely available, reliably identifies most stroke mimics, and distinguishes acute ischaemic from haemorrhagic stroke within the first 5-7 days [127-129]. Immediate CT scanning is the most cost-effective strategy for imaging acute stroke patients [130], but is not sensitive for old haemorrhage. Overall, CT is less sensitive than MRI, but equally specific, for early ischaemic changes [131]. Two thirds of patients with moderate to severe stroke have visible ischaemic changes within the first few hours [131-135], but no more than $50 \%$ of patients with minor stroke have a visible relevant ischaemic lesion on CT, especially within the first few hours of stroke [136]. Training in identification of early ischaemic changes on CT $[135,137,138]$, and the use of scoring systems [134], improve detection of early ischaemic changes.

Early CT changes in ischaemic stroke include decreases in tissue X-ray attenuation, tissue swelling with effacement of cerebrospinal fluid spaces, and arterial hyperattenuation, which indicates the presence of intraluminal thrombus with high specificity [139]. CT is highly specific for the early identification of ischaemic brain damage $[132,140,141]$. The presence of early signs of ischaemia on CT should not exclude patients from thrombolysis within the first $3 \mathrm{~h}$, though patients with a hypoattenuating ischaemic lesion which exceeds one third of the middle cerebral artery (MCA) territory may benefit less from thrombolysis [126, 134, 135, 142, 143].

Some centres prefer to use MRI as first-line routine investigation for acute stroke. MRI with DWI has the advantage of higher sensitivity for early ischaemic changes than CT [131]. This higher sensitivity is particularly useful in the diagnosis of posterior circulation stroke and lacunar or small cortical infarctions. MRI can also detect small and old haemorrhages for a prolonged period with $\mathrm{T}_{2}{ }^{*}$ (gradient echo) sequences [144]. However, DWI can be negative in patients with definite stroke [145].

Restricted diffusion on DWI, measured by the apparent diffusion coefficient (ADC), is not $100 \%$ specific for ischaemic brain damage. Although abnormal tissue on DWI often proceeds to infarction it can recover, which indicates that DWI does not show only permanently damaged tissue $[146,147]$. Tissue with only modestly reduced ADC values may be permanently damaged; there is as yet no reliable ADC threshold to differentiate dead from still viable tissue $[148,149]$. Other MRI sequences $\left(\mathrm{T}_{2}\right.$, FLAIR, $\left.\mathrm{T}_{1}\right)$ are less sensitive in the early detection of ischaemic brain damage.

MRI is particularly important in acute stroke patients with unusual presentations, stroke varieties, and uncom- mon aetiologies, or in whom a stroke mimic is suspected but not clarified on CT. If arterial dissection is suspected, MRI of the neck with fat-suppressed $\mathrm{T}_{1}$-weighted sequences is required to detect intramural haematoma.

MRI is less suited for agitated patients or for those who may vomit and aspirate. If necessary, emergency life support should be continued while the patient is being imaged, as patients (especially those with severe stroke) may become hypoxic while supine during imaging [125]. The risk of aspiration is increased in the substantial proportion of patients who are unable to protect their airway.

Perfusion imaging with CT or MRI and angiography may be used in selected patients with ischaemic stroke (e.g. unclear time window, late admission) to aid the decision on whether to use thrombolysis, although there is no clear evidence that patients with particular perfusion patterns are more or less likely to benefit from thrombolysis [150-153]. Selected patients with intracranial arterial occlusion may be candidates for intra-arterial thrombolysis, although there is only limited evidence to support this $[154,155]$. Patients with combined obstructions of the internal carotid artery (ICA) and MCA have less chance of recovering with intravenous thrombolysis than patients with isolated MCA obstructions [156]. In patients with MCA trunk occlusions, the frequency of severe extracranial occlusive disease in the carotid distribution is high $[157,158]$.

Mismatch between the volume of brain tissue with critical hypoperfusion (which can recover after reperfusion) and the volume of infarcted tissue (which does not recover even with reperfusion) can be detected with MR diffusion/perfusion imaging with moderate reliability [159], but this is not yet a proven strategy for improving the response to thrombolysis up to $9 \mathrm{~h}$ [160]. There is disagreement on how to best identify irreversible ischaemic brain injury and to define critically impaired blood flow $[150,153,161]$. Quantification of MR perfusion is problematic [162], and there are widely differing associations between perfusion parameters and clinical and radiological outcomes [150]. Decreases in cerebral blood flow on CT are associated with subsequent tissue damage [151, 152], but the therapeutic value of CT perfusion imaging is not yet established. Although infarct expansion may occur in a high proportion of patients with mismatch, up to $50 \%$ of patients without mismatch may also have infarct growth and so might benefit from tissue salvage $[153,163]$. The 'imaging/clinical' mismatch, i.e. the mismatch between the extent of the lesion seen on DWI or $\mathrm{CT}$ and the extent of the lesion as expected from the severity of the neurological deficit, has produced mixed re- 
sults $[164,165]$. Hence, neither perfusion imaging with CT or MRI nor the mismatch concept can be recommended for routine treatment decisions.

Microhaemorrhages are present on $\mathrm{T}_{2}{ }^{*} \mathrm{MRI}$ in up to $60 \%$ of patients with haemorrhagic stroke, and are associated with older age, hypertension, diabetes, leukoaraiosis, lacunar stroke, and amyloid angiopathy [166]. The incidence of symptomatic intracranial haemorrhage following thrombolysis in ischaemic stroke patients was not increased in those having cerebral microbleeds on pretreatment $\mathrm{T}_{2}{ }^{*}$-weighted MRI [167].

Vascular imaging should be performed rapidly to identify patients with tight symptomatic arterial stenosis who could benefit from endarterectomy or angioplasty. Non-invasive imaging with colour-coded duplex imaging of the extracranial and intracranial arteries, CT angiography (CTA), or contrast-enhanced MR angiography (CE-MRA) is widely available. These approaches are relatively risk-free, whereas intra-arterial angiography has a $1-3 \%$ risk of causing stroke in patients with symptomatic carotid lesions $[168,169]$. Digital subtraction angiography may be needed in some circumstances, for example when other tests have been inconclusive.

Carotid ultrasound, MRA and CTA visualise carotid stenosis. Systematic reviews and individual patient data meta-analysis indicate that CE-MRA is the most sensitive and specific non-invasive imaging modality for carotid artery stenosis, closely followed by Doppler ultrasound and CTA, with non-contrast MRA being the least reliable $[170,171]$.

Some data suggest that vertebrobasilar TIA and minor stroke are associated with a high risk of recurrent stroke [172]. Extracranial vertebral ultrasound diagnosis is useful, but intracranial ultrasound of the vertebrobasilar system can be misleading due to low specificity. Limited data suggest that contrast-enhanced MRA and CTA offer better non-invasive imaging of the intracranial vertebral and basilar arteries [173].

Unlike other imaging modalities ultrasound is fast, non-invasive and can be administered using portable machines. It is therefore applicable to patients unable to co-operate with MRA or CTA [158]. However, Doppler studies alone often provide only limited information, are investigator dependent and require skilled operators, although they allow repeated measurements at the bedside.

Transcranial Doppler ultrasound (TCD) is useful for the diagnosis of abnormalities in the large cerebral arteries at the base of the skull. However, between 7 and 20\% of acute stroke patients, particularly elderly individuals and those from certain ethnic groups do not have an adequate acoustic window $[174,175]$. This problem can be considerably reduced by using ultrasound contrast agents, which also allow perfusion studies in the acute phase [176-178] and continuous monitoring of cerebral haemodynamic responses [179]. The combination of ultrasound imaging techniques and MRA reveals excellent results equal to digital subtraction angiography [180]. Cerebral reactivity and cerebral autoregulation are impaired in patients with occlusive extracerebral arterial disease (particularly carotid stenosis and occlusion) and inadequate collateral supply, who are at increased risk of recurrent stroke [181, 182]. TCD is the only technique that detects circulating intracranial emboli [183], which are particularly common in patients with large artery disease. In patients with symptomatic carotid artery stenoses, they are a strong independent predictor of early recurrent stroke and TIA [184], and have been used as a surrogate marker to evaluate antiplatelet agents [185]. TCD microbubble detection can be used to identify a right-to-left shunt which mainly results from a patent foramen ovale (PFO) [186].

\section{Imaging in Patients with TIA, Minor Non-Disabling}

Stroke, and Stroke with Spontaneous Recovery

Patients presenting with TIA are at high risk of early recurrent stroke (up to $10 \%$ in the first $48 \mathrm{~h}$ ) [187]. They therefore need urgent clinical diagnosis to treat associated general abnormalities, modify active risk factors and identify specific treatable causes, particularly arterial stenosis and other embolic sources. Vascular imaging is a priority in those patients with TIA or minor stroke, more than in those with major stroke in whom surgery is not going to be of benefit in the short term. Immediate preventive treatment will reduce stroke, disability and death $[86,188]$. Simple clinical scoring systems can be used to identify patients at particularly high risk [187]. Patients with minor non-disabling stroke and rapid spontaneous clinical recovery are also at high risk of recurrent stroke [58].

Patients with widely varying brain pathology may present with transient neurological deficits indistinguishable from TIA. CT reliably detects some of these pathologies (e.g. intracerebral haemorrhage, subdural haematoma, tumours) [130], but others (e.g. multiple sclerosis, encephalitis, hypoxic brain damage, etc.) are better identified on MRI, while others (e.g. acute metabolic disturbances) are not visible at all. Intracranial haemorrhage is a rare cause of TIA. 
Between $20-50 \%$ of patients with TIAs may have acute ischaemic lesions on DWI $[145,189,190]$. These patients are at increased risk of early recurrent disabling stroke [190]. However, there is currently no evidence that DWI provides better stroke prediction than clinical risk scores [191]. The risk of recurrent disabling stroke is also increased in patients with TIA and an infarct on CT [192].

The ability of DWI to identify very small ischaemic lesions may be particularly helpful in patients presenting late or in patients with mild non-disabling stroke, in whom the diagnosis may be difficult to establish on clinical grounds [131]. $\mathrm{T}_{2}{ }^{*} \mathrm{MRI}$ is the only reliable method to identify haemorrhages after the acute phase, when blood is no longer visible on CT [144].

\section{Other Diagnostic Tests}

Recommendations

- In patients with acute stroke and TIA, early clinical evaluation, including physiological parameters and routine blood tests, is recommended (Class I, Level A)

- For all stroke and TIA patients, a sequence of blood tests is recommended (tables 3 and 5)

- It is recommended that all acute stroke and TIA patients should have a 12-lead electrocardiography (ECG). In addition, continuous ECG recording is recommended for ischaemic stroke and TIA patients (Class I, Level A)

- It is recommended that for stroke and TIA patients seen after the acute phase, 24-hour Holter ECG monitoring should be performed when arrhythmias are suspected and no other causes of stroke are found (Class I, Level A)

- Echocardiography is recommended in selected patients (Class III, Level B)

\section{Cardiac Evaluation}

Cardiac and ECG abnormalities are common in acute stroke patients [193]. In particular, prolonged heart rate corrected QT interval, ST depression, and T wave inversion are prevalent in acute ischaemic stroke, especially if the insular cortex is involved $[194,195]$. Hence, all acute stroke and TIA patients should have a 12-channel ECG.

Cardiac monitoring should be conducted routinely after an acute cerebrovascular event to screen for serious cardiac arrhythmias. It is unclear whether continuous ECG recording at the bedside is equivalent to Holter monitoring for the detection of atrial fibrillation (AF) in acute stroke patients. Holter monitoring is superior to routine ECG for the detection of AF in patients anticipated to have thromboembolic stroke with sinus rhythm [196]; however, serial 12-channel ECG might be sufficient
Table 5. Subsequent laboratory tests, according to the type of stroke and suspected aetiology

\begin{tabular}{ll}
\hline All patients & $\begin{array}{l}\text { Full blood count, electrolytes, glu- } \\
\text { cose, lipids, creatinine, CRP or } \\
\text { erythrocyte sedimentation rate }\end{array}$ \\
\hline $\begin{array}{l}\text { Cerebral venous } \\
\text { thrombosis, } \\
\text { hypercoagulopathy }\end{array}$ & $\begin{array}{l}\text { Thrombophilia screen, AT3, factor } \\
\text { 2, 5, mutations, factor 8, protein C, } \\
\text { protein S, antiphospholipid anti- } \\
\text { bodies, d-dimer, homocysteine }\end{array}$ \\
\hline Bleeding disorder & $\begin{array}{l}\text { INR, activated partial thrombo- } \\
\text { plastin time, fibrinogen, etc. }\end{array}$ \\
\hline $\begin{array}{l}\text { Vasculitis or } \\
\text { systemic disorder }\end{array}$ & $\begin{array}{l}\text { Cerebral spinal fluid, autoantibody } \\
\text { screen, specific antibodies or PCR } \\
\text { for HIV, syphilis, borreliosis, tuber- } \\
\text { culosis, fungi, illicit drug screening, } \\
\text { blood culture }\end{array}$ \\
\hline $\begin{array}{l}\text { Suspected genetic disor- } \\
\text { ders, e.g. mitochondrial } \\
\text { disorders (MELAS), } \\
\text { CADASIL, sickle cell } \\
\text { disease, Fabry disease, } \\
\text { multiple cavernoma, etc. }\end{array}$ & Genetic testing \\
\hline
\end{tabular}

to detect new AF in a stroke unit setting [197]. A recent systematic review found that new AF was detected by Holter ECG in $4.6 \%$ of patients with recent ischaemic stroke or TIA, irrespective of baseline ECG and clinical examination [198]. Extended duration of monitoring, prolonged event loop recording, and confining Holter monitoring to patients with non-lacunar stroke may improve detection rates [199].

Echocardiography can detect many potential causes of stroke [200], but there is controversy about the indications for, and type of, echocardiography in stroke and TIA patients. Transoesophageal echocardiography (TOE) has been claimed to be superior to transthoracic echocardiography for the detection of potential cardiac sources of embolism [201], independent of age [202].

Echocardiography is particularly required in patients with:

- evidence of cardiac disease on history, examination, or ECG

- suspected cardiac source of embolism (e.g. infarctions in multiple cerebral or systemic arterial territories)

- suspected aortic disease

- suspected paradoxical embolism

- no other identifiable causes of stroke. 
Table 6. NNT to prevent one stroke per year in patients who undergo surgery for ICA stenosis (modified from Hankey and Warlow [583] and Rothwell et al. [339])

\begin{tabular}{ll}
\hline Disease & $\begin{array}{l}\text { NNT to avoid } \\
\text { one stroke/year }\end{array}$ \\
\hline Asymptomatic $(60-99 \%)$ & 85 \\
Symptomatic $(70-99 \%)$ & 27 \\
Symptomatic $(50-69 \%)$ & 75 \\
Symptomatic $(>50 \%)$ in men & 45 \\
Symptomatic $(>50 \%)$ in women & 180 \\
Symptomatic $(>50 \%)>75$ years & 25 \\
Symptomatic $(>50 \%)<65$ years & 90 \\
Symptomatic $(>50 \%)<2$ weeks after the event & 25 \\
Symptomatic $(>50 \%)>12$ weeks after the event & 625 \\
Symptomatic $(\leq 50 \%)$ & No benefit \\
\hline
\end{tabular}

All percentages reflect the NASCET method.

Transthoracic echocardiography is sufficient for evaluation of mural thrombi, particularly in the apex of the left ventricle; this technique has $>90 \%$ sensitivity and specificity for ventricular thrombi after MI [203]. TOE is superior for evaluation of the aortic arch, left atrium, and atrial septum [200]. It also allows risk stratification for further thromboembolic events in patients with AF [204].

The role of cardiac CT and cardiac MRI in the detection of embolic sources in stroke patients has not been evaluated systematically.

\section{Blood Tests}

Blood tests required on emergency admission are listed in table 3. Subsequent tests depend on the type of stroke and suspected aetiology (table 5).

\section{Primary Prevention}

The aim of primary prevention is to reduce the risk of stroke in asymptomatic people. Relative risk (RR), absolute risk (AR), odds ratio (OR), numbers needed to treat (NNT) to avoid one major vascular event per year, and numbers needed to harm to cause one major complication per year, are provided for each intervention in tables 6-8.

\section{Management of Vascular Risk Factors}

\section{Recommendations}

- BP should be checked regularly. It is recommended that high BP should be managed with lifestyle modification and individualized pharmacological therapy (Class I, Level A) aiming at normal levels of $120 / 80 \mathrm{~mm} \mathrm{Hg}$ (Class IV, GCP). For prehypertensive (120-139/80-90 $\mathrm{mm} \mathrm{Hg}$ ) with congestive heart failure, MI, diabetes, or chronic renal failure antihypertensive medication is indicated (Class 1, Level A)

- Blood glucose should be checked regularly. It is recommended that diabetes should be managed with lifestyle modification and individualized pharmacological therapy (Class IV, Level C). In diabetic patients, high BP should be managed intensively (Class I, Level A) aiming for levels below 130/80 mm $\mathrm{Hg}$ (Class IV, Level C). Where possible, treatment should include an angiotensin-converting enzyme inhibitor or angiotensin receptor antagonist (Class I, Level A)

- Blood cholesterol should be checked regularly. It is recommended that high blood cholesterol (e.g. LDL >150 mg/dl; $3.9 \mathrm{mM}$ ) should be managed with lifestyle modification (Class IV, Level C) and a statin (Class I, Level A)

- It is recommended that cigarette smoking be discouraged (Class III, Level B)

- It is recommended that heavy use of alcohol be discouraged (Class III, Level B)

- Regular physical activity is recommended (Class III, Level B)

- A diet low in salt and saturated fat, high in fruit and vegetables and rich in fibre is recommended (Class III, Level B)

- Subjects with an elevated body mass index are recommended to take a weight-reducing diet (Class III, Level B)

- Antioxidant vitamin supplements are not recommended (Class I, Level A)

- Hormone replacement therapy is not recommended for the primary prevention of stroke (Class I, Level A)

A healthy lifestyle, consisting of abstinence from smoking, low-normal body mass index, moderate alcohol consumption, regular exercise and healthy diet, is associated with a reduction in ischaemic stroke (RR 0.29; 95\% CI 0.14-0.63) [205].

\section{High Blood Pressure}

A high $(>120 / 80 \mathrm{~mm} \mathrm{Hg})$ BP is strongly and directly related to vascular and overall mortality without evidence of any threshold [206]. Lowering BP substantially reduces stroke and coronary risks, depending on the magnitude of the reduction [207-209]. BP should be lowered to 140/85 $\mathrm{mm} \mathrm{Hg}$ or below [210]; antihypertensive treatment should be more aggressive in diabetic patients (see below) [211]. A combination of two or more antihypertensive agents is often necessary to achieve these targets.

Most studies comparing different drugs do not suggest that any class is superior [207, 208, 212]. However, the LIFE (Losartan Intervention for Endpoint reduction in 
Table 7. RR reduction (RRR), AR reduction (ARR) and NNT to avoid one major vascular event per year in patients with antithrombotic therapy (modified from CAPRIE Steering Committee [319], Halkes et al. [322], Hankey and Warlow [583])

\begin{tabular}{llllr}
\hline Disease & Treatment & $\begin{array}{l}\text { RRR } \\
\%\end{array}$ & $\begin{array}{l}\text { ARR } \\
\% / \text { year }\end{array}$ & $\begin{array}{l}\text { NNT to avoid } \\
\text { 1 event/year }\end{array}$ \\
\hline Non-cardioembolic & Aspirin/PCB & 13 & 1.0 & 100 \\
ischaemic stroke or TIA & Aspirin + DIP/PCB & 28 & 1.9 & 53 \\
& Aspirin + DIP/aspirin & 18 & 1.0 & 104 \\
& Clop/PCB & 23 & 1.6 & 62 \\
Atrial fibrillation & Clop/aspirin & 10 & 0.6 & 166 \\
(primary prevention) & Warfarin/PCB & 62 & 2.7 & 37 \\
Atrial fibrillation & Aspirin/PCB & 22 & 1.5 & 67 \\
(secondary prevention) & Warfarin/PCB & 67 & 8 & 13 \\
& Aspirin/PCB & 21 & 2.5 & 40 \\
\hline
\end{tabular}

$\mathrm{PCB}=$ Placebo Clop = clopidogrel; DIP = dipyridamole.

Table 8. RRR, ARR and NNT to avoid one major vascular event per year in patients with risk factor modifications (modified from Yusuf et al. [288], PROGRESS Collaborative Group [290], Amarenco et al. [294], Hankey and Warlow [583])

\begin{tabular}{|c|c|c|c|c|}
\hline Clinical condition & Treatment & $\begin{array}{l}\text { RRR } \\
\%\end{array}$ & $\begin{array}{l}\text { ARR } \\
\% / \text { year }\end{array}$ & $\begin{array}{l}\text { NNT to avoid } \\
1 \text { event/year }\end{array}$ \\
\hline General population with increased BP & Antihypertensive & 42 & 0.4 & 250 \\
\hline General population with increased vascular risk & ACE inhibitor & 22 & 0.65 & 154 \\
\hline Post-stroke/TIA with increased BP & Antihypertensive & 31 & 2.2 & 45 \\
\hline Post-stroke/TIA with normal BP & ACE inhibitor \pm diuretic & 24 & 0.85 & 118 \\
\hline \multirow[t]{2}{*}{ Post-stroke/TIA } & Statins & 16 & 0.44 & 230 \\
\hline & Smoking cessation & 33 & 2.3 & 43 \\
\hline
\end{tabular}

hypertension) trial found that losartan was superior to atenolol in hypertensive patients with left ventricular hypertrophy (NNT to prevent stroke 270) [213, 214]. Similarly, the ALLHAT (Antihypertensive and Lipid-Lowering treatment to prevent Heart Attack) trial found that chlorthalidone was more effective than amlodipine and lisinopril [215]. Beta-blockers may still be considered an option for initial and subsequent antihypertensive treatment [210]. In elderly subjects, controlling isolated systolic hypertension (systolic BP $>140 \mathrm{~mm} \mathrm{Hg}$ and diastolic $\mathrm{BP}<90 \mathrm{~mm} \mathrm{Hg}$ ) is beneficial $[208,216]$.

\section{Diabetes Mellitus}

There is no evidence that improving glucose control reduces stroke [217]. In diabetic patients, BP should be lowered to below 130/80 $\mathrm{mm} \mathrm{Hg}$ [211]. Treatment with a statin reduces the risk of major cardiovascular (CV) events, including stroke [218-220].

Guidelines for Management of Ischaemic Stroke and TIA 2008

\section{Hyperlipidaemia}

In a review of 26 statin trials (95,000 patients), the incidence of stroke was reduced from 3.4 to $2.7 \%$ [221]. This was due mainly to a reduction in non-fatal stroke, from 2.7 to $2.1 \%$. The review included the Heart Protection Study which was, in part, a secondary prevention trial [222]; this trial found an excess of myopathy of one per 10,000 patients treated per annum [222]. There are no data to suggest that statins prevent stroke in patients with low-density lipoprotein cholesterol below $150 \mathrm{mg} / \mathrm{dl}$ (3.9 $\mathrm{mM})$.

\section{Cigarette Smoking}

Observational studies have shown cigarette smoking to be an independent risk factor for ischaemic stroke [223] in both men and women [224-228]. Spousal cigarette smoking may be associated with an increased stroke risk [229]. A meta-analysis of 22 studies indicates that

Cerebrovasc Dis 2008;25:457-507 
smoking doubles the risk of ischaemic stroke [230]. Subjects who stop smoking reduce this risk by $50 \%$ [225]. Making workplaces smoke-free would result in considerable health and economic benefits [231].

\section{Alcohol Consumption}

Heavy alcohol drinking ( $>60 \mathrm{~g} /$ day) increases the risk of ischaemic stroke (RR 1.69; 95\% CI 1.34-2.15) and haemorrhagic stroke (RR 2.18; 95\% CI 1.48-3.20). In contrast, light consumption ( $<12 \mathrm{~g} /$ day $)$ is associated with a reduction in all stroke (RR 0.83; 95\% CI 0.75-0.91) and ischaemic stroke (RR 0.80; 95\% CI 0.67-0.96), and moderate consumption (12-24 g/day) with a reduction in ischaemic stroke (RR 0.72; 95\% CI 0.57-0.91) [232]. Red wine consumption is associated with the lowest risk in comparison with other beverages [233]. BP elevation appears to be an important intermediary in the relation between alcohol consumption and stroke [234].

\section{Physical Activity}

In a meta-analysis of cohort and case-control studies, physically active individuals had a lower risk of stroke or death than those with low activity (RR 0.73; 95\% CI 0.670.79). Similarly, moderately active individuals had a lower risk of stroke, compared with those who were inactive (RR 0.80 ; 95\% CI 0.74-0.86) [235]. This association is mediated, in part, through beneficial effects on body weight, $\mathrm{BP}$, serum cholesterol, and glucose tolerance. Leisurebased physical activity ( $2-5 \mathrm{~h}$ per week) has been independently associated with a reduced severity of ischaemic stroke at admission and better short-term outcome [236].

\section{Diet}

Fruit, Vegetable, and Fish Intake

In observational studies, high fruit and vegetable intake was associated with a decreased risk of stroke, compared with lower intake (RR 0.96 for each increment of 2 servings/day; 95\% CI 0.93-1.00) [237]. The risk of ischaemic stroke was lower in people who consumed fish at least once per month (RR 0.69; 95\% CI 0.48-0.99) [238]. Whole grain intake was associated with a reduction in CV disease (OR 0.79; 95\% CI 0.73-0.85) but not stroke [239]. Dietary calcium intake from dairy products was associated with lower mortality from stroke in a Japanese population [240]. However, in a further study there was no interaction between the intake of total fat or cholesterol, and stroke risk in men [241].

In a randomized controlled trial in women, dietary interventions did not reduce the incidence of coronary events and stroke despite there being an $8.2 \%$ reduction of total fat intake and an increased consumption of vegetables, fruits and grains [242].

\section{Body Weight}

A high body mass index $(\geq 25)$ is associated with an increased risk of stroke in men [243] and women [244], mainly mediated by concomitant arterial hypertension and diabetes. Abdominal adiposity is a risk factor for stroke in men but not women [245]. Although weight loss reduces BP [246], it does not lower stroke risk [247].

\section{Vitamins}

A low intake of vitamin D is associated with an increased risk of stroke [248], but supplements of calcium plus vitamin D do not reduce the risk of stroke [249]. Supplements of tocopherol and beta carotene do not reduce stroke [250]. A meta-analysis of trials with vitamin E supplementation found that it might increase mortality when used at high doses ( $\geq 400$ IU/day) [251].

High homocysteine levels are associated with increased stroke risk (OR 1.19; 95\% CI 1.05-1.31) [252]. Since folic acid fortification of enriched grain products was mandated by the US Food and Drug Administration, there has been a reduction in stroke mortality rates, in contrast to countries without fortification [253]. A metaanalysis concluded that folic acid supplementation can reduce the risk of stroke (RR 0.82; 95\% CI 0.68-1.00) [254]; the benefit was greatest in trials with long treatment durations or larger homocysteine-lowering effects, and in countries where grain was not fortified.

\section{Postmenopausal Oestrogen Replacement Therapy}

Stroke rates rise rapidly in women after the menopause. However, in an analysis based on a 16-year followup of 59,337 postmenopausal women participating in the Nurses' Health Study, there was only a weak association between stroke and oestrogen replacement [255]. According to the HERS II trial, hormone replacement in healthy women is associated with an increased risk of ischaemic stroke [256]. A Cochrane systematic review [257] found hormone replacement therapy to be associated with an increased risk of stroke (RR 1.44; 95\% CI 1.10-1.89). A secondary analysis of the Women's Health Initiative randomized controlled trial suggests that the risk of stroke is increased with hormone replacement therapy only in women with prolonged hormone use ( $>5$ years; RR 1.32; 95\% CI 1.12-1.56) [258, 259]. 


\section{Antithrombotic Therapy}

\section{Recommendations}

- Low-dose aspirin is recommended in women aged 45 years or more who are not at increased risk for intracerebral haemorrhage and who have good gastrointestinal tolerance; however, its effect is very small (Class I, Level A)

- It is recommended that low-dose aspirin may be considered in men for the primary prevention of MI; however, it does not reduce the risk of ischaemic stroke (Class I, Level A)

- Antiplatelet agents other than aspirin are not recommended for primary stroke prevention (Class IV, GCP)

- Aspirin may be recommended for patients with non-valvular AF who are younger than 65 years and free of vascular risk factors (Class I, Level A)

- Unless contraindicated, either aspirin or an oral anticoagulant (international normalized ratio, INR, 2.0-3.0) is recommended for patients with non-valvular AF who are aged 6575 years and free of vascular risk factors (Class I, Level A)

- Unless contraindicated, an oral anticoagulant (INR 2.0-3.0) is recommended for patients with non-valvular AF who are aged $>75$, or who are younger but have risk factors such as high $\mathrm{BP}$, left ventricular dysfunction, or diabetes mellitus (Class I, Level A)

- It is recommended that patients with AF who are unable to receive oral anticoagulants should be offered aspirin (Class I, Level A)

- It is recommended that patients with AF who have mechanical prosthetic heart valves should receive long-term anticoagulation with a target INR based on the prosthesis type, but not less than INR 2-3 (Class II, Level B)

- Low-dose aspirin is recommended for patients with asymptomatic ICA stenosis $>50 \%$ to reduce their risk of vascular events (Class II, Level B)

\section{Low-Risk Subjects}

Six large randomized trials have evaluated the benefits of aspirin for the primary prevention of CV events in men and women (47,293 on aspirin, 45,580 controls) with a mean age of 64.4 years [260-265]. Aspirin reduced coronary events and CV events, but not stroke, CV mortality, or all-cause mortality [266]. In women, aspirin reduced stroke (OR 0.83; 95\% CI 0.70-0.97) and ischaemic stroke (OR 0.76; 95\% CI 0.63-0.93) [267]. In a separate study in 39,876 healthy women aged 45 years or more, aspirin reduced stroke (RR 0.83; 95\% CI 0.69-0.99) and ischaemic stroke (RR 0.76; 95\% CI 0.63-0.93), and caused a non-significant increase in haemorrhagic stroke, over 10 years; it did not reduce the risk of fatal or nonfatal MI, or CV death [268].

No data are currently available on the use of other antiplatelet agents in primary prevention in low-risk subjects.

\section{Subjects with Vascular Risk Factors}

A systematic review of randomized studies comparing antithrombotic agents with placebo in patients with elevated $\mathrm{BP}$ and no prior $\mathrm{CV}$ disease showed that aspirin did not reduce stroke or total CV events [267]. In the CHARISMA (Clopidogrel for High Atherothrombotic Risk and Ischemic Stabilization, Management, and Avoidance) trial, the combination of aspirin and clopidogrel was less effective than aspirin alone in the subgroup of patients with multiple vascular risk factors but no ischaemic event [269].

\section{Large Artery Atheroma}

Patients with atherosclerotic arterial disease have an increased risk of MI, stroke, and CV death. Aspirin reduces $\mathrm{MI}$ in patients with asymptomatic carotid artery disease [270], and reduces stroke after carotid artery surgery [271].

\section{Atrial Fibrillation}

$\mathrm{AF}$ is a strong independent risk factor for stroke. A meta-analysis of randomized trials with at least 3 months' follow-up showed that antiplatelet agents reduced stroke (RR 0.78; 95\% CI 0.65-0.94) in patients with non-valvular AF [272]. Warfarin (target INR 2.0-3.0) is more effective than aspirin at reducing stroke (RR 0.36; 95\% CI 0.26-0.51) [272]. As the risk of stroke in people with AF varies considerably, risk stratification should be used to determine whether patients should be given oral anticoagulation, aspirin or nothing [14]. Oral anticoagulation is more effective in patients with $\mathrm{AF}$ who have one or more risk factors, such as previous systemic embolism, age over 75 years, high BP or poor left ventricular function [14]. In the meta-analysis described above, absolute increases in major extracranial haemorrhage were less than the absolute reductions in stroke [272]. The WASPO (Warfarin vs. Aspirin for Stroke Prevention in Octogenarians) [273] and BAFTA (Birmingham Atrial Fibrillation Treatment of the Aged) [274] trials showed that warfarin was safe and effective in older individuals. The ACTIVE W (Atrial fibrillation Clopidogrel Trial with Irbesartan for prevention of Vascular Events) study found that the combination of aspirin and clopidogrel was less effective than warfarin and had a similar bleeding rate [275].

Patients with a prosthetic heart valve, with or without AF, should receive long-term anticoagulation with a target INR based on the prosthesis type (bio-prosthetic valves: INR 2.0-3.0; mechanical valves: INR 3.0-4.0 [276]). 


\section{Carotid Surgery and Angioplasty}

\section{Recommendations}

- Carotid surgery is not recommended for asymptomatic individuals with significant carotid stenosis (North American Symptomatic Carotid Endarterectomy Trial - NASCET 6099\%), except in those at high risk of stroke (Class I, Level C)

- Carotid angioplasty, with or without stenting, is not recommended for patients with asymptomatic carotid stenosis (Class IV, GCP)

- It is recommended that patients should take aspirin before and after surgery (Class I, Level A)

Trials of carotid surgery for asymptomatic carotid stenosis have concluded that although surgery reduces the incidence of ipsilateral stroke (RR 0.47-0.54) and any stroke, the absolute benefit is small (approximately $1 \%$ per annum) [277-279], whereas the perioperative stroke or death rate is $3 \%$. Medical management is the most appropriate option for most asymptomatic subjects; only centres with a perioperative complication rate of $3 \%$ or less should contemplate surgery. Patients with a high risk of stroke (men with stenosis of more than $80 \%$ and a life expectancy of more than 5 years) may derive some benefit from surgery in appropriate centres [277, 279]. All stenoses are graded following the NASCET method (distal stenosis) [280].

Carotid endarterectomy (CEA) is effective in younger patients, and possibly also in older individuals, but does not appear to benefit women [277]. Patients with occlusion of the ICA contralateral to the operated carotid artery do not benefit from CEA [281, 282]. The risk of ipsilateral stroke increases with the degree of stenosis [281, 283]; CEA appears to be effective irrespective of the degree of ipsilateral stenosis over the range of 60-99\% [277]. CEA is not beneficial for asymptomatic patients who have a life expectancy of less than 5 years. Aspirin should not be stopped in patients undergoing carotid surgery [284]. Patients should be followed-up by the referring physician after surgery. There are no data from randomized trials about the benefits and risks of carotid angioplasty, compared with CEA, in asymptomatic patients [285].

\section{Secondary Prevention}

\section{Optimal Management of Vascular Risk Factors}

Recommendations

- It is recommended that BP be checked regularly. BP lowering is recommended after the acute phase, including in patients with normal BP (Class I, Level A)
- It is recommended that blood glucose should be checked regularly. It is recommended that diabetes should be managed with lifestyle modification and individualized pharmacological therapy (Class IV, GCP)

- In patients with type 2 diabetes who do not need insulin, treatment with pioglitazone is recommended after stroke (Class III, Level B)

- Statin therapy is recommended in subjects with non-cardioembolic stroke (Class I, Level A)

- It is recommended that cigarette smoking be discouraged (Class III, Level C)

- It is recommended that heavy use of alcohol be discouraged (Class IV, GCP)

- Regular physical activity is recommended (Class IV, GCP)

- A diet low in salt and saturated fat, high in fruit and vegetables, and rich in fibre is recommended (Class IV, GCP)

- Subjects with an elevated body mass index are recommended to adopt a weight-reducing diet (Class IV, Level C)

- Antioxidant vitamin supplements are not recommended (Class I, Level A)

- Hormone replacement therapy is not recommended for the secondary prevention of stroke (Class I, Level A)

- Sleep-disordered breathing such as obstructive sleep apnoea (OSA) is recommended to be treated with continuous positive airway pressure breathing (Class III, Level GCP)

- It is recommended that endovascular closure of PFO be considered in patients with cryptogenic stroke and high-risk PFO (Class IV, GCP)

\section{High Blood Pressure}

A meta-analysis of seven randomized controlled trials showed that antihypertensive drugs reduced stroke recurrence after stroke or TIA (RR 0.76; 95\% CI 0.63-0.92) [286]. This analysis included the PATS (indapamide, a diuretic), HOPE (ramipril) and PROGRESS (perindopril, with or without indapamide) studies [287-290]. The reduction in stroke occurs regardless of BP and type of stroke [290]. Hence, BP should be lowered and monitored indefinitely after stroke or TIA. The absolute target BP level and reduction are uncertain and should be individualized, but benefit has been associated with an average reduction of about $10 / 5 \mathrm{~mm} \mathrm{Hg}$, and normal $\mathrm{BP}$ levels have been defined as $<120 / 80 \mathrm{~mm} \mathrm{Hg}$ [291]. However, BP should not be lowered intensively in patients with suspected haemodynamic stroke or in those with bilateral carotid stenosis. The angiotensin receptor antagonist eprosartan may be more effective than the calcium channel blocker nitrendipine [292].

\section{Diabetes Mellitus}

The prospective, double-blind PROactive trial randomized 5,238 patients with type 2 diabetes and a history of macrovascular disease to pioglitazone or placebo. In patients with previous stroke $(\mathrm{n}=486$ in the piogli-
ESO Executive Committee and ESO Writing Committee 
tazone group, $\mathrm{n}=498$ in the placebo group), there was a trend towards benefit with pioglitazone for the combined end point of death and major vascular events (HR 0.78; 95\% CI $0.60-1.02 ; \mathrm{p}=0.067)$. In a secondary analysis, pioglitazone reduced fatal or nonfatal stroke (HR 0.53; 95\% CI 0.34-0.85; $\mathrm{p}=0.0085)$ and CV death, nonfatal MI, or nonfatal stroke (HR 0.72; 95\% CI 0.52-1.00; $\mathrm{p}=$ 0.0467) [293].

\section{Hyperlipidaemia}

In the SPARCL (Stroke Prevention by Aggressive Reduction in Cholesterol Levels) trial, statin therapy with atorvastatin reduced stroke recurrence (HR 0.84; 95\% CI 0.71-0.99) [294], while in the Heart Protection Study simvastatin reduced vascular events in patients with prior stroke, and reduced stroke in patients with other vascular disease (RR 0.76) [222]. Neither trial assessed efficacy by stroke subtype, and SPARCL did not include patients with presumed cardioembolic stroke [222, 294]. The risk of haemorrhagic stroke was slightly increased in both trials $[222,294]$. The AR reduction achieved with statin therapy is low (NNT 112-143 for 1 year). Statin withdrawal at the acute stage of stroke may be associated with an increased risk of death or dependency [295].

\section{Cigarette Smoking}

There are no specific data in secondary prevention. See 'Primary Prevention'.

\section{Diet}

Overweight

There are no specific data in secondary prevention. See 'Primary Prevention'. Weight loss may be beneficial after stroke as it lowers BP [246].

\section{Vitamins}

Beta carotene increased the risk of $\mathrm{CV}$ death in a metaanalysis of primary and secondary prevention trials (RR 1.10; 95\% CI 1.03-1.17) [296]. Vitamin E supplementation does not prevent vascular events [297]. Fat-soluble antioxidant supplements may increase mortality [298].

Vitamins which lower homocysteine (folate, $\mathrm{B}_{12}, \mathrm{~B}_{6}$ ) do not appear to reduce stroke recurrence and may increase vascular events [299-302], but further trials are ongoing [303].

\section{Sleep-Disordered Breathing}

Sleep-disordered breathing represents both a risk factor and a consequence of stroke and is linked with poorer long-term outcome and increased long-term stroke mortality [304]. More than $50 \%$ of stroke patients have sleep-disordered breathing, mostly in the form of OSA. This can improve spontaneously after stroke, but may need treatment. Continuous positive airway pressure is the treatment of choice for OSA. Oxygen and other forms of ventilation may be helpful in other (e.g. central) forms of SDB.

\section{Patent Foramen Ovale}

Case reports and case control studies indicate an association between the presence of PFO and cryptogenic stroke in both younger and older stroke patients [305, 306]. Two population-based studies pointed in the same direction but did not confirm a significant association $[307,308]$. In patients with PFO alone the overall risk of recurrence is low. However, when the PFO is combined with an atrial septal aneurysm, an Eustachian valve, a Chiari network, or in patients who have suffered more than one stroke the risk of recurrence can be substantial [309]. Endovascular closure of PFOs with or without septal aneurysms is feasible in such patients [310] and may lower the risk of recurrent stroke compared to medical treatment [311]; however, RCTs are still lacking.

\section{Postmenopausal Oestrogen Replacement Therapy}

Hormone replacement therapy does not protect against vascular events and may increase stroke severity [312].

\section{Antithrombotic Therapy}

\section{Recommendations}

- It is recommended that patients receive antithrombotic therapy (Class I, Level A)

- It is recommended that patients not requiring anticoagulation should receive antiplatelet therapy (Class I, Level A). Where possible, combined aspirin and dipyridamole, or clopidogrel alone, should be given. Alternatively, aspirin alone, or triflusal alone, may be used (Class I, Level A)

- The combination of aspirin and clopidogrel is not recommended in patients with recent ischaemic stroke, except in patients with specific indications (e.g. unstable angina or non-Q-wave MI, or recent stenting); treatment should be given for up to 9 months after the event (Class I, Level A)

- It is recommended that patients who have a stroke on antiplatelet therapy should be re-evaluated for pathophysiology and risk factors (Class IV, GCP)

- Oral anticoagulation (INR 2.0-3.0) is recommended after ischaemic stroke associated with AF (Class I, Level A). Oral anticoagulation is not recommended in patients with comorbid conditions such as falls, poor compliance, uncontrolled epilepsy, or gastrointestinal bleeding (Class III, Level C). Increasing age alone is not a contraindication to oral anticoagulation (Class I, Level A) 
It is recommended that patients with cardioembolic stroke unrelated to AF should receive anticoagulants (INR 2.0-3.0) if the risk of recurrence is high (Class III, Level C)

- It is recommended that anticoagulation should not be used after non-cardio-embolic ischaemic stroke, except in some specific situations, such as aortic atheromas, fusiform aneurysms of the basilar artery, cervical artery dissection, or PFO in the presence of proven deep vein thrombosis (DVT) or atrial septal aneurysm (Class IV, GCP)

- It is recommended that combined low-dose aspirin and dipyridamole should be given if oral anticoagulation is contraindicated (Class IV, GCP)

\section{Antiplatelet Therapy}

Antiplatelet therapy reduces vascular events, including non-fatal MI, nonfatal stroke and vascular death in patients with previous stroke or TIA (RR 0.78; 95\% CI $0.76-0.80)$ [313].

\section{Aspirin}

Aspirin reduces recurrence irrespective of dose (50$1,300 \mathrm{mg} /$ day) [314-317], although high doses (>150 mg/ day) increase adverse events. In patients with symptomatic intracranial atherosclerosis, aspirin is as effective as oral anticoagulation and has fewer complications [318]

\section{Clopidogrel}

Clopidogrel is slightly more effective than aspirin in preventing vascular events (RR 0.91; 95\% CI 0.84-0.97) [319]. It may be more effective in high-risk patients (i.e. those with previous stroke, peripheral artery disease, symptomatic coronary disease, or diabetes) [269].

\section{Dipyridamole}

Dipyridamole reduces stroke recurrence with similar efficacy to aspirin [320].

\section{Triflusal}

Triflusal reduces stroke recurrence with similar efficacy to aspirin but with fewer adverse events [321].

\section{Dipyridamole plus Aspirin}

The combination of aspirin (38-300 mg/day) and dipyridamole (200 mg extended release twice daily) reduces the risk of vascular death, stroke or MI, compared with aspirin alone (RR 0.82; 95\% CI 0.74-0.91) [320, 322]. Dipyridamole may cause headache; the incidence of this may be reduced by increasing the dose gradually [323, 324].

\section{Clopidogrel plus Aspirin}

Compared with clopidogrel alone, the combination of aspirin and clopidogrel did not reduce the risk of ischaemic stroke, MI, vascular death, or re-hospitalization [325]; however, life-threatening or major bleeding was increased with the combination. Similarly, in the CHARISMA study, the combination of aspirin and clopidogrel did not reduce the risk of MI, stroke, or death from CV causes, compared with aspirin alone [269]. In patients who have had an acute coronary event within 12 months, or coronary stenting, the combination of clopidogrel and aspirin reduces the risk of new vascular events [326].

\section{Oral Anticoagulation}

Oral anticoagulation after non-cardiac ischaemic stroke is not superior to aspirin, but causes more bleeding [327-329]. Oral anticoagulation (INR 2.0-3.0) reduces the risk of recurrent stroke in patients with non-valvular AF (whether of permanent, chronic or paroxysmal type) [330] and most other cardiac sources of emboli. Anticoagulation should be taken long term, or for at least 3 months after cardioembolic stroke due to MI [331]. There is a controversial discussion about the optimal time point when to start oral anticoagulation. After TIA or minor stroke, one could start immediately, but after major stroke with significant infarction upon neuroimaging (e.g. above a third of the MCA territory) one should wait for some (e.g. 4) weeks. However, this decision has to be individualized.

In patients with $\mathrm{AF}$ and stable coronary disease, aspirin should not be added to oral anticoagulation [332]. Anticoagulation may be beneficial in patients with aortic atheroma [333], fusiform aneurysms of the basilar artery [334] or cervical dissection [335]. The ongoing ARCH trial is comparing the combination of clopidogrel plus aspirin with oral anticoagulation in secondary prevention of patients with atherosclerotic plaques in the aortic arch.

\section{Recurrent Vascular Event on Antiplatelet Therapy}

The treatment of patients who have a recurrent vascular event on antiplatelet therapy remains unclear. Alternative causes of stroke should be sought and consistent risk-factor management is mandatory especially in those patients. Alternative treatment strategies may be considered: leave unchanged, change to another antiplatelet agent, add another antiplatelet agent, or use oral anticoagulation. 


\section{Surgery and Angioplasty}

\section{Recommendations}

- CEA is recommended for patients with 70-99\% stenosis (Class I, Level A). CEA should only be performed in centres with a perioperative complication rate (all strokes and death) of less than $6 \%$ (Class I, Level A)

- It is recommended that CEA be performed as soon as possible after the last ischaemic event, ideally within 2 weeks (Class II, Level B)

- It is recommended that CEA may be indicated for certain patients with stenosis of 50-69\%; males with very recent hemispheric symptoms are most likely to benefit (Class III, Level C). CEA for stenosis of 50-69\% should only be performed in centres with a perioperative complication rate (all stroke and death) of less than 3\% (Class I, Level A)

- CEA is not recommended for patients with stenosis of less than $50 \%$ (Class I, Level A)

- It is recommended that patients remain on antiplatelet therapy both before and after surgery (Class I, Level A)

- Carotid percutaneous transluminal angioplasty and/or stenting (CAS) is only recommended in selected patients (Class I, Level A). It should be restricted to the following subgroups of patients with severe symptomatic carotid artery stenosis: those with contra-indications to CEA, stenosis at a surgically inaccessible site, re-stenosis after earlier CEA, and post-radiation stenosis (Class IV, GCP). Patients should receive a combination of clopidogrel and aspirin immediately before and for at least 1 month after stenting (Class IV, GCP)

- It is recommended that endovascular treatment may be considered in patients with symptomatic intracranial stenosis (Class IV, GPC)

\section{Carotid Endarterectomy}

The grading of stenosis should be performed according to the NASCET criteria. Although ECST (European Carotid Surgery Trialists) and NASCET use different methods of measurement, it is possible to convert the percentage stenosis derived by one method to the other [336]. CEA reduces the risk of recurrent disabling stroke or death (RR 0.52) in patients with severe (70-99\%) ipsilateral ICA stenosis [280, 337, 338]. Patients with less severe ipsilateral carotid stenosis (50-69\%) may also benefit [338]. Surgery is potentially harmful in patients with mild or moderate degrees of stenosis $(<50 \%)$ [338].

CEA should be performed as soon as possible (ideally within 2 weeks) after the last cerebrovascular event [339]. Surgical procedure is important in preventing stroke; carotid patch angioplasty may reduce the risk of perioperative arterial occlusion and restenosis [340].

Older patients ( $>75$ years) without organ failure or serious cardiac dysfunction benefit from CEA [339]. Women with severe $(>70 \%)$ symptomatic stenosis should undergo CEA, whereas women with more moderate stenosis should be treated medically [341]. Patients with amauro- sis fugax, severe stenosis and a high risk profile should be considered for CEA; those with amaurosis fugax and few risk factors do better with medical treatment. Patients with mild-to-moderate intracranial stenosis and severe extracranial stenosis should be considered for CEA.

The benefit from CEA is less in patients with lacunar stroke [342]. Patients with leukoaraiosis carry an increased perioperative risk [343]. Occlusion of the contralateral ICA is not a contraindication to CEA but carries a higher perioperative risk. The benefit from endarterectomy is marginal in patients with carotid near-occlusion.

\section{Carotid Angioplasty and Stenting}

Several trials have compared CAS and CEA in secondary stroke prevention (table 9) [344-347]. However, the SAPPHIRE (Stenting and Angioplasty with Protection in Patients at High Risk for Endarterectomy) trial included more than $70 \%$ asymptomatic patients, and therefore should not be used for decisions about secondary prevention [346]. In CAVATAS (Carotid and Vertebral Artery Transluminal Angioplasty Study), the majority of the patients in the endovascular group underwent angioplasty, and only $26 \%$ were treated with a stent [347]. The two most recent studies revealed different results. SPACE (Stent-protected Angioplasty versus Carotid Endarterectomy in symptomatic patients) marginally failed to prove the non-inferiority of CAS compared to CEA; for the endpoint ipsilateral stroke or death up to day 30 , the event rates after 1,200 patients were $6.8 \%$ for CAS and $6.3 \%$ for CEA patients (absolute difference $0.5 \%$; $95 \%$ CI $-1.9 \%$ to 2.9\%; $p=0.09$ ) [345]. The French EVA3S (Endarterectomy versus Stenting in Patients with Symptomatic Severe Carotid Stenosis) trial was stopped prematurely after the inclusion of 527 patients because of safety concerns and lack of efficacy. The RR of any stroke or death after CAS, compared with CEA, was 2.5 (95\% CI 1.2-5.1) [344]. An updated meta-analysis of these studies revealed a significantly higher risk of any stroke and death within 30 days after CAS, compared with CEA (OR 1.41; 95\% CI 1.07$1.87 ; \mathrm{p}=0.016)$. However, significant heterogeneity was found in this analysis $(\mathrm{p}=0.035)$ [348]. After the periprocedural period, few ipsilateral strokes occurred with either procedure (table 9).

\section{Intracranial and Vertebral Artery Occlusive Disease \\ Extracranial-Intracranial Anastomosis}

Anastomosis between the superficial temporal and middle cerebral arteries is not beneficial in preventing stroke in patients with MCA or ICA stenosis or occlusion [349]. 
Table 9. Risk of stroke or death from large-scale randomized trials comparing endovascular and surgical treatment in patients with severe carotid artery stenosis (intention to treat data)

\begin{tabular}{|c|c|c|c|c|c|c|}
\hline \multirow[t]{2}{*}{ Outcome } & \multicolumn{2}{|c|}{ Any stroke or death at 30 days } & \multicolumn{2}{|c|}{ Disabling stroke or death at 30 days } & \multicolumn{2}{|c|}{ Ipsilateral stroke after 30 days } \\
\hline & CAS & CEA & CAS & CEA & CAS & CEA \\
\hline CAVATAS [347] & $25(10.0)$ & $25(9.9)$ & $16(6.4)$ & $15(5.9)$ & $6^{1}$ & $10^{1}$ \\
\hline SAPPHIRE [346] & $8(4.8)$ & $9(5.4)$ & unknown & unknown & unknown & unknown \\
\hline SPACE $[345,584]$ & $46(7.7)$ & $38(6.5)$ & $29(4.8)$ & $23(3.9)$ & $4(0.7)^{2}$ & $1(0.2)^{2}$ \\
\hline EVA3S [344] & $25(9.6)$ & $10(3.9)$ & $9(3.4)$ & $4(1.5)$ & $2(0.6)^{2}$ & $1(0.3)^{2}$ \\
\hline
\end{tabular}

Figures in parentheses indicate percentages.

${ }^{1}$ Follow-up duration 1.95 years in mean. ${ }^{2}$ Up to 6 months.

Stenting of Intracranial or Vertebral Artery Stenoses

Patients with symptomatic intracranial stenoses of $\geq 50 \%$ are at high risk of recurrent strokes, both in the anterior and posterior circulation (12\% after 1 year and $15 \%$ after 2 years in the territory of the stenosed artery) $[318,350]$. Severe stenoses $(\geq 70 \%)$ carry a higher risk than moderate stenoses (50 to <70\%) [350]. After stenting, recurrent strokes are reported in about $5-7 \%$ of patients with moderate or severe stenoses after 1 year, and in around $8 \%$ after 2 years [351,352]. However, the incidence of complications after either angioplasty or stenting may be up to $6 \%$ [353-355]. No randomized controlled trials have evaluated angioplasty, stenting or both for intracranial stenosis. Several non-randomized trials have shown feasibility and acceptable safety of intracranial stenting, but the risk of restenosis remains high [355, 356]. Also stenting of the extracranial segments of the vertebral artery is technically feasible with a moderate periprocedural risk as, for example, demonstrated in the SSYLVIA trial; but especially at the origin, there is a particularly high rate of restenoses [356].

\section{General Stroke Treatment}

Recommendations

- Intermittent monitoring of neurological status, pulse, BP, temperature and oxygen saturation is recommended for $72 \mathrm{~h}$ in patients with significant persisting neurological deficits (Class IV, GCP)

- It is recommended that oxygen should be administered if the oxygen saturation falls below 95\% (Class IV, GCP)

- Regular monitoring of fluid balance and electrolytes is recommended in patients with severe stroke or swallowing problems (Class IV, GCP)

- Normal saline $(0.9 \%)$ is recommended for fluid replacement during the first $24 \mathrm{~h}$ after stroke (Class IV, GCP)
- Routine BP lowering is not recommended following acute stroke (Class IV, GCP)

- Cautious BP lowering is recommended in patients with extremely high BPs (>220/120 mm Hg) on repeated measurements, or with severe cardiac failure, aortic dissection, or hypertensive encephalopathy (Class IV, GCP)

- It is recommended that abrupt BP lowering be avoided (Class II, Level C)

- It is recommended that low BP secondary to hypovolaemia or associated with neurological deterioration in acute stroke should be treated with volume expanders (Class IV, GCP)

- Monitoring serum glucose levels is recommended (Class IV, GCP)

- Treatment of serum glucose levels $>180 \mathrm{mg} / \mathrm{dl}(>10 \mathrm{mM})$ with insulin titration is recommended (Class IV, GCP)

- It is recommended that severe hypoglycaemia $[<50 \mathrm{mg} / \mathrm{dl}$ $(<2.8 \mathrm{mM})$ ] should be treated with intravenous dextrose or infusion of $10-20 \%$ glucose (Class IV, GCP points)

- It is recommended that the presence of pyrexia (temperature $>37.5^{\circ} \mathrm{C}$ ) should prompt a search for concurrent infection (Class IV, GCP)

- Treatment of pyrexia (temperature $>37.5^{\circ} \mathrm{C}$ ) with paracetamol and fanning is recommended (Class III, Level C)

- Antibiotic prophylaxis is not recommended in immunocompetent patients (Class II, Level B)

The term 'general treatment' refers to treatment strategies aimed at stabilizing the critically ill patient in order to control systemic problems that may impair stroke recovery; the management of such problems is a central part of stroke treatment $[2,106]$. General treatment includes respiratory and cardiac care, fluid and metabolic management, BP control, the prevention and treatment of conditions such as seizures, venous thromboembolism, dysphagia, aspiration pneumonia, other infections, or pressure ulceration, and occasionally management of elevated intracranial pressure (ICP). However, many aspects of general stroke treatment have not been adequately assessed in randomized clinical trials (RCTs). 
It is common practice to actively manage neurological status and vital physiological functions such as BP, pulse, oxygen saturation, blood glucose and temperature. Neurological status can be monitored using validated neurological scales such as the NIH Stroke Scale [104] or the Scandinavian Stroke Scale [357]. There is little direct evidence from RCTs to indicate how intensively monitoring should be carried out, but in stroke unit trials [119] it was common practice to have a minimum of 4-hourly observations for the first $72 \mathrm{~h}$ after stroke. Clinical trials using continuous telemetry $[358,359]$ suggest there may be some benefit from more intensive continuous monitoring in terms of improved detection of complications and reduced length of stay, but clinical outcomes are inconclusive. In practice, more intensive monitoring is often provided for subgroups of patients, such as those with reduced consciousness, progressing neurological deficits, or a history of cardiorespiratory disease. Close monitoring is also required for the first $24 \mathrm{~h}$ after thrombolysis. More invasive monitoring procedures, such as central venous catheters or ICP monitoring, are used only in highly selected patient groups.

\section{Pulmonary Function and Airway Protection}

Normal respiratory function with adequate blood oxygenation is believed to be important in the acute stroke period to preserve ischaemic brain tissue. However, there is no convincing evidence that routine provision of oxygen at low flow rates to all acute stroke patients is effective [360]. Identification and treatment of hypoxia is believed to be important in individuals with extensive brain stem or hemispheric stroke, seizure activity, or complications such as pneumonia, cardiac failure, pulmonary embolism (PE), or exacerbation of COPD. Blood oxygenation is usually improved by the administration of 2-4 1 of oxygen via a nasal tube. Ventilation may be necessary in patients with severely compromised respiratory function. However, before ventilation is performed the general prognosis, coexisting medical conditions, and the presumed wishes of the patient need to be considered.

\section{Cardiac Care}

Cardiac arrhythmias, particularly AF, are relatively common after stroke, and heart failure, $\mathrm{MI}$ and sudden death are also recognized complications [361, 362]. A significant minority of stroke patients show raised blood troponin levels indicative of cardiac damage [363]. Every stroke patient should have an initial ECG. Cardiac monitoring should be conducted to screen for AF. Optimizing cardiac output with maintenance of high normal BP and a normal heart rate is a standard component of stroke management. The use of inotropic agents is not routine practice, but fluid replacement therapy is commonly used to correct hypovolaemia. Increases in cardiac output may increase cerebral perfusion. Restoration of normal cardiac rhythm using drugs, cardioversion or pacemaker support may occasionally be required.

\section{Fluid Replacement Therapy}

Many stroke patients are dehydrated on admission to hospital, and this is associated with a poor outcome [364]. Although clinical trial evidence is limited, delivery of intravenous fluids is commonly considered part of general management of acute stroke, particularly in patients at risk of dehydration due to reduced consciousness or impaired swallowing. Experience in the management of hyperglycaemia supports the avoidance of dextrose in the early post-stroke phase [365]. More specialist fluid replacement therapy with haemodilution has not been shown to improve stroke outcomes [366].

\section{Blood Pressure Management}

BP monitoring and treatment is a controversial area in stroke management. Patients with the highest and lowest levels of BP in the first $24 \mathrm{~h}$ after stroke are more likely to have early neurological decline and poorer outcomes [367]. A low or low-normal BP at stroke onset is unusual [368], and may be the result of a large cerebral infarct, cardiac failure, ischaemia, hypovolaemia or sepsis. BP can usually be raised by adequate rehydration with crystalloid (saline) solutions; patients with low cardiac output may occasionally need inotropic support. However clinical trials of actively elevating a low BP in acute stroke have yielded inconclusive results.

A systematic review covering a variety of BP-altering agents has not provided any convincing evidence that active management of BP after acute stroke influences patient outcomes [369]. Small studies looking at surrogate markers of cerebral blood flow such as SPECT have indicated that neither perindopril nor losartan lower cerebral blood flow when given within 2-7 days of stroke onset [370]. Several ongoing trials are examining whether BP 
should be lowered after acute stroke, and whether antihypertensive therapy should be continued or stopped in the first few days after stroke [371, 372]. In the absence of reliable evidence from clinical trials, many clinicians have developed protocols for the management of extremely high BP. In some centres it is common practice to begin cautious BP reduction when levels exceed 220 $\mathrm{mm} \mathrm{Hg}$ systolic and $120 \mathrm{~mm} \mathrm{Hg}$ diastolic. However, in many centres $\mathrm{BP}$ reduction is only considered in the presence of severe cardiac insufficiency, acute renal failure, aortic arch dissection, or malignant hypertension. In patients undergoing thrombolysis, it is common practice to avoid systolic BPs above $185 \mathrm{~mm} \mathrm{Hg}$.

The use of sublingual nifedipine should be avoided because of the risk of an abrupt decrease in BP [373]. Intravenous labetalol or urapadil are frequently used in North America. Sodium nitroprusside is sometimes recommended.

\section{Blood Glucose Management}

Hyperglycaemia occurs in up to $60 \%$ of stroke patients without known diabetes [374, 375]. Hyperglycaemia after acute stroke is associated with larger infarct volumes and cortical involvement, and with poor functional outcome [376-378]. There is limited evidence as to whether active reduction of glucose in acute ischaemic stroke improves patient outcomes. The largest randomized trial of blood glucose lowering by glucose potassium insulin infusion [365], compared with standard intravenous saline infusion, found no difference in mortality or functional outcomes in patients with mild-to-moderate blood glucose elevations [median $137 \mathrm{mg} / \mathrm{dl}(7.6 \mathrm{~mm})]$. This regime was labour intensive and associated with episodes of hypoglycaemia. At present, the routine use of insulin infusion regimes in patients with moderate hyperglycaemia cannot be recommended. However, it is common practice in stroke units to reduce blood glucose levels exceeding 180 $\mathrm{mg} / \mathrm{dl}$ (10 mM) [119]. The use of intravenous saline and avoidance of glucose solutions in the first $24 \mathrm{~h}$ after stroke is common practice, and appears to reduce blood glucose levels [365].

Hypoglycaemia $[<50 \mathrm{mg} / \mathrm{dl}(2.8 \mathrm{~mm})]$ may mimic an acute ischaemic infarction, and should be treated by intravenous dextrose bolus or infusion of $10-20 \%$ glucose [379].

\section{Body Temperature Management}

In experimental stroke, hyperthermia is associated with increased infarct size and poor outcome [380]. Raised temperature can be centrally driven or a result of concurrent infection, and is associated with poorer clinical outcomes [381-383]. A raised body temperature should prompt a search for infection and treatment where appropriate. Studies with antipyretic medication have been inconclusive, but treatment of raised body temperature $\left(>37.5^{\circ} \mathrm{C}\right)$ with paracetamol is common practice in stroke patients.

\section{Specific Treatment}

Recommendations

- Intravenous rtPA ( $0.9 \mathrm{mg} / \mathrm{kg}$ body weight, maximum $90 \mathrm{mg})$, with $10 \%$ of the dose given as a bolus followed by a $60-\mathrm{min}$ infusion, is recommended within $3 \mathrm{~h}$ of onset of ischaemic stroke (Class I, Level A)

- Intravenous rtPA may be of benefit also for acute ischaemic stroke beyond $3 \mathrm{~h}$ after onset (Class I, Level B) but is not recommended for routine clinical practice

- The use of multimodal imaging criteria may be useful for patient selection for thrombolysis but is not recommended for routine clinical practice (Class III, Level C)

- It is recommended that $\mathrm{BP}$ of $185 / 110 \mathrm{~mm} \mathrm{Hg}$ or higher is lowered before thrombolysis (Class IV, GCP)

- It is recommended that intravenous rtPA may be used in patients with seizures at stroke onset, if the neurological deficit is related to acute cerebral ischaemia (Class IV, GCP)

- It is recommended that intravenous rtPA may also be administered in selected patients under 18 years and over 80 years of age, although this is outside the current European labelling (Class III, Level C)

- Intra-arterial treatment of acute MCA occlusion within a 6-hour time window is recommended as an option (Class II, Level B)

- Intra-arterial thrombolysis is recommended for acute basilar occlusion in selected patients (Class III, Level B). Intravenous thrombolysis for basilar occlusion is an acceptable alternative even after $3 \mathrm{~h}$ (Class III, Level B)

- It is recommended that aspirin (160-325 mg loading dose) be given within $48 \mathrm{~h}$ after ischaemic stroke (Class I, Level A)

- It is recommended that if thrombolytic therapy is planned or given, aspirin or other antithrombotic therapy should not be initiated within $24 \mathrm{~h}$ (Class IV, GCP)

- The use of other antiplatelet agents (single or combined) is not recommended in the setting of acute ischaemic stroke (Class III, Level C)

- The administration of glycoprotein-IIb-IIIa inhibitors is not recommended (Class I, Level A)

- Early administration of unfractionated heparin (UFH), low molecular weight heparin or heparinoids is not recommended for the treatment of patients with acute ischaemic stroke (Class I, Level A)

- Currently, there is no recommendation to treat ischaemic stroke patients with neuroprotective substances (Class I, Level A)
ESO Executive Committee and ESO Writing Committee 


\section{Thrombolytic Therapy}

\section{Intravenous Tissue Plasminogen Activator}

Thrombolytic therapy with $\mathrm{rtPA}(0.9 \mathrm{mg} / \mathrm{kg}$ body weight, maximum dose $90 \mathrm{mg}$ ) given within $3 \mathrm{~h}$ after stroke onset significantly improves outcome in patients with acute ischaemic stroke [126]: the NNT to achieve a favourable clinical outcome after 3 months is 7. By contrast, the ECASS (European Cooperative Acute Stroke Study) and ECASS II studies did not show statistically significant superiority of rtPA for the primary endpoints when treatment was given within $6 \mathrm{~h}[384,385]$. Trials with rtPA, involving a total of 2,889 patients, have shown a significant reduction in the number of patients with death or dependency (OR 0.83; 95\% CI 0.73-0.94) [386]. A pooled analysis of individual data of rtPA trials showed that, even within a 3-hour window, earlier treatment results in a better outcome (0-90 min: OR 2.11; 95\% CI 1.33-3.55; 90-180 min: OR 1.69; 95\% CI 1.09-2.62) [387]. This analysis suggested a benefit up to $4.5 \mathrm{~h}$. Ongoing trials (ECASS III, IST-3) are further investigating the benefits of rtPA beyond $3 \mathrm{~h}$.

The NINDS (National Institute of Neurological Disorders and Stroke) Study showed that the extent of early ischaemic changes (using the ASPECT score) had no effect on treatment response within the 3-hour time window [388]. However, European regulatory agencies do not advocate rtPA treatment in patients with severe stroke (NIHSSS $\geq 25$ ), extended early ischaemic changes on CT scan, or age above 80 years (unlike the US labelling). Nevertheless, observational studies suggest that rtPA given within $3 \mathrm{~h}$ of stroke onset is safe and effective in patients over 80 years of age [389-391], but more randomized data are pending. The effect of gender on the response to rtPA is uncertain [392].

Thrombolytic therapy appears to be safe and effective across various types of hospitals, if the diagnosis is established by a physician with stroke expertise and brain CT is assessed by an experienced physician [393-395]. Whenever possible, the risks and benefits of rtPA should be discussed with the patient and family before treatment is initiated.

BP must be below 185/110 mm Hg before, and for the first $24 \mathrm{~h}$ after, thrombolysis. Management of high $\mathrm{BP}$ is required [126]. Protocol violations are associated with higher mortality rates [396, 397].

Continuous transcranial ultrasound was associated with an increased rate of early recanalization after rtPA in a small randomized trial [398]; this effect may be facilitated by the administration of microbubbles [399].
However, a RCT has recently been stopped for undisclosed reasons.

Intravenous rtPA may be of benefit also for acute ischaemic stroke beyond $3 \mathrm{~h}$ after onset, but is not recommended in clinical routine. The use of multimodal imaging criteria may be useful for patient selection. Several large observational studies suggest improved safety and possibly improved efficacy in patients treated with intravenous rtPA beyond $3 \mathrm{~h}$ based on advanced imaging findings [131, 160, 400, 401]. However, available data on mismatch, as defined by multimodal MRI or CT, are too limited to guide thrombolysis in routine practice (see also the section on imaging) [153].

Patients with seizures at stroke onset have been excluded from thrombolytic trials because of potential confusion with post-ictal Todd's phenomena. Case series have suggested that thrombolysis may be used in such patients when there is evidence for new ischaemic stroke [389].

Post-hoc analyses have identified the following potential factors associated with increased risk of intracerebral bleeding complications after rtPA use [402]:

- elevated serum glucose

- history of diabetes

- baseline symptom severity

- advanced age

- increased time to treatment

- previous aspirin use

- history of congestive heart failure

- low plasminogen activator inhibitor activity

- NINDS protocol violations.

However, none of these factors reversed the overall benefit of rtPA.

\section{Other Intravenous Thrombolytics}

Intravenous streptokinase was associated with an unacceptable risk of haemorrhage and death $[403,404]$. Intravenous desmoteplase administered 3-9 h after acute ischaemic stroke in patients selected on the basis of perfusion/diffusion mismatch was associated with a higher rate of reperfusion and better clinical outcome, compared with placebo, in two small RCTs $[405,406]$. These findings were not confirmed in the phase III DIAS (Desmoteplase in Acute Ischemic Stroke)-II study, but this agent will be evaluated further.

\section{Intra-Arterial and Combined (IV+IA) Thrombolysis}

Intra-arterial thrombolytic treatment of proximal MCA occlusion using pro-urokinase (PUK) within $6 \mathrm{~h}$ was significantly associated with better outcome in the PROACT II (Pro-urokinase for Acute Ischemic Stroke) 
trial [154]. Additional smaller RCTs with PUK (PROACT I) or urokinase (MELT) and a meta-analysis of PROACT I, PROACT II and MELT indicate a benefit of intra-arterial thrombolytic therapy in patients with proximal MCA occlusions [407]. PUK is not available and intra-arterial thrombolysis with tPA is not substantiated by RCTs, but observational data and non-randomised comparisons are available [155, 408].

A randomized trial comparing standard intravenous rtPA with a combined intravenous and intra-arterial approach (IMS3) has started [409].

Intra-arterial treatment of acute basilar occlusion with urokinase or rtPA has been available for more than 20 years, but has not been tested in an adequately powered RCT [410], although encouraging results have been obtained in observational studies [411, 412]. A systematic analysis found no significant differences between intravenous or intra-arterial thrombolysis for basilar occlusion [413].

\section{Intra-Arterial Recanalization Devices}

The MERCI (Mechanical Embolus Removal in Cerebral Embolism) trial evaluated a device that removed the thrombus from an intracranial artery. Recanalization was achieved in $48 \%(68 / 141)$ of patients in whom the device was deployed within $8 \mathrm{~h}$ of the onset of stroke symptoms [414]. No RCTs with outcome data are available for any recanalization devices.

\section{Antiplatelet Therapy}

The results of two large randomized, non-blinded, intervention studies indicate that aspirin is safe and effective when started within $48 \mathrm{~h}$ after stroke $[415,416]$. In absolute terms, 13 more patients were alive and independent at the end of follow-up for every 1,000 patients treated. Furthermore, treatment increased the odds of making a complete recovery from the stroke (OR 1.06; 95\% CI 1.01-1.11): 10 more patients made a complete recovery for every 1,000 patients treated. Antiplatelet therapy was associated with a small but definite excess of two symptomatic intracranial haemorrhages for every 1,000 patients treated, but this was more than offset by a reduction of seven recurrent ischaemic strokes and about one PE for every 1,000 patients treated.

A randomized, double-blind, placebo-controlled trial showed that aspirin ( $325 \mathrm{mg}$ ), given once daily for 5 consecutive days and starting within $48 \mathrm{~h}$ of stroke onset, did not significantly reduce stroke progression, compared with placebo (RR 0.95 ; 95\% CI 0.62-1.45) in patients with incomplete paresis [417].

The use of clopidogrel, dipyridamole, or combinations of oral antiplatelet agents in acute ischaemic stroke has not been evaluated.

In a double-blind phase II, the glycoprotein-IIb-IIIa inhibitor abciximab produced a non-significant shift in favourable outcomes, as measured by modified Rankin scores (mRS) at 3 months, compared with placebo (OR 1.20 ; 95\% CI 0.84-1.70) [418]. A phase III study evaluating the safety and efficacy of abciximab was terminated prematurely after 808 patients had been enrolled because of an increased rate of symptomatic or fatal intracranial bleeding with abciximab compared to placebo (5.5 vs. $0.5 \% ; \mathrm{p}=0.002)$. This trial also did not demonstrate an improvement in outcomes with abciximab [419].

\section{Early Anticoagulation}

Subcutaneous UFH at low or moderate doses [415], nadroparin [420, 421], certoparin [422], tinzaparin [423], dalteparin [424] and intravenous danaparoid [425] have failed to show an overall benefit of anticoagulation when initiated within $24-48 \mathrm{~h}$ from stroke onset. Improvements in outcome or reductions in stroke recurrence rates were mostly counterbalanced by an increased number of haemorrhagic complications. In a meta-analysis of 22 trials, anticoagulant therapy was associated with about nine fewer recurrent ischaemic strokes per 1,000 patients treated (OR 0.76; 95\% CI 0.65-0.88), and with about nine more symptomatic intracranial haemorrhages per 1,000 (OR 2.52; 95\% CI 1.92-3.30) [426]. However, the quality of the trials varied considerably. The anticoagulants tested were standard UFH, low molecular weight heparins, heparinoids, oral anticoagulants, and thrombin inhibitors.

Few clinical trials have assessed the risk-benefit ratio of very early administration of UFH in acute ischaemic stroke. In one study, patients with nonlacunar stroke anticoagulated within $3 \mathrm{~h}$ had more self-independence (38.9 vs. $28.6 \%$; $\mathrm{p}=0.025)$, fewer deaths ( 16.8 vs. $21.9 \%$; $\mathrm{p}=$ $0.189)$, and more symptomatic brain haemorrhages (6.2 vs. $1.4 \% ; p=0.008$ ) [427]. In the RAPID (Rapid Anticoagulation Prevents Ischemic Damage) trial, patients allocated UFH had fewer early recurrent strokes and a similar incidence of serious haemorrhagic events, compared with those receiving aspirin [428]. In the UFH group, ischaemic or haemorrhagic worsening was associated with inadequate plasma levels of UFH. In view of these 
findings, the value of UFH administered shortly after symptom onset is still debated $[429,430]$.

RCTs have not identified a net benefit of heparin for any stroke subtype. A meta-analysis restricted to patients with acute cardioembolic stroke showed that anticoagulants given within $48 \mathrm{~h}$ of clinical onset were associated with a non-significant reduction in recurrence of ischaemic stroke, but no substantial reduction in death or disability [431]. Despite this lack of evidence, some experts recommend full-dose heparin in selected patients, such as those with cardiac sources of embolism with high risk of re-embolism, arterial dissection or high-grade arterial stenosis prior to surgery. Contraindications for heparin treatment include large infarcts (e.g. more than $50 \%$ of MCA territory), uncontrollable arterial hypertension and advanced microvascular changes in the brain.

\section{Neuroprotection}

No neuroprotection programme has shown improved outcome on its predefined primary endpoint. Recent RCTs with the free radical trapping agent NXY-059 [432], and magnesium sulphate [433] were negative. A randomized, placebo-controlled, phase III trial of intravenous rtPA followed by antioxidant therapy with uric acid is ongoing, following a safe phase II study [434]. A metaanalysis has suggested a mild benefit with citocoline [435]; a clinical trial with this agent is in progress.

\section{Brain Oedema and Elevated Intracranial Pressure}

\section{Recommendations}

- Surgical decompressive therapy within $48 \mathrm{~h}$ after symptom onset is recommended in patients up to 60 years of age with evolving malignant MCA infarcts (Class I, Level A)

- It is recommended that osmotherapy can be used to treat elevated ICP prior to surgery if this is considered (Class III, Level C)

- No recommendation can be given regarding hypothermic therapy in patients with space-occupying infarctions (Class IV, GCP)

- It is recommended that ventriculostomy or surgical decompression be considered for treatment of large cerebellar infarctions that compress the brainstem (Class III, Level C)

Space-occupying brain oedema is a main cause of early deterioration and death in patients with large supratentorial infarcts. Life-threatening brain oedema usually develops between the 2 nd and 5 th day after stroke onset, but up to a third of patients can have neurological deterioration within $24 \mathrm{~h}$ after symptom onset $[436,437]$.

\section{Medical Therapy}

Medical therapy in patients with large space-occupying infarctions and brain oedema is based mostly on observational data. Basic management includes head positioning at an elevation of up to $30^{\circ}$, avoidance of noxious stimuli, pain relief, appropriate oxygenation and normalizing body temperature. If ICP monitoring is available, cerebral perfusion pressure should be kept above $70 \mathrm{~mm}$ $\mathrm{Hg}$ [438]. Intravenous glycerol $(4 \times 250 \mathrm{ml}$ of $10 \%$ glycerol over 30-60 min) or mannitol (25-50 g every 3-6 h) is first line medical treatment if clinical or radiological signs of space-occupying oedema occur $[439,440]$. Intravenous hypertonic saline solutions are probably similarly effective [441]. Hypotonic and glucose-containing solutions should be avoided as replacement fluids. Dexamethasone and corticosteroids are not useful [442]. Thiopental given as a bolus can quickly and significantly reduce ICP, and can be used to treat acute crises. Barbiturate treatment requires ICP and electroencephalography (EEG) monitoring and careful haemodynamic monitoring, as a significant BP drop may occur.

\section{Hypothermia}

Mild hypothermia (i.e. brain temperature between $32-33^{\circ} \mathrm{C}$ ) reduces mortality in patients with severe MCA infarcts, but may cause severe side effects including recurrent ICP crisis during re-warming $[443,444]$. In a small RCT, mild hypothermia $\left(35^{\circ} \mathrm{C}\right)$ in addition to decompressive surgery produced a trend towards a better clinical outcome than decompressive surgery alone $(\mathrm{p}=$ 0.08) [445].

\section{Decompressive Surgery \\ Malignant MCA Infarction}

A pooled analysis of 93 patients included in the DECIMAL (decompressive craniectomy in malignant MCA infarcts), DESTINY (decompressive surgery for the treatment of malignant infarction of the MCA), and HAMLET (hemicraniectomy after MCA infarction with lifethreatening edema trial) trials showed that, compared with the control group, at 1 year more patients in the decompressive surgery group had an $\mathrm{mRS} \leq 4$ or $\mathrm{mRS} \leq 3$, and more survived (NNTs 2, 4 and 2, respectively) [446, 447]. There was no increase in the proportion of patients who survived surgery in a vegetative stage (mRS 5). Inclusion criteria for this combined analysis were age 18-60 years, NIHSSS $>15$, decrease in level of consciousness to 
a score of 1 or greater on item 1a of the NIHSS, infarct signs on CT of $50 \%$ or more of the MCA territory or $>145$ $\mathrm{cm}^{3}$ on DWI, and inclusion $<45 \mathrm{~h}$ after onset (surgery $<48 \mathrm{~h}$ ). Follow-up of survival and functional status beyond 1 year is currently ongoing in the DECIMAL and DESTINY studies [447].

A systematic review of 12 observational retrospective studies found age above 50 years to be a predictor of poor outcome. The timing of surgery, side of infarction, clinical signs of herniation before surgery, and involvement of other vascular territories did not significantly affect outcome [448].

\section{Cerebellar Infarction}

Ventriculostomy and decompressive surgery are considered treatments of choice for space-occupying cerebellar infarctions, although RCTs are lacking. As in space-occupying supratentorial infarction, the operation should be performed before signs of herniation are present. The prognosis among survivors can be very good, even in patients who are comatose before surgery.

\section{Prevention and Management of Complications}

\section{Recommendations}

- It is recommended that infections after stroke should be treated with appropriate antibiotics (Class IV, GCP)

- Prophylactic administration of antibiotics is not recommended, and levofloxacin can be detrimental in acute stroke patients (Class II, Level B)

- Early rehydration and graded compression stockings are recommended to reduce the incidence of venous thromboembolism (Class IV, GCP)

- Early mobilization is recommended to prevent complications such as aspiration pneumonia, DVT and pressure ulcers (Class IV, GCP)

- It is recommended that low-dose subcutaneous heparin or low molecular weight heparins should be considered for patients at high risk of DVT or PE (Class I, Level A)

- Administration of anticonvulsants is recommended to prevent recurrent post-stroke seizures (Class I, Level A). Prophylactic administration of anticonvulsants to patients with recent stroke who have not had seizures is not recommended (Class IV, GCP)

- An assessment of falls risk is recommended for every stroke patient (Class IV, GCP)

- Calcium/vitamin D supplements are recommended in stroke patients at risk of falls (Class II, Level B)

- Bisphosphonates (alendronate, etidronate and risedronate) are recommended in women with previous fractures (Class II, Level B)

- In stroke patients with urinary incontinence, specialist assessment and management is recommended (Class III, Level C)
- Swallowing assessment is recommended but there are insufficient data to recommend a specific approach for treatment (Class III, GCP)

- Oral dietary supplements are only recommended for nondysphagic stroke patients who are malnourished (Class II, Level B)

- Early commencement of nasogastric (NG) feeding (within $48 \mathrm{~h}$ ) is recommended in stroke patients with impaired swallowing (Class II, Level B)

- It is recommended that percutaneous enteral gastrostomy (PEG) feeding should not be considered in stroke patients in the first 2 weeks (Class II, Level B)

\section{Aspiration and Pneumonia}

Bacterial pneumonia is one of the most important complications in stroke patients [449], and is mainly caused by aspiration [450]. Aspiration is frequently found in patients with reduced consciousness and in those with swallowing disturbances. Oral feeding should be withheld until the patient has demonstrated intact swallowing with small amounts of water and intact coughing on command. NG or PEG feeding may prevent aspiration pneumonia, although reflux of liquid feed, hypostasis, diminished cough and immobilization increase the risk. Frequent changes of the patient's position in bed and pulmonary physical therapy may prevent aspiration pneumonia. A brain-mediated immunodepressive state contributes to post-stroke infection [451, 452]. Prophylactic administration of levofloxacin $(500 \mathrm{mg} / 100 \mathrm{ml} /$ day for 3 days) is not better than optimal care for the prevention of infection in patients with nonseptic acute stroke and was inversely associated with outcome at day 90 (OR 0.19; $95 \%$ CI 0.04 to $0.87 ; \mathrm{p}=0.03$ ) [453].

\section{Deep Vein Thrombosis and Pulmonary Embolism}

It is generally accepted that the risk of DVT and PE can be reduced by early hydration and early mobilization. Although graded compression stockings are effective in preventing venous thromboembolism in surgical patients, their efficacy after stroke is unproven [454]. In stroke patients, low-dose LMWH reduced the incidence of both DVT (OR 0.34; 95\% CI 0.19-0.59) and PE (OR 0.36 ; 95\% CI 0.15-0.87), without an increased risk of intracerebral (OR 1.39; 95\% CI 0.53-3.67) or extracerebral haemorrhage (OR 1.44; 95\% CI 0.13-16), NNT: 7 and 38 for DVT and PE, respectively, while low-dose UFH decreased the thrombosis risk (OR 0.17; 95\% CI 0.11-0.26), but had no influence on PE (OR 0.83, 95\% CI 0.53-1.31); 
the risk of ICH was not statistically significantly increased (OR 1.67; 95\% CI 0.97-2.87) [455]. Nevertheless, prophylaxis with subcutaneous low-dose heparin $(5,000$ IU twice daily) or low molecular weight heparins is indicated in patients at high risk of DVT or PE (e.g. due to immobilization, obesity, diabetes, previous stroke) [456, 457].

\section{Pressure Ulcer}

In patients at high risk of developing pressure ulcers, use of support surfaces, frequent repositioning, optimizing nutritional status, and moisturizing sacral skin are appropriate preventive strategies [458]. The skin of the incontinent patient must be kept dry. For patients at particularly high risk, an air-filled or fluid-filled mattress system should be used.

\section{Seizures}

Partial or secondary generalized seizures may occur in the acute phase of ischaemic stroke. Standard anti-epileptic drugs should be used based on general principles of seizure management. There is no evidence that primary prophylactic anticonvulsive treatment is beneficial.

\section{Agitation}

Agitation and confusion may be a consequence of acute stroke, but may also be due to complications such as fever, volume depletion or infection. Adequate treatment of the underlying cause must precede any type of sedation or antipsychotic treatment.

\section{Falls}

Falls are common (up to 25\%) after stroke in the acute setting [459], during in-patient rehabilitation [460], and in the long term [461]. Likely risk factors for falls in stroke survivors [462] include cognitive impairment, depression, polypharmacy and sensory impairment [463, 464]. A multidisciplinary prevention package that focuses on personal and environmental factors has been found to be successful in general rehabilitation settings $[465,466]$. There is a $5 \%$ incidence of serious injury [459], including hip fractures (which are fourfold more common than in age-matched controls [467]), which is associated with poor outcome [468]. Exercise [469], calcium supplements [470] and bisphosphonates [471] improve bone strength and decrease fracture rates in stroke patients. Hip protectors can reduce the incidence of fracture for high-risk groups in institutional care, but evidence is less convincing for their use in a community setting [472].

\section{Urinary Tract Infections and Incontinence}

The majority of hospital-acquired urinary tract infections are associated with the use of indwelling catheters $[473,474]$. Intermittent catheterization has not been shown to reduce the risk of infection. Once urinary infection is diagnosed, appropriate antibiotics should be chosen: to avoid bacterial resistance developing, prophylactic antibiotics are best avoided.

Urinary incontinence is common after stroke, particularly in older, more disabled and cognitively impaired patients [475]. Recent estimates suggest a prevalence of $40-60 \%$ in an acute stroke population, of whom $25 \%$ are still incontinent at discharge and $15 \%$ remain incontinent at 1 year [476]. Urinary incontinence is a strong predictor of poor functional outcome, even after correcting for age and functional status [477]. However, data from the available trials are insufficient to guide continence care of adults after stroke [474, 478]. However, there is suggestive evidence that professional input through structured assessment and management of care and specialist continence nursing may reduce urinary incontinence and related symptoms after stroke. Structured assessment and physical management have been shown to improve continence rates in both inpatients and outpatients [474, 476]. However, trials of interventions are insufficient in number and quality to make any recommendations [478].

\section{Dysphagia and Feeding}

Oropharyngeal dysphagia occurs in up to $50 \%$ of patients with unilateral hemiplegic stroke [479]. The prevalence of dysphagia is highest in the acute stages of stroke, and declines to around $15 \%$ at 3 months [480]. Dysphagia is associated with a higher incidence of medical complications and increased overall mortality [479].

Withholding or limiting oral intake can worsen the catabolic state that may be associated with an acute illness such as stroke. Estimates of the incidence of malnu- 
trition vary from $7-15 \%$ at admission $[481,482]$ and $22-$ $35 \%$ at 2 weeks [483]. Among patients requiring prolonged rehabilitation, the prevalence of malnutrition may reach 50\% [484]. Malnutrition predicts a poor functional outcome [485] and increased mortality [486, 487]. However, routine supplementation for all acute stroke patients did not improve outcomes or reduce complications [488]. There are no adequately powered trials of targeting supplementation to stroke patients at high risk of malnutrition.

For patients with continuing dysphagia, options for enteral nutrition include NG or PEG feeding. A trial of early (median $48 \mathrm{~h}$ after stroke) versus delayed (1 week) NG feeding found no significant benefit of early feeding, although there was a trend to fewer deaths in the early NG group [488]. In a related trial examining PEG and NG feeding within 30 days, PEG feeding was no better than NG and in fact was potentially harmful [488]. PEG feeding has also been studied in longer-term dysphagia. Two trials comparing PEG and NG feeding found a trend towards improved nutrition with PEG feeding that did not reach statistical significance $[489,490]$. Studies that have addressed quality of life found it was not improved by PEG feeding [491, 492].

\section{Rehabilitation}

Even with optimal stroke unit care including thrombolysis, fewer than one third of patients recover fully from stroke [387]. Rehabilitation aims to enable people with disabilities to reach and maintain optimal physical, intellectual, psychological and/or social function [493]. Goals of rehabilitation can shift from initial input to minimize impairment to more complex interventions designed to encourage active participation.

\section{Setting for Rehabilitation}

\section{Recommendations}

- Admission to a stroke unit is recommended for acute stroke patients to receive coordinated multidisciplinary rehabilitation (Class I, Level A)

- Early initiation of rehabilitation is recommended (Class III, Level C)

- It is recommended that early discharge from stroke unit care is possible in medically stable patients with mild or moderate impairment providing that rehabilitation is delivered in the community by a multidisciplinary team with stroke expertise (Class I, Level A)
- It is recommended to continue rehabilitation after discharge during the first year after stroke (Class II, Level A)

- It is recommended to increase the duration and intensity of rehabilitation (Class II, Level B)

A key characteristic of stroke units is rehabilitation delivered by a specialized multidisciplinary team [494]. The Stroke Unit Trialists' Collaboration [61] has shown improved survival and functional outcomes for patients treated in a dedicated stroke ward, and there are also longterm functional benefits of dedicated stroke unit care; follow-up at 5 and 10 years has revealed persisting efficacy compared with controls $[495,496]$. The financial and social implications of prolonged hospitalization have prompted increasing interest in services to facilitate early return to the community. A multidisciplinary early supported discharge team with stroke expertise, comprising (at least) nursing, physiotherapy and OT, can significantly reduce bed days for selected stroke patients [497] who have mild or moderate impairment at baseline [498]. However, specialist discharge services are required: mortality was substantially increased when patients were discharged early with only generic community support [499].

A meta-analysis showed that continued rehabilitation after discharge during the 1st year after stroke reduces the risk of deterioration in function and improves activities of daily living (ADL) [500]. The interventions included OT, physiotherapy, and multidisciplinary teams, and therefore no definitive statement can be made concerning the optimal mode of service delivery.

\section{Timing, Duration and Intensity of Rehabilitation}

The optimal timing of rehabilitation is unclear. Proponents of early therapy cite evidence from functional neuroimaging [501] and animal studies [502, 503] that define the peri-infarct period as the crucial time to begin rehabilitation. Early initiation of rehabilitation is a key component of stroke unit care [61] but there is a lack of consensus on the definition of 'early therapy'. Trials comparing 'early' and 'late' initiation of rehabilitation have reported improved prognosis if therapy is started within 20-30 days [504, 505]. Many of the immediate complications of stroke (DVT, skin breakdown, contracture formation, constipation, and hypostatic pneumonia) are related to immobility [506], and hence mobilization is a fundamental component of early rehabilitation. The optimal timing of first mobilization is unclear, but mobilization within the first few days appears to be well toler- 
ated [507]. Preliminary results from the ongoing AVERT study of rehabilitation within $24 \mathrm{~h}$ suggest that immediate physical therapy is well tolerated with no increase in adverse events [508].

There are few studies of rehabilitation beyond a year after the acute event, and data are inconclusive to make a recommendation on rehabilitation in this phase [509].

Greater intensity of rehabilitation, especially time spent working on ADL, is associated with improved functional outcomes [510, 511]. A systematic review of rehabilitation therapies for improving arm function also suggests a dose-response relationship, although heterogeneity of included studies precluded a formal measure of effect size [512]. Greatest benefits were observed in studies of lower limb exercises and general ADL training.

Organisation and 'quality' of care may be more important than absolute hours of therapy [513]. In a comparison between a dedicated stroke multidisciplinary team and usual ward-based rehabilitation, the dedicated team achieved better outcomes with significantly fewer hours of therapy [514].

\section{Elements of Rehabilitation}

\section{Recommendations}

- Physiotherapy is recommended, but the optimal mode of delivery is unclear (Class I, Level A)

- Occupational therapy is recommended, but the optimal mode of delivery is unclear (Class I, Level A)

- While assessment for communication deficits is recommended, there are insufficient data to recommend specific treatments (Class III, GCP)

- It is recommended that information is provided to patient and carers but evidence does not support use of a dedicated stroke liaison service for all patients (Class II, Level B)

- It is recommended that rehabilitation be considered for all stroke patients, but there is limited evidence to guide appropriate treatment for the most severely disabled (Class II, Level B)

- While assessment for cognitive deficits appears desirable, there are insufficient data to recommend specific treatments (Class I, Level A)

- It is recommended that patients be monitored for depression during hospital stay and throughout follow-up (Class IV, Level B)

- Drug therapy and non-drug interventions are recommended to improve mood (Class I, Level A)

- Drug therapy should be considered to treat post-stroke emotionalism (Class II, Level B)

- Tricyclic or anticonvulsant therapy is recommended to treat post-stroke neuropathic pain in selected patients (Class III, Level B)

Guidelines for Management of Ischaemic

Stroke and TIA 2008
- It is recommended that botulinum toxin be considered to treat post-stroke spasticity, but functional benefits are uncertain (Class III, Level B)

The results from stroke unit trials favour coordinated multidisciplinary teams of staff with expertise in stroke care [515]. The composition of these teams is not formally prescribed, but usually includes stroke physicians, nursing staff, physiotherapists, occupational therapists, and speech and language therapists.

\section{Physiotherapy}

There is no clearly superior model of physiotherapy for stroke rehabilitation [516, 517], but some evidence exists to support specific interventions. Several groups have shown that strength can be improved in a dose-dependent manner, without increasing spasticity [512]. Functional electrical stimulation may increase strength, but the effect on clinically relevant outcomes is uncertain [518].

A systematic review did not demonstrate efficacy of treadmill training to improve walking [519]. Electromechanical gait training in combination with physical therapy may be more effective than physiotherapy alone [520]. There are limited data to support the widespread use of orthoses and assistive devices [521].

$\mathrm{CV}$ fitness can deteriorate during the recovery phase of a stroke. This physical deconditioning impairs active rehabilitation and is a risk marker for further events [522]. Meta-analysis has shown that aerobic training can improve exercise capacity in individuals with mild to moderate motor deficit after stroke [469].

Constraint-induced movement therapy involves intensive task-orientated exercise of the paretic limb, with restraint of the non-paretic limb. The EXCITE study reported positive results for this method 3-9 months after stroke in a group of medically stable stroke survivors, with some arm movement benefit persisting at 1 year [523].

\section{Occupational Therapy}

A systematic review of nine trials comparing OTbased ADL therapy with usual care reported improved functional outcomes in the active intervention group [524]. The data do not justify conclusions on the optimal mode of OT delivery.

A meta-analysis of community-based OT trials found improved performance on ADL measures. The greatest effects were seen in older patients and with the use of 
targeted interventions [525]. Specific leisure-based OT therapies did not translate into improved ADL. A trial of providing OT intervention to care home residents after stroke found less functional deterioration in the active intervention group [526]. No controlled trial data describe the effectiveness of OT beyond 1 year after stroke.

\section{Speech and Language Therapy}

SLT may optimize safe swallowing, and may assist communication. Two trials of formal SLT input for dysphagia found no significant difference to usual care [527]. A study comparing simple written instruction to graded levels of speech and language intervention for dysphagia found no difference in outcomes between the groups [528].

Aphasia and dysarthria are common symptoms after stroke, and impact on quality of life [529]. A systematic review of SLT for dysarthria in non-progressive brain damage (stroke and head injury) found no good-quality evidence for benefit [530]. Similarly, a systematic review of SLT for aphasia [531] reported insufficient good-quality evidence to recommend formal or informal interventions. The studies included in this review were community based and had an average time to therapy of 3 months: they offer little to inform acute ward-based rehabilitation. Two related meta-analyses of studies with weaker design concluded that improvement in speech is greater if SLT is initiated early $[532,533]$. Limited evidence supports the possible use of modified constraint-induced therapy for patients with aphasia $[534,535]$.

\section{Stroke Liaison and Information Provision}

A recent systematic review comparing dedicated stroke liaison to usual care found no evidence of improvement in ADL, subjective health status or carers' health [536]. On subgroup analysis, success of a stroke liaison service was predicted by younger age, less severe deficit, and an emphasis on education within the service.

Inadequate provision of information is predictive of poor quality of life in stroke patients and their families [537]. There is some evidence that combining information with educational sessions improves knowledge and is more effective than providing information alone [538]. As the patient progresses from hospital-based rehabilitation to the community, involvement of carers in rehabilitation becomes increasingly important. Formal training of caregivers in delivery of care reduces personal costs and improves quality of life [539].

\section{Other Groups}

Depending on patient-specific goals, input from various other therapists may be appropriate. Such groups include dieticians, orthoptists and social workers. Although there has been limited formal research in this area, some authors have argued that dedicated staffing creates an 'enriched environment' that encourages practice in rehabilitation activities outside periods of formal therapy [540].

\section{Cognitive Deficits}

Cognitive deficits are common following stroke and impact on quality of life. At present, there is no evidence for the efficacy of specific memory rehabilitation [541]. Cognitive training for attention deficit has not resulted in meaningful clinical improvement in ADL measures [542]. Training for spatial neglect has improved impairment measures, but an effect on ADL performance has not been demonstrated [543]. A few studies have assessed rehabilitation training strategies in visual inattention and apraxia: no specific conclusions can be drawn [544].

\section{Sexuality}

Sexuality can suffer after a stroke. Underlying physical limitations and comorbid vascular disease may be compounded by side effects of medications [545]. It may be desirable to discuss issues of sexuality and intimacy with patients [546]. Provision of support and information is important: many patients wrongly fear that resuming an active sex life may result in further stroke [547].

\section{Complications Affecting Rehabilitation}

Rehabilitation can be compromised by complications, which may be strong predictors of poor functional outcome and mortality. Common complications during inpatient rehabilitation include depression, shoulder pain, falls, urinary disturbances and aspiration pneumonia [548]. Some of these are discussed under 'Prevention and Management of Complications'.

\section{Post-Stroke Depression}

Post-stroke depression is associated with poor rehabilitation results and ultimately poor outcome $[549,550]$.
ESO Executive Committee and ESO Writing Committee 
In clinical practice, only a minority of depressed patients are diagnosed and even fewer are treated [551]. Depression has been reported in up to $33 \%$ of stroke survivors, compared with $13 \%$ of age- and sex-matched controls [552], but reliable estimates of the incidence and prevalence of depression in a stroke cohort are limited [550]. Predictors of post-stroke depression in the rehabilitation setting include increasing physical disability, cognitive impairment and stroke severity [550]. There is no consensus on the optimal method for screening or diagnosis of post-stroke depression. Standard depression screening tools may be inappropriate for patients with aphasia or cognitive impairment $[553,554]$.

Antidepressant drugs such as selective serotonin reuptake inhibitors (SSRIs) and heterocyclics can improve mood after stroke $[555,556]$, but there is less evidence that these agents can effect full remission of a major depressive episode or prevent depression. SSRIs are better tolerated than heterocyclics [557]. There is no good evidence to recommend psychotherapy for treatment or prevention of post-stroke depression [558], although such therapy can elevate mood. There is a lack of robust evidence regarding the effect of treating post-stroke depression on rehabilitation or functional outcomes.

Emotionalism is a distressing symptom for patients and carers. SSRIs may reduce emotional outbursts but effects on quality of life are not clear [559].

\section{Pain and Spasticity}

Post-stroke shoulder pain is common [560], especially in patients with impaired arm function and poor functional status, and is associated with poorer outcome. Passive movement of a paretic limb may be preventive [561]. Electrical stimulation is commonly used for treatment, but its efficacy is unproven [562]. A Cochrane systematic review found insufficient data to recommend the use of orthotic devices for shoulder subluxation, despite a trend towards efficacy for arm strapping of the affected limb [563].

Lamotrigine and gabapentin may be considered for neuropathic pain [564]. They appear to be well tolerated, but cognitive side effects should be considered.

Spasticity in the chronic phase may adversely affect ADL and quality of life [565]. Posture and movement therapy, relaxing therapy, splints and supports are all commonly employed, but a sound evidence base is lacking [566]. Pharmacotherapy with botulinum toxin has proven effects on muscle tone in arms and legs, but functional benefits are less well studied [567-569]. Oral agents are limited in their use because of side effects [570].

\section{Eligibility for Rehabilitation}

An important predictor of rehabilitation outcome is initial stroke severity [549]. Pre-stroke disability is clearly also a strong determinant of outcome [571]. Other factors, such as sex [572], stroke aetiology [573], age [574] and topography of lesion [575], have all been studied as potential predictors of rehabilitation outcome; however, there is no evidence that these non-modifiable factors should influence decisions on rehabilitation [576]. Admission to a dedicated stroke unit improves outcomes for all strokes irrespective of age, sex and severity [61].

Exclusion from rehabilitation on the basis of prestroke dependence remains a contentious issue [577, 578]. Patients with the most severe cognitive or physical impairments have been excluded from most rehabilitation trials, and therefore caution is required in extrapolating results to this group [579]. Limited data suggest that active rehabilitation allows severely disabled patients to return home [580, 581]. For those unable to participate actively, passive movements to prevent contractures or pressure sores have been recommended [2].

\section{Acknowledgement}

We want to thank Dr. Michael Shaw for his assistance during the preparation of the manuscript. 


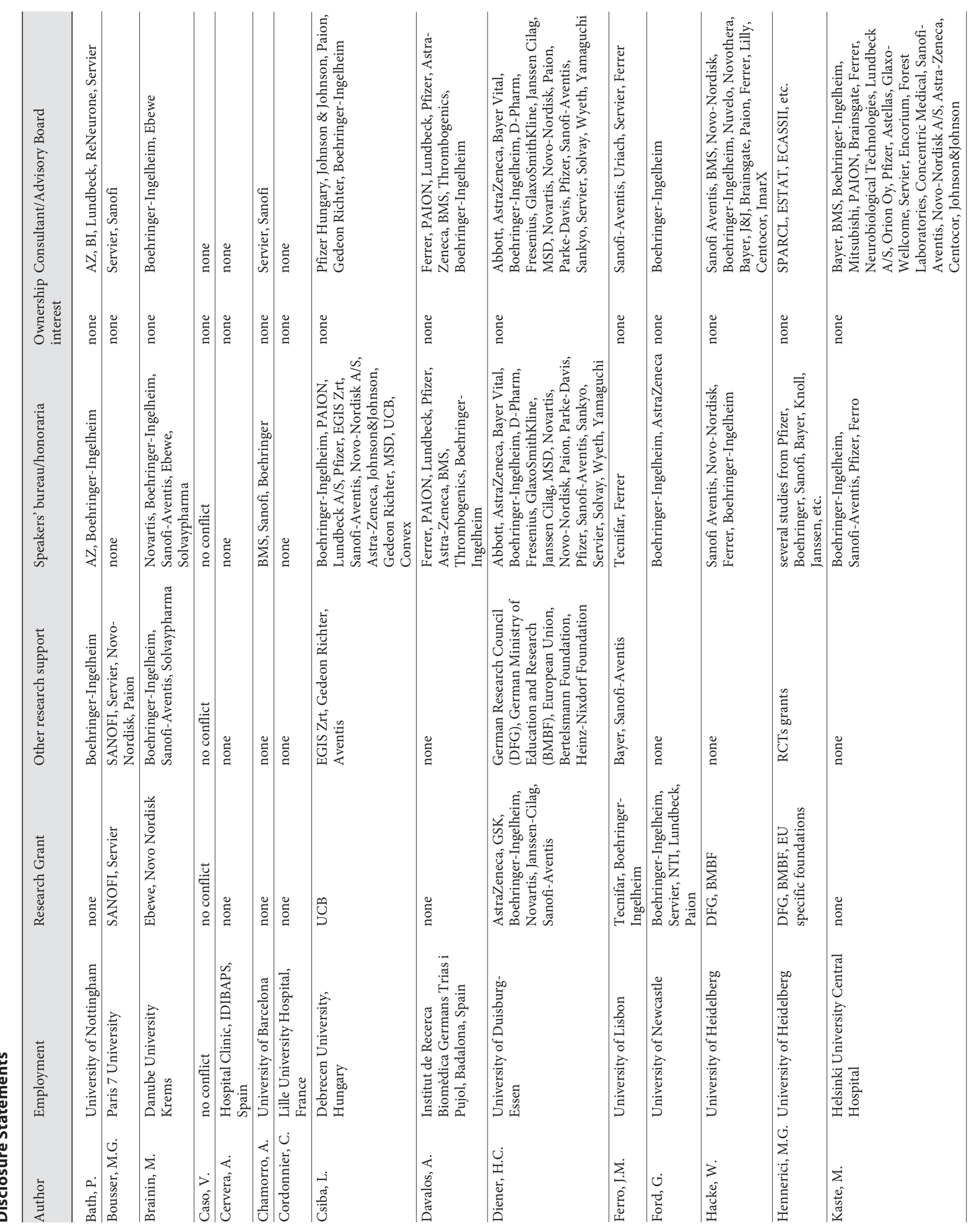




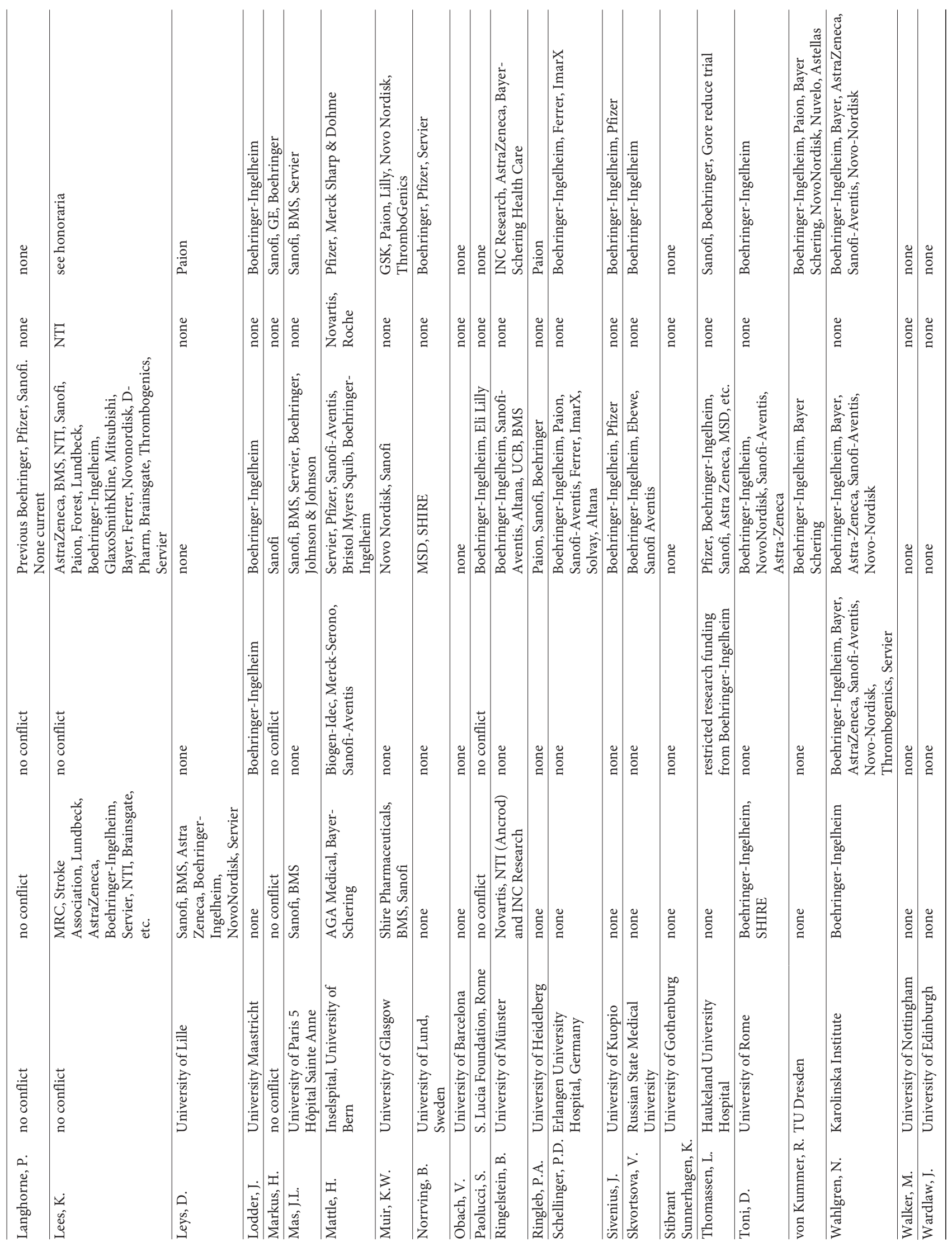




\section{Appendix}

ESO (EUSI) Recommendation Writing Committee

Chair: Werner Hacke, Heidelberg, Germany.

Co-Chairs: Marie-Germaine Bousser, Paris, France; Gary Ford, Newcastle, UK.

Education, Referral and Emergency Room

Co-Chairs: Michael Brainin, Krems, Austria; José Ferro, Lisbon, Portugal.

Members: Charlotte Cordonnier, Lille, France; Heinrich P. Mattle, Bern, Switzerland; Keith Muir, Glasgow, UK; Peter D. Schellinger, Erlangen, Germany.

Substantial assistance received from: Isabel Henriques, Lisbon, Portugal.

\section{Stroke Units}

Co-Chairs: Hans-Christoph Diener, Essen, Germany; Peter Langhorne, Glasgow, UK.

Members: Antony Davalos, Barcelona, Spain; Gary Ford, Newcastle, UK; Veronika Skvortsova, Moscow, Russia.

Imaging and Diagnostics

Co-Chairs: Michael Hennerici, Mannheim, Germany; Markku Kaste, Helsinki, Finland.

Members: Hugh S. Markus, London, UK; E. Bernd Ringelstein, Münster, Germany; Rüdiger von Kummer, Dresden, Germany; Joanna Wardlaw, Edinburgh, UK.

Substantial assistance received from: Dr. Oliver Müller, Heidelberg, Germany.

\section{Prevention}

Co-Chairs: Philip Bath, Nottingham, UK; Didier Leys, Lille, France.

Members: Álvaro Cervera, Barcelona, Spain; László Csiba, Debrecen, Hungary; Jan Lodder, Maastricht, The Netherlands; Nils Gunnar Wahlgren, Stockholm, Sweden.

General Treatment

Co-Chairs: Christoph Diener, Essen, Germany; Peter Langhorne, Glasgow, UK.

Members: Antony Davalos, Barcelona, Spain; Gary Ford, Newcastle, UK; Veronika Skvortsova, Moscow, Russia.

Acute Treatment and Treatment of Complications

Co-Chairs: Angel Chamorro, Barcelona, Spain; Bo Norrving, Lund, Sweden.

Members: Valerica Caso, Perugia, Italy; Jean-Louis Mas, Paris, France; Victor Obach, Barcelona, Spain; Peter A. Ringleb, Heidelberg, Germany; Lars Thomassen, Bergen, Norway.

Rehabilitation

Co-Chairs: Kennedy Lees, Glasgow, UK; Danilo Toni, Rome, Italy.

Members: Stefano Paolucci, Rome, Italy; Juhani Sivenius, Kuopio, Finland; Katharina Stibrant Sunnerhagen, Göteborg, Sweden; Marion F. Walker, Nottingham, UK.

Substantial assistance received from: Dr. Yvonne Teuschl, Dr. Isabel Henriques, Dr. Terence Quinn.

\section{References}

Important references for special topics are marked with asterisks.

1 European Stroke Initiative: European Stroke Initiative recommendations for stroke management. European Stroke Council, European Neurological Society and European Federation of Neurological Societies. Cerebrovasc Dis 2000;10:335-351.

$\checkmark 2$ The European Stroke Initiative Executive Committee and the EUSI Writing Committee: European Stroke Initiative Recommendations for Stroke Management - Update 2003. Cerebrovasc Dis 2003;16:311-337.

3 Steiner T, Kaste M, Forsting M, Mendelow D, Kwiecinski H, Szikora I, Juvela S, Marchel A, Chapot R, Cognard C, Unterberg A, Hacke W: Recommendations for the management of intracranial haemorrhage. I. Spontaneous intracerebral haemorrhage. The European Stroke Initiative Writing Committee and the Writing Committee for the EUSI Executive Committee. Cerebrovasc Dis 2006;22:294-316.

$\checkmark 4$ Lopez AD, Mathers CD, Ezzati M, Jamison DT, Murray CJ: Global and regional burden of disease and risk factors, 2001: systematic analysis of population health data. Lancet 2006;367:1747-1757.
-5 Brainin M, Bornstein N, Boysen G, Demarin V: Acute neurological stroke care in Europe results of the European Stroke Care Inventory. Eur J Neurol 2000;7:5-10.

6 Rothwell PM, Coull AJ, Silver LE, Fairhead JF, Giles MF, Lovelock CE, Redgrave JN, Bull LM, Welch SJ, Cuthbertson FC, Binney LE, Gutnikov SA, Anslow P, Banning AP, Mant D, Mehta Z: Population-based study of eventrate, incidence, case fatality, and mortality for all acute vascular events in all arterial territories (Oxford Vascular Study). Lancet 2005;366:1773-1783.

7 O’Brien JT, Erkinjuntti T, Reisberg B, Roman G, Sawada T, Pantoni L, Bowler JV, Ballard C, DeCarli C, Gorelick PB, Rockwood K, Burns A, Gauthier S, DeKosky ST: Vascular cognitive impairment. Lancet Neurol 2003; 2:89-98.

8 * Adams HP Jr, del Zoppo G, Alberts MJ, Bhatt DL, Brass L, Furlan A, Grubb RL, Higashida RT, Jauch EC, Kidwell C, Lyden PD, Morgenstern LB, Qureshi AI, Rosenwasser RH, Scott PA, Wijdicks EF: Guidelines for the early management of adults with ischemic stroke: a guideline from the American Heart Association/American Stroke Association Stroke Council, Clinical Cardiology
Council, Cardiovascular Radiology and Intervention Council, and the Atherosclerotic Peripheral Vascular Disease and Quality of Care Outcomes in Research Interdisciplinary Working Groups: the American Academy of Neurology affirms the value of this guideline as an educational tool for neurologists. Stroke 2007;38:1655-1711.

$>9$ Albers GW, Hart RG, Lutsep HL, Newell DW, Sacco RL: AHA Scientific Statement. Supplement to the guidelines for the management of transient ischemic attacks: A statement from the Ad Hoc Committee on Guidelines for the Management of Transient Ischemic Attacks, Stroke Council, American Heart Association. Stroke 1999;30:25022511.

10 Alberts MJ, Hademenos G, Latchaw RE, Jagoda A, Marler JR, Mayberg MR, Starke RD, Todd HW, Viste KM, Girgus M, Shephard T, Emr M, Shwayder P, Walker MD: Recommendations for the establishment of primary stroke centers. Brain Attack Coalition. JAMA 2000;283:3102-3109.

- 11 Alberts MJ, Latchaw RE, Selman WR, Shephard T, Hadley MN, Brass LM, Koroshetz W, Marler JR, Booss J, Zorowitz RD, Croft JB, Magnis E, Mulligan D, Jagoda A, O’Connor
ESO Executive Committee and ESO Writing Committee 
R, Cawley CM, Connors JJ, Rose-DeRenzy JA, Emr M, Warren M, Walker MD: Recommendations for comprehensive stroke centers: a consensus statement from the Brain Attack Coalition. Stroke 2005;36:1597-1616.

-12 Biller J, Feinberg WM, Castaldo JE, Whittemore AD, Harbaugh RE, Dempsey RJ, Caplan LR, Kresowik TF, Matchar DB, Toole J, Easton JD, Adams HP Jr, Brass LM, Hobson RW 2nd, Brott TG, Sternau L: Guidelines for carotid endarterectomy: a statement for healthcare professionals from a special writing group of the Stroke Council, American Heart Association. Stroke 1998;29:554-562.

13 Diener HC, Allenberg JR, Bode C, Busse O, Forsting F, Grau AJ, Haberl RL, Hacke W, Hamann GF, Hennerici M, Grond K, Ringelstein B, Ringleb PA: Primär- und Sekundärprävention der zerebralen Ischämie; in Diener HC (ed): Leitlinien für Diagnostik und Therapie in der Neurologie. Stuttgart, Thieme, 2005.

- 14 Fuster V, Ryden LE, Asinger RW, Cannom DS, Crijns HJ, Frye RL, Halperin JL, Kay GN, Klein WW, Levy S, McNamara RL, Prystowsky EN, Wann LS, Wyse DG, Gibbons RJ, Antman EM, Alpert JS, Faxon DP, Gregoratos G, Hiratzka LF, Jacobs AK, Russell RO, Smith SC Jr, Alonso-Garcia A, BlomstromLundqvist C, de Backer G, Flather M, Hradec J, Oto A, Parkhomenko A, Silber S, Torbicki A: ACC/AHA/ESC Guidelines for the Management of Patients with Atrial Fibrillation: Executive Summary A Report of the American College of Cardiology/American Heart Association Task Force on Practice Guidelines and the European Society of Cardiology Committee for Practice Guidelines and Policy Conferences (Committee to Develop Guidelines for the Management of Patients With Atrial Fibrillation) Developed in Collaboration with the North American Society of Pacing and Electrophysiology. Circulation 2001;104:2118-2150.

-15 Goldstein LB, Adams R, Alberts MJ, Appel LJ, Brass LM, Bushnell CD, Culebras A, Degraba TJ, Gorelick PB, Guyton JR, Hart RG, Howard G, Kelly-Hayes M, Nixon JV, Sacco RL: Primary prevention of ischemic stroke: a guideline from the American Heart Association/American Stroke Association Stroke Council: cosponsored by the Atherosclerotic Peripheral Vascular Disease Interdisciplinary Working Group; Cardiovascular Nursing Council; Clinical Cardiology Council; Nutrition, Physical Activity, and Metabolism Council; and the Quality of Care and Outcomes Research Interdisciplinary Working Group: the American Academy of Neurology affirms the value of this guideline. Stroke 2006;37:1583-1633.

16 Hacke W, Kaste M, Skyhoj Olsen T, Orgogozo JM, Bogousslavsky J: European Stroke Initiative (EUSI) recommendations for stroke management. The European Stroke Initiative Writing Committee. Eur J Neurol 2000;7:607-623.
17 Sacco RL, Adams R, Albers G, Alberts MJ, Benavente O, Furie K, Goldstein LB, Gorelick P, Halperin J, Harbaugh R, Johnston SC, Katzan I, Kelly-Hayes M, Kenton EJ, Marks M, Schwamm LH, Tomsick T: Guidelines for prevention of stroke in patients with ischemic stroke or transient ischemic attack: a statement for healthcare professionals from the American Heart Association/American Stroke Association Council on Stroke: cosponsored by the Council on Cardiovascular Radiology and Intervention: the American Academy of Neurology affirms the value of this guideline. Stroke 2006;37:577-617.

18 The National Board of Health and Welfare: Swedish National Guidelines for the Management of Stroke, Version for Health and Medical Personnel 2000; article number 2002-2102-2001.

19 Kjellstrom T, Norrving B, Shatchkute A: Helsingborg Declaration 2006 on European stroke strategies. Cerebrovasc Dis 2007;23: 231-241.

20 Kwan J, Hand P, Sandercock P: A systematic review of barriers to delivery of thrombolysis for acute stroke. Age Ageing 2004;33:116-121.

21 Evenson KR, Rosamond WD, Morris DL: Prehospital and in-hospital delays in acute stroke care. Neuroepidemiology 2001;20: 65-76.

22 Ferro J, Melo T, Oliveira V, Crespo M, Canhão $\mathrm{P}$, Pinto $\mathrm{A}$ : An analysis of the admission delay of acute stroke. Cerebrovasc Dis 1994; 4:72-75.

23 Moser D, Kimble L, Alberts M, Alonzo A, Croft J, Dracup K, Evenson K, Go A, Hand M, Kothari R, Mensah G, Morris D, Pancioli A, Riegel B, Zerwic J: Reducing delay in seeking treatment by patients with acute coronary syndrome and stroke (a scientific statement from the American Heart Association Council on cardiovascular nursing and stroke council. Circulation 2006;114:168182.

24 Gil Nunez A, Vivancos Mora J: Organization of medical care in acute stroke (importance of a good network). Cerebrovasc Dis 2004; 17(suppl 1):113-123.

$\longrightarrow 25$ Keskin O, Kalemoglu M, Ulusoy R: A clinic investigation into prehospital and emergency department delays in acute stroke care. Med Princ Pract 2005;14:408-412.

26 Chang K, Tseng M, Tan T: Prehospital delay after acute stroke in Kaohsiung, Taiwan. Stroke 2004;35:700-704.

27 Yu R, San Jose M, Manzanilla B, Oris M, Gan $\mathrm{R}$ : Sources and reasons for delays in the care of acute stroke patients. J Neurol Sci 2002; 199:49-54

28 Mosley I, Nicol M, Donnan G, Patrick I, Kerr F, Dewey H: The impact of ambulance practice on acute stroke care. Stroke 2007;38: 2765-2770.

29 Wein TH, Staub L, Felberg R, Hickenbottom SL, Chan W, Grotta JC, Demchuk AM, Groff J, Bartholomew LK, Morgenstern LB: Activation of emergency medical services for acute stroke in a nonurban population: the T.L.L. Temple Foundation Stroke Project. Stroke 2000;31:1925-1928.

30 Rosamond W, Evenson K, Schroeder E, Morris D, Johnson A, Brice J: Calling emergency medical services for acute stroke: a study of 9-1-1 tapes. Prehosp Emerg Care 2005;9:1923.

31 Mandelzweig L, Goldbourt U, Boyko V, Tanne D: Perceptual, social, and behavioral factors associated with delays in seeking medical care in patients with symptoms of acute stroke. Stroke 2006;37:1248-1253.

-32 Montaner J, Vidal C, Molina C, Alvarez-Sabin J: Selecting the target and the message for a stroke public education campaign: a local survey conducted by neurologists. Eur J Epidemiol 2001;17:581-586.

33 Porteous GH, Corry MD, Smith WS: Emergency medical services dispatcher identification of stroke and transient ischemic attack. Prehosp Emerg Care 1999;3:211-216.

- 34 DeLemos C, Atkinson R, Croopnick S, Wentworth D, Akins P: How effective are 'community' stroke screening programs at improving stroke knowledge and prevention practices? Results of a 3-month follow-up study. Stroke 2003;34:e247-e249.

- 35 Agyeman O, Nedeltchev K, Arnold M, Fischer U, Remonda L, Isenegger J, Schroth G, Mattle H: Time to admission in acute ischemic stroke and transient ischemic attack. Stroke 2006;37:963-966.

-36 Harraf F, Sharma AK, Brown MM, Lees KR, Vass RI, Kalra L: A multicentre observational study of presentation and early assessment of acute stroke. BMJ 2002;325:17.

- 37 Schneider A, Pancioli A, Khoury J, Rademacher E, Tuchfarber A, Miller R, Woo D, Kissela B, Broderick J: Trends in community knowledge of the warning signs and risk factors for stroke. JAMA 2003;289:343-346.

-38 Nedeltchev K, Fischer U, Arnold M, Kappeler L, Mattle H: Low awareness of transient ischemic attacks and risk factors of stroke in a Swiss urban community. J Neurol 2007; 254:179-184.

-39 Müller-Nordhorn J, Nolte C, Rossnagel K, Jungehülsing G, Reich A, Roll S, Villringer A, Willich S: Knowledge about risk factors for stroke. A population-based survey with 28,090 participants. Stroke 2006;37:946950.

40 Parahoo K, Thompson K, Cooper M, Stringer M, Ennis E, McCollam P: Stroke: awareness of the signs, symptoms and risk factors - a population-based survey. Cerebrovasc Dis 2003; 16:134-140.

-41 Evci E, Memis S, Ergin F, Beser E: A population-based study on awareness of stroke in Turkey. Eur J Neurol 2007;14:517-522.

42 Sug Yoon S, Heller R, Levi C, Wiggers J, Fitzgerald P: Knowledge of stroke risk factors, warning symptoms, and treatment among an Australian urban population. Stroke 2001;32:1926-1930. 
43 Pandian J, Jaison A, Deepak S, Kalra G, Shamsher S, Lincoln D, Abraham G: Public awareness of warning symptoms, risk factors, and treatment of stroke in northwest India. Stroke 2005;36:644-648.

44 DuBard C, Garrett J, Gizlice Z: Effect of language on heart attack and stroke awareness among U.S. Hispanics. Am J Prev Med 2006; 30:189-196.

-45 Luiz T, Moosmann A, Koch C, Behrens S, Daffertshofer M, Ellinger K: Optimized logistics in the prehospital management of acute stroke (in German). Anasthesiol Intensivmed Notfallmed Schmerzther 2001;36: 735-741.

46 Schmidt N, Huwel J, Weisner B: Causes of a prolonged prehospital phase in patients admitted to a stroke unit. Can it be influenced by campaigns to educate the public? (in German). Nervenarzt 2005;76:181-185.

-47 Alberts M, Perry A, Dawson D, Bertels C: Effects of public and professional education on reducing the delay in presentation and referral of stroke patients. Stroke 1992;23:352356.

48 Barsan W, Brott T, Broderick J, Haley EC J, Levy D, Marler J: Urgent therapy for acute stroke. Effects of a stroke trial on untreated patients. Stroke 1994;25:2132-2137.

49 Hodgson C, Lindsay P, Rubini F: Can mass media influence emergency department visits for stroke? Stroke 2007;38:2115-2122.

50 Morgenstern L, Staub L, Chan W, Wein T, Bartholomew L, King M, Felberg R, Burgin W, Groff J, Hickenbottom S, Saldin K, Demchuk A, Kalra A, Dhingra A, Grotta J: Improving delivery of acute stroke therapy: The TLL Temple Foundation Stroke Project. Stroke 2002;33:160-166.

-51 Morgenstern L, Bartholomew L, Grotta J, Staub L, King M, Chan W: Sustained benefit of a community and professional intervention to increase acute stroke therapy. Arch Intern Med 2003;163:2198-2202.

52 Wojner-Alexandrov A, Alexandrov A, Rodriguez D, Persse D, Grotta J: Houston paramedic and emergency stroke treatment and outcomes study (HoPSTO). Stroke 2005;36: 1512-1518.

53 Kwan J, Hand P, Sandercock P: Improving the efficiency of delivery of thrombolysis for acute stroke: a systematic review. QJM 2004; 97:273-279.

54 Behrens S, Daffertshofer M, Interthal C, Ellinger K, van Ackern K, Hennerici M: Improvement in stroke quality management by an educational programme. Cerebrovasc Dis 2002;13:262-266.

55 Billings-Gagliardi S, Fontneau N, Wolf M, Barrett S, Hademenos G, Mazor K: Educating the next generation of physicians about stroke: incorporating stroke prevention into the medical school curriculum. Stroke 2001; $32: 2854-2859$.
56 Wang M, Lavine S, Soukiasian H, Tabrizi R, Levy M, Giannotta S: Treating stroke as a medical emergency: a survey of resident physicians' attitudes toward 'brain attack' and carotid endarterectomy. Neurosurgery 2001; 48:1109-1115.

57 Derex L, Adeleine P, Nighoghossian N, Honnorat J, Trouillas P: Factors influencing early admission in a French stroke unit. Stroke 2002;33:153-159.

58 Barber PA, Zhang J, Demchuk AM, Hill MD, Buchan AM: Why are stroke patients excluded from TPA therapy? An analysis of patient eligibility. Neurology 2001;56:1015-1020.

59 Camerlingo M, Casto L, Censori B, Ferraro B, Gazzaniga G, Partziguian T, Signore M, Panagia C, Fascendini A, Cesana BM, Mamoli A: Experience with a questionnaire administered by emergency medical service for pre-hospital identification of patients with acute stroke. Neurol Sci 2001;22:357-361.

60 Nor A, Mc Allister C, Louw S, Dyker A, Davis M, Jenkinson D, Ford G: Agreement between ambulance paramedic- and physician-recorded neurological signs using the Face Arm Speech Test (FAST) in acute stroke patients. Stroke 2004;35:1355-1359.

61 * Stroke Unit Trialists' Collaboration: Organised inpatient (stroke unit) care for stroke. Cochrane Database Syst Rev 2007: CD000197.

62 Stroke Unit Trialists' Collaboration: A systematic review of the randomised trials of organised impatient (stroke unit) care after stroke. BMJ 1997;314:1151-1159.

63 Barsan W, Brott T, Broderick J, Haley E, Levy D, Marler J: Time of hospital presentation in patients with acute stroke. Arch Intern Med 1993;153:2558-2561.

64 Harbison J, Massey A, Barnett L, Hodge D, Ford G: Rapid ambulance protocol for acute stroke. Lancet 1999;353:1935.

65 Sobesky J, Frackowiak M, Zaro Weber O, Hahn M, Möller-Hartmann W, Rudolf J, Neveling M, Grond M, Schmulling S, Jacobs A, Heiss W: The Cologne stroke experience: safety and outcome in 450 patients treated with intravenous thrombolysis. Cerebrovasc Dis 2007;24:56-65.

66 Thomas SH, Kociszewski C, Schwamm LH, Wedel SK: The evolving role of helicopter emergency medical services in the transfer of stroke patients to specialized centers. Prehosp Emerg Care 2002;6:210-214.

67 Svenson J, O’Connor J, Lindsay M: Is air transport faster? A comparison of air versus ground transport times for interfacility transfers in a regional referral system. Air Med J 2006;25:170-172.

68 Silliman S, Quinn B, Huggert V, Merino J: Use of a field-to-stroke center helicopter transport program to extend thrombolytic therapy to rural residents. Stroke 2003;34:729-733.

69 Diaz M, Hendey G, Winters R: How far is by air? The derivation of an air:ground coefficient. J Emerg Med 2003;24:199-202.
70 Diaz M, Hendey G, Bivins H: When is helicopter faster? A comparison of helicopter and ground ambulance transport times. J Trauma 2005;58:148-153.

71 Silbergleit R, Scott P, Lowell M, Silbergleit R: Cost-effectiveness of helicopter transfer of stroke patients for thrombolysis. Acad Emerg Med 2003;10:966-972.

$>72$ Shafqat S, Kvedar J, Guanci M, Chang Y, Schwamm L: Role for telemedicine in acute stroke: feasibility and reliability of remote administration of the NIH Stroke Scale. Stroke 1999;30:2141-2145.

73 Wiborg A, Widder B, et al: Teleneurology to improve stroke care in rural areas. Stroke 2003;34:2951-2956.

74 Handschu R, Littmann R, Reulbach U, Gaul C, Heckmann J, Neundorfer B, Scibor M: Telemedicine in emergency evaluation of acute stroke: interrater agreement in remote video examination with a novel multimedia system. Stroke 2003;34:2842-2846.

75 Wang S, Lee S, Pardue C, Ramsingh D, Waller J, Gross H, Nichols FT 3rd, Hess D, Adams R: Remote evaluation of acute ischemic stroke: reliability of National Institutes of Health Stroke Scale via telestroke. Stroke 2003;34:e188-e191.

76 Audebert H, Kukla C, Clarmann von Claranau S, Kuhn J, Vatankhah B, Schenkel J, Ickenstein G, Haberl R, Horn M: Telemedicine for safe and extended use of thrombolysis in stroke: the Telemedical Pilot Project for Integrative Stroke Care (TEMPiS) in Bavaria. Stroke 2005;36:287-291.

77 Audebert H, Kukla C, Vatankhah B, Glotzler B, Schenkel J, Hofer S, Fürst A, Haberl R: Comparison of tissues plasminogen activator administration management between Telestroke Network hospitals and academic stroke centers: the Telemedical Pilot Project for Integrative Stroke Care in Bavaria, Germany. Stroke 2006;37:1822-1827.

78 Hess D, Wang S, Hamilton W, Lee S, Pardue C, Waller J, Gross H, Nichols F, Hall C, Adams R: REACH: clinical feasibility of a rural telestroke network. Stroke 2005;36:20182020

79 Schwab S, Vatankhah B, Kukla C, Hauchwitz M, Bogdahn U, Furst A, Audebert HJ, Horn $\mathrm{M}$ : Long-term outcome after thrombolysis in telemedical stroke care. Neurology 2007;69: 898-903.

$>80$ Audebert H, Schenkel J, Heuschmann P, Bogdahn U, Haberl R: Effects of the implementation of a telemedical stroke network: the Telemedic Pilot Project for Integrative Stroke Care (TEMPiS) in Bavaria, Germany. Lancet Neurol 2006;5:742-748.

81 Schwamm L, Rosenthal E, Hirshberg A, Schaefer P, Little E, Kvedar J, Petkovska I, Koroshetz W, Levine S: Virtual TeleStroke support for the emergency department evaluation of acute stroke. Acad Emerg Med 2004;11:1193-1197.
ESO Executive Committee and ESO Writing Committee 
82 Bélvis R, Cocho D, Martí-Fàbregas J, Pagonabarraga J, Aleu A, García-Bargo M, Pons J, Coma E, García-Alfranca F, Jimémez-Fàbrega X, Martí-Vilalta J: Benefits of a prehospital stroke code system. Feasibility and efficacy in the first year of clinical practice in Barcelona/Spain. Cerebrovasc Dis 2005; 19 : 96-101.

83 de la Ossa NP, Sanchez-Ojanguren J, Palomeras E, Millan M, Arenillas JF, Dorado L, Guerrero C, Abilleira S, Davalos A: Influence of the stroke code activation source on the outcome of acute ischemic stroke patients. Neurology 2008;70:1238-1243.

84 Giles MF, Rothwell PM: Risk of stroke early after transient ischaemic attack: a systematic review and meta-analysis. Lancet Neurol 2007;6:1063-1072.

85 Lavallee PC, Meseguer E, Abboud H, Cabrejo L, Olivot JM, Simon O, Mazighi M, Nifle C, Niclot P, Lapergue B, Klein IF, Brochet E, Steg PG, Leseche G, Labreuche J, Touboul PJ, Amarenco P: A transient ischaemic attack clinic with round-the-clock access (SOSTIA): feasibility and effects. Lancet Neurol 2007;6:953-960.

86 * Rothwell PM, Giles MF, Chandratheva A, Marquardt L, Geraghty O, Redgrave JN, Lovelock CE, Binney LE, Bull LM, Cuthbertson FC, Welch SJ, Bosch S, Carasco-Alexander F, Silver LE, Gutnikov SA, Mehta Z: Effect of urgent treatment of transient ischaemic attack and minor stroke on early recurrent stroke (EXPRESS study): a prospective population-based sequential comparison. Lancet 2007;370:1432-1442.

-87 Kwan J, Sandercock P: In-hospital care pathways for stroke: a Cochrane systematic review. Stroke 2003;34:587-588.

-88 Suzuki M, Imai A, Honda M, Kobayashi K, Ohtsuka S: Role of a critical pathway for door-to-CT-completion interval in the management of acute ischemic stroke patients in the emergency room. Keio J Med 2004;53: 247-250.

89 Mehdiratta M, Woolfenden A, Chapman K, Johnston D, Schulzer M, Beckman J, Teal P: Reduction in IV t-PA door to needle times using an acute stroke triage pathway. Can J Neurol Sci 2006;33:214-216.

-90 NINDS rt-PA Stroke Study Group: A systems approach to immediate evaluation and management of hyperacute stroke. Experience at eight centers and implications for community practice and patient care. The National Institute of Neurological Disorders and Stroke (NINDS) rt-PA Stroke Study Group. Stroke 1997;28:1530-1540.

91 Acker J, Pancioli A, Crocco T, Eckstein M, Jauch E, Larrabee H, Meltzer N, Mergendahl W, Munn J, Prentiss S, Sand C, Saver J, Eigel B, Gilpin B, Schoeberl M, Solis P, Bailey J, Horton K, Stranne S; American Heart Association; American Stroke Association Expert Panel on Emergency Medical Services Systems, Stroke Council: Implementation strategies for emergency medical services within stroke systems of care: a policy statement from the American Heart Association/ American Stroke Association Expert Panel on Emergency Medical Services Systems and the Stroke Council. Stroke 2007;38: 3097-3115.

92 Alberts M, Latchaw R, Selman W, Shephard T, Hadley M, Brass L, Koroshetz W, Marler J, Booss J, Zorowitz R, Croft J, Magnis E, Mulligan D, Jagoda A, O'Connor R, Cawley C, Connors J, Rose-DeRenzy J, Emr M, Warren M, Walker M: Brain Attack Coalition. Recommendations for comprehensive stroke centers: a consensus statement from the Brain Attack Coalition. Stroke 2005;36:1597-1616.

$\$ 93$ Douglas VC, Tong DC, Gillum LA, Zhao S, Brass LM, Dostal J, Johnston SC: Do the Brain Attack Coalition's criteria for stroke centers improve care for ischemic stroke? Neurology 2005;64:422-427.

\$4 Alvarez Sabín J, Molina C, Abilleira S, Montaner J, García F, Alijotas J: 'Stroke code'. Shortening the delay in reperfusion treatment of acute ischemic stroke. Med Clin (Barc) 1999;113:481-483.

95 Lindsberg P, Häppölä O, Kallela M, Valanne L, Kuisma M, Kaste M: Door to thrombolysis: ER reorganization and reduced delays to acute stroke treatment. Neurology 2006;67:334-336.

96 Hamidon B, Dewey H: Impact of acute stroke team emergency calls on in-hospital delays in acute stroke care. J Clin Neurosci 2007;14:831-834.

97 Goldstein L, Simel D: Is this patient having a stroke? JAMA 2005;293:2391-2402.

$\$ 98$ Harbison J, Hossain O, Jenkinson D, Davis J, Louw S, Ford G: Diagnostic accuracy of stroke referrals from primary care, emergency room physicians and ambulance staff using the face arm speech test. Stroke 2003;34:71-76.

99 Hand P, Kwan J, Lindley R, Dennis M, Wardlaw J: Distinguishing between stroke and mimic at the bedside: The Brain Attack Study. Stroke 2006;37:769-775.

100 Nor AM, Davis J, Sen B, Shipsey D, Louw SJ, Dyker AG, Davis M, Ford GA: The Recognition of Stroke in the Emergency Room (ROSIER) scale: development and validation of a stroke recognition instrument. Lancet Neurol 2005;4:727-734.

101 Mitchell J, Ballard D, Whisnant J, Ammering C, Samsa G, Matchar D: What role do neurologists play in determining the costs and outcomes of stroke patients? Stroke 1996;27:1937-1943.

102 Goldstein L, Matchar D, Hoff-Lindquist J, Samsa G, Study HRVS: Neurologist care is associated with increased testing but improved outcomes. Neurology 2003;61:792796.

103 Tilley B, Lyden P, Brott T, Lu M, Levine S, Welch K: Total Quality improvement method for reduction of delays between emergency department admission and treatment of acute ischemic stroke. The National Institute of Neurological Disorders and Stroke rt-PA Stroke Study Group. Arch Neurol 1997;54:1466-1474.

104 Lyden P, Brott T, Tilley B, Welch KM, Mascha EJ, Levine S, Haley EC, Grotta J, Marler J: Improved reliability of the NIH Stroke Scale using video training. NINDS TPA Stroke Study Group. Stroke 1994;25:22202226.

105 Trapl M, Enderle P, Nowotny M, Teuschl Y, Matz K, Dachenhausen A, Brainin M: Dysphagia bedside screening for acute-stroke patients: the Gugging Swallowing Screen. Stroke 2007;38:2948-2952.

106 Leys D, Ringelstein EB, Kaste M, Hacke W: The main components of stroke unit care: results of a European expert survey. Cerebrovasc Dis 2007;23:344-352.

107 LaMonte MP, Bahouth MN, Hu P, Pathan MY, Yarbrough KL, Gunawardane R, Crarey $\mathrm{P}$, Page $\mathrm{W}$ : Telemedicine for acute stroke: triumphs and pitfalls. Stroke 2003; 34:725-728.

$108 \mathrm{Wu} \mathrm{O}$, Langhorne P: The challenge of acute-stroke management: does telemedicine offer a solution? Int J Stroke 2006; 1: 201-207.

109 Ronning OM, Guldvog B, Stavem K: The benefit of an acute stroke unit in patients with intracranial haemorrhage: a controlled trial. J Neurol Neurosurg Psychiatry 2001;70:631-634.

110 Seenan P, Long M, Langhorne P: Stroke units in their natural habitat: systematic review of observational studies. Stroke 2007; 38:1886-1892.

111 Candelise L, Gattinoni M, Bersano A, Micieli G, Sterzi R, Morabito A: Stroke-unit care for acute stroke patients: an observational follow-up study. Lancet 2007;369: 299-305.

112 Walsh T, Cotter S, Boland M, Greally T, O'Riordan R, Lyons D: Stroke unit care is superior to general rehabilitation unit care. Ir Med J 2006;99:300-302.

- 113 Launois R, Giroud M, Megnigbeto AC, Le Lay K, Presente G, Mahagne MH, Durand I, Gaudin AF: Estimating the cost-effectiveness of stroke units in France compared with conventional care. Stroke 2004;35: 770-775.

- 114 Epifanov Y, Dodel R, Haacke C, Schaeg M, Schoffski O, Hennerici M, Back T: Costs of acute stroke care on regular neurological wards: a comparison with stroke unit setting. Health Policy 2007;81:339-349.

115 Patel A, Knapp M, Perez I, Evans A, Kalra L: Alternative strategies for stroke care: cost-effectiveness and cost-utility analyses from a prospective randomized controlled trial. Stroke 2004;35:196-203.

116 * Brady BK, McGahan L, Skidmore B: Systematic review of economic evidence on stroke rehabilitation services. Int J Technol Assess Health Care 2005;21:15-21. 
-117 Moodie M, Cadilhac D, Pearce D, Mihalopoulos C, Carter R, Davis S, Donnan G: Economic evaluation of Australian stroke services: a prospective, multicenter study comparing dedicated stroke units with other care modalities. Stroke 2006;37:27902795.

-118 Dewey HM, Sherry LJ, Collier JM: Stroke rehabilitation 2007: what should it be? Int J Stroke 2007;2:191-200.

119 Langhorne P, Pollock A: What are the components of effective stroke unit care? Age Ageing 2002;31:365-371.

-120 Teasell R, Foley N, Bhogal S, Bagg S, Jutai J: Evidence-based practice and setting basic standards for stroke rehabilitation in Canada. Top Stroke Rehabil 2006;13:59-65.

-121 Langhorne P, Dey P, Woodman M, Kalra L, Wood-Dauphinee S, Patel N, Hamrin E: Is stroke unit care portable? A systematic review of the clinical trials. Age Ageing 2005; 34:324-330.

122 Fryback D, Thornbury J: The efficacy of diagnostic imaging. Med Decis Making 1991; 11:88-94.

123 Schramm P, Schellinger P, Klotz E, Kallenberg K, Fiebach J, Külkens S, Heiland S, Knauth M, Sartor K: Comparison of perfusion CT and CTA source images with PWI and DWI in patients with acute stroke $<6 \mathrm{~h}$. Stroke 2004;35:1562-1568.

-124 Barber P, Hill M, Eliasziw M, Demchuk A, Warwick Pexman J, Hudon M, Tomanek A, Frayne R, Buchan A: Neuroimaging of the brain in acute ischemic stroke: a comparison of computed tomography and magnetic resonance diffusion weighted imaging. J Neurol Neurosurg Psychiatry 2005;76: 1528-1533.

-125 Hand P, Wardlaw J, Rowat A, Haisma J, Lindley R, Dennis M: MR brain imaging in patients with acute stroke - feasibility and patient-related difficulties. J Neurol Neurosurg Psychiatry 2005;76:1525-1527.

$126 *$ The National Institute of Neurological Disorders and Stroke rt-PA Stroke Study Group: Tissue plasminogen activator for acute ischemic stroke. New Engl J Med 1995;333:1581-1587.

127 * Wardlaw J, Keir S, Dennis M: The impact of delays in computed tomography of the brain on the accuracy of diagnosis and subsequent management in patients with $\mathrm{mi}^{-}$ nor stroke. JNNP 2003;74:77-81.

${ }_{128}$ * Kidwell C, Chalela J, Saver J, Starkman S, Hill M, Demchuk A, Butman J, Patronas N, Alger J, Latour L, Luby M, Baird A, Leary M, Tremwel M, Ovbiagele B, Fredieu A, Suzuki S, Villablanca J, Davis S, Dunn B, Todd J, Ezzeddine M, Haymore J, Lynch J, Davis L, Warach S: Comparison of MRI and CT for detection of acute intracerebral hemorrhage. JAMA 2004;292:1823-1830.

-129 * Schellinger PD, Fiebach JB: Intracranial hemorrhage: the role of magnetic resonance imaging. Neurocrit Care 2004;1:3145 .
130 Wardlaw JM, Keir SL, Seymour J, Lewis S, Sandercock PA, Dennis MS, Cairns J: What is the best imaging strategy for acute stroke? Health Technol Assess 2004;8:1-180.

131 * Chalela J, Kidwell C, Nentwich L, Luby M, Butmann J, Demchuk A, Hill M, Patronas N, Latour L, Warach S: Magnetic resonance imaging and computed tomography in emergency assessment of patients with suspected acute stroke: a prospective comparison. Lancet 2007;369:293-298.

-132 von Kummer R, Bourquain H, Bastianello S, Bozzao L, Manelfe C, Meier D, Hacke W: Early prediction of irreversible brain damage after ischemic stroke by computed tomography. Radiology 2001;219:95-100.

133 von Kummer R, Allen K, Holle R, Bozzao L, Bastianello S, Manelfe C, Bluhmki E, Ringleb P, Meier D, Hacke W: Acute stroke: usefulness of early CT findings before thrombolytic therapy. Radiology 1997;205:327333.

134 Barber P, Demchuk A, Zhang J, Buchan A: Validity and reliability of a quantitative computed tomography score in predicting outcome of hyperacute stroke before thrombolytic therapy. Lancet 2000;355: 1670-1674.

135 Wardlaw J, Mielke O: Early signs of brain infarction at CT: Observer reliability and outcome after thrombolytic treatment systematic review. Radiology 2005;235: 444-453.

136 Wardlaw J, West T, Sandercock P, Lewis S, Mielke O: The International Stroke Trials Collaborative Group: Visible infarction on computed tomography is an independent predictor of poor functional outcome after stroke, and not of haemorrhagic transformation. JNNP 2003;74:452-458.

137 von Kummer R: Effect of training in reading CT scans on patient selection for ECASS II. Neurology 1998;51(suppl 3):S50-S52.

138 Wardlaw J, Farrall A, Perry D, von Kummer R, Mielke O, Moulin T, Ciccone A, Hill M: Factors influencing detection of early CT signs of cerebral ischaemia - an internetbased, international, multi-observer study. Stroke 2007;38:1250-1256.

139 von Kummer R, Meyding-Lamadé U, Forsting M, Rosin L, Rieke K, Hacke W, Sartor $\mathrm{K}$ : Sensitivity and prognostic value of early computed tomography in middle cerebral artery trunk occlusion. AJNR Am J Neuroradiol 1994;15:9-15.

140 Dzialowski I, Weber J, Doerfler A, Forsting $\mathrm{M}$, von Kummer R: Brain tissue water uptake after middle cerebral artery occlusion assessed with CT. J Neuroimaging 2004; 14: $42-48$.

141 Dzialowski I, Weber J, Klotz E, Göricke S, Dörfler A, Forsting M, von Kummer R: CT monitoring of ischemic brain tissue water content during middle cerebral artery occlusion and reperfusion. Radiology 2007; 243:720-726
142 Hill M, Rowley H, Adler F, Eliasziew M, Furlan A, Higashida R, Wechsler L, Roberts H, Dillon W, Fischbein N, Firszt C, Schulz $\mathrm{G}$, Buchan A: Selection of acute ischemic stroke patients for intra-arterial thrombolysis with pro-urokinase by using ASPECTS. Stroke 2003;34:1925-1931.

143 Patel S, Levine S, Tilley B, Grotta J, Lu M, Frankel M, Haley E, Brott T, Broderick J, Horowitz S, Lyden P, Lewandowski C, Marler J, Welch K: Lack of clinical significance of early ischemic changes on computed tomography in acute stroke. JAMA 2001;286: 2830-2838.

144 * Dimigen M, Keir S, Dennis M, Wardlaw J: Long-term visibility of primary intracerebral hemorrhage on magnetic resonance imaging. J Stroke Cerebrovasc Dis 2004;13: 104-108.

145 Ay H, Oliveira-Filho J, Buonanno F, Schaefer P, Furie K, Chang Y, Rordorf G, Schwamm L, Gonzalez R, Koroshetz W: 'Footprints' of transient ischemic attacks: a diffusion-weighted MRI study. Cerebrovasc Dis 2002;14:177-186.

146 Fiehler J, Knudsen K, Kucinski T, Kidwell C, Alger J, Thomalla G, Eckert B, Wittkugel O, Weiller C, Zeumer H, Röther J: Predictors of apparent diffusion coefficient normalization in stroke patients. Stroke 2004; 35:514-519.

147 * Oppenheim C, Lamy C, Touze E, Calvet D, Hamon M, Mas JL, Meder JF: Do transient ischemic attacks with diffusionweighted imaging abnormalities correspond to brain infarctions? AJNR Am J Neuroradiol 2006;27:1782-1787.

148 Wardlaw J, Keir S, Bastin M, Armitage P, Rana A: Is diffusion imaging appearance an independent predictor of outcome after ischemic stroke? Neurology 2002;59:13811387.

149 Hand P, Wardlaw J, Rivers C, Armitage P, Bastin M, Lindley R, Dennis M: MR diffusion-weighted imaging and outcome prediction after ischemic stroke. Neurology 2006;66:1159-1163.

150 Kane I, Carpenter T, Chappell F, Rivers C, Armitage P, Sandercock P, Wardlaw J: Comparison of 10 different magnetic resonance perfusion imaging processing methods in acute ischemic stroke: effect on lesion size, proportion of patients with diffusion/perfusion mismatch, clinical scores, and radiologic outcomes. Stroke 2007;38:3158-3164.

151 Wintermark M, Reichhart M, Thiran J, Maeder P, Chalaron M, Schnyder P, Bogousslavsky J, Meul R: Prognostic accuracy of cerebral blood flow measurement by perfusion computed tomography, at the time of emergency room admission, in acute stroke patients. Ann Neurol 2002;51:417-432.

152 Lev M, Gonzalez R, Schaefer P, Koroshetz W, Dillon W, Wintermark M: Cerebral blood flow thresholds in acute stroke triage. Stroke 2006;37:1334-1339.
ESO Executive Committee and ESO Writing Committee 
153* Kane I, Sandercock P, Wardlaw J: Magnetic resonance perfusion diffusion mismatch and thrombolysis in acute ischaemic stroke: a systematic review of the evidence to date. JNNP 2007;78:485-490.

-154 * Furlan A, Higashida R, Wechsler L, Gent M, Rowley H, Kase C, Pessin M, Ahuja A, Callahan F, Clark WM, Silver F, Rivera F: Intra-arterial prourokinase for acute ischemic stroke. The PROACT II study: a randomized controlled trial. Prolyse in Acute Cerebral Thromboembolism. JAMA 1999; 282:2003-2011.

-155 Mattle HP, Arnold M, Georgiadis D, Baumann C, Nedeltchev K, Benninger D, Remonda L, von Budingen C, Diana A, Pangalu A, Schroth G, Baumgartner RW: Comparison of intraarterial and intravenous thrombolysis for ischemic stroke with hyperdense middle cerebral artery sign. Stroke 2008;39:379-383.

-156 Rubiera M, Ribo M, Delgado-Mederos R, Santamarina E, Degado P, Montaner J, Alvarez-Sabin J, Molina C: Tandem internal carotid artery/middle cerebral artery occlusion. An independent predictor of poor outcome after systemic thrombolysis. Stroke 2006;37:2301-2305.

- 157 Fischer U, Arnold M, Nedeltchev K, Brekenfeld C, Ballinari P, Remonda L, Schroth G, Mattle H: NIHSS score and arteriographic findings in acute ischemic stroke. Stroke 2005;36:2121-2125.

-158 Allendoerfer J, Goertler M, von Reutern G: Prognostic relevance of ultra-early doppler sonography in acute ischaemic stroke: a prospective multicentre study. Lancet Neurol 2005;5:835-840.

-159 Coutts S, Simon J, Tomanek A, Barber P, Chan J, Hudon M, Mitchell J, Frayne M, Buchan A, Demchuk A: Reliability of assessing percentage of diffusion-perfusion mismatch. Stroke 2003;34:1681-1683.

160 * Albers GW, Thijs VN, Wechsler L, Kemp S, Schlaug G, Skalabrin E, Bammer R, Kakuda W, Lansberg MG, Shuaib A, Coplin W, Hamilton S, Moseley M, Marks MP: Magnetic resonance imaging profiles predict clinical response to early reperfusion: the diffusion and perfusion imaging evaluation for understanding stroke evolution (DEFUSE) study. Ann Neurol 2006;60: 508-517.

-161 * Bandera E, Botteri M, Minelli C, Sutton A, Abrams K, Latronico N: Cerebral blood flow threshold of ischemic penumbra and infarct core in acute ischemic stroke: a systematic review. Stroke 2006;37:1334-1339.

$\checkmark 162$ Carpenter T, Armitage P, Bastin M, Wardlaw J: DSC Perfusion MRI - Quantification and reduction of systematic errors arising in areas of reduced cerebral blood flow. Magn Reson Med 2006;56:1342-1349.
163 Rivers C, Wardlaw J, Armitage P, Bastin M, Carpenter T, Cvoro V, Hand P, Dennis M Do acute diffusion- and perfusion-weighted MRI lesions identify final infarct volume in ischaemic stroke? Stroke 2006;37:98104.

164 Dávalos A, Blanco M, Pedraza S, Leira R, Castellanos M, Pumar J, Silva Y, Serena J, Castillo J: The clinical-DWI mismatch: a new diagnostic approach to the brain tissue at risk of infarction. Neurology 2004;62: 2187-2192.

165 Kent D, Hill M, Ruthazer R, Coutts S, Demchuk A, Dzialowski I, Wunderlich O, von Kummer R: 'Clinical-CT mismatch' and the response to systemic thrombolytic therapy in acute ischemic stroke. Stroke 2005; 36:1695-1699.

166 Cordonnier C, Al-Shahi Salman R, Wardlaw J: Spontaneous brain microbleeds: systematic review, subgroup analyses and standards for study design and reporting. Brain 2007;130:1988-2003.

167 Fiehler J, Albers GW, Boulanger JM, Derex L, Gass A, Hjort N, Kim JS, Liebeskind DS, Neumann-Haefelin T, Pedraza S, Rother J, Rothwell P, Rovira A, Schellinger PD, Trenkler J; MR STROKE Group: Bleeding risk analysis in stroke imaging before thrombolysis (BRASIL): pooled analysis of $\mathrm{T}_{2}{ }^{*}$-weighted magnetic resonance imaging data from 570 patients. Stroke 2007;38: 2738-2744.

168 Forsting M, Wanke I: Funeral for a friend. Stroke 2003;34:1324-1332.

169 Willinsky R, Taylor S, TerBrugge K, Farb R, Tomlinson G, Montanera W: Neurologic complications of cerebral angiography: prospective analysis of 2,899 procedures and review of the literature. Radiology 2003;227:522-528.

170 * Wardlaw J, Chappell F, Best J, Wartolowska K, Berry E; on behalf of the NHS R\&D Health Technology Assessment Carotid Stenosis Imaging Group: Non-invasive imaging compared with intra-arterial angiography in the diagnosis of symptomatic carotid stenosis: a meta-analysis. Lancet 2006; 367:1503-1512.

171 Wardlaw JM, Chappell FM, Stevenson M, De Nigris E, Thomas S, Gillard J, Berry E, Young G, Rothwell P, Roditi G, Gough M, Brennan A, Bamford J, Best J: Accurate, practical and cost-effective assessment of carotid stenosis in the UK. Health Technol Assess 2006;10:1-182.

172 Flossmann E, Rothwell P: Prognosis of ver tebrobasilar transient ischaemic attack and minor stroke. Brain 2003;126:1940-1954.

173 Khan S, Cloud G, Kerry S, Markus H: Imaging of vertebral artery stenosis: a systematic review. J Neurol Neurosurg Psychiatry 2007;78:1218-1225.
174 Postert T, Federlein J, Przuntek H, Buttner $\mathrm{T}$ : Insufficient and absent acoustic temporal bone window: potential and limitations of transcranial contrast-enhanced colorcoded sonography and contrast-enhanced power-based sonography. Ultrasound Med Biol 1997;23:857-862.

175 Alexandrov AV, Burgin WS, Demchuk AM, El-Mitwalli A, Grotta JC: Speed of intracranial clot lysis with intravenous tissue plasminogen activator therapy: sonographic classification and short-term improvement. Circulation 2001;103:2897-2902.

176 Droste D, Jurgens R, Nabavi D, Schuierer G, Weber S, Ringelstein E: Echocontrast-enhanced ultrasound of extracranial internal carotid artery high-grade stenosis and occlusion. Stroke 1999;30:2302-2306.

177 Droste D, Jurgens R, Weber S, Tietje R, Ringelstein E: Benefit of echocontrast-enhanced transcranial color-coded duplex ultrasound in the assessment of intracranial collateral pathways. Stroke 2000;31:920923.

178 Droste D, Nabavi D, Kemeny V, SchulteAltedorneburg G, Ritter M, Weber S, Ringelstein E: Echocontrast enhanced transcranial colour-coded duplex offers improved visualization of the vertebrobasilar system. Acta Neurol Scand 1998;98:198199.

179 Ringelstein E, Van Eyck S, Mertens I: Evaluation of cerebral vasomotor reactivity by various vasodilating stimuli: comparison of $\mathrm{CO}_{2}$ to acetazolamide. Cereb Blood Flow Metab 1992;12:162-168.

180 * Nederkoorn P, van der Graaf Y, Hunink M: Duplex ultrasound and magnetic resonance angiography compared with digital subtraction angiography in carotid artery stenosis: a systematic review. Stroke 2003; 34:1324-1332.

181 Markus H, Cullinane M: Severely impaired cerebrovascular reactivity predicts stroke and TIA risk in patients with carotid artery stenosis and occlusion. Brain 2001;124: 457-467.

182 Blaser T, Hofmann K, Buerger T, Effenberger $\mathrm{O}$, Wallesch $\mathrm{C}$, Goertler M: Risk of stroke, transient ischemic attack, and vessel occlusion before endarteriectomy in patients with symptomatic severe carotid stenosis. Stroke 2002;33:1057-1062.

183 Ringelstein E, Droste D, Babikian V, Evans D, Grosset D, Kaps M, Markus H, Russell D, Siebler M: International Consensus Group on Microembolus Detection. Consensus on microembolus detection by TCD. Stroke 1998;29:725-729.

184 Markus H, MacKinnon A: Asymptomatic embolisation, detected by Doppler ultrasound, predicts stroke risk in symptomatic carotid artery stenosis. Stroke 2005;36: 971-975. 
-185 Markus H, Droste D, Kaps M, Larrue V, Lees K, Siebler M, Ringelstein E: Dual antiplatelet therapy with clopidogrel and aspirin in symptomatic carotid stenosis evaluated using Doppler embolic signaldetection; the CARESS Trial. Circulation 2005;111: 2233-2240.

-186 Klötzsch C, Janssen G, Berlit P: Transesophageal echocardiography and contrastTCD in the detection of a patent foramen ovale: experiences with 111 patients. Neurology 1994;44:1603-1606.

187 Rothwell P, Buchan A, Johnston S: Recent advances in management of transient ischaemic attacks and minor ischaemic strokes. Lancet Neurol 2005;5:323-331.

-188 Daffertshofer M, Mielke O, Pullwitt A, Felsenstein M, Hennerici M: Transient ischemic attacks are more than 'ministrokes'. Stroke 2004;35:2453-2458.

-189 Crisostomo R, Garcia M, Tong D: Detection of diffusion-weighted MRI abnormalities in patients with transient ischemic attack: correlation with clinical characteristics. Stroke 2003;34:932-937.

190 Coutts S, Simon J, Eliasziw M, Sohn C, Hill M, Barber P, Palumbo V, Kennedy J, Roy J, Gagnon A, Scott J, Buchan A, Demchuk A: Triaging transient ischemic attack and minor stroke patients using acute magnetic resonance imaging. Ann Neurol 2005;57: 848-854.

-191 Redgrave J, Coutts S, Schulz U, Briley D, Rothwell P: Systematic review of associations between the presence of acute ischemic lesions on diffusion-weighted imaging and clinical predictors of early stroke risk after transient ischemic attack. Stroke 2007;38:1482-1488.

- 192 Douglas V, Johnston C, Elkins J, Sidney S, Gress D, Johnston GS: Head computed tomography findings predict short-term stroke risk after transient ischemic attack. Stroke 2003;34:2894-2898.

-193 Christensen H, Fogh Christensen A, Boysen GG: Abnormalities on ECG and telemetry predict stroke outcome at 3 months. J Neurol Sci 2005;234:99-103.

-194 Fure B, Bruun Wyller T, Thommessen B: Electrocardiographic and troponin $\mathrm{T}$ changes in acute ischaemic stroke. J Intern Med 2006;259:592-597.

195 Tatschl C, Stollberger C, Matz K, Yilmaz N Eckhardt R, Nowotny M, Dachenhausen A, Brainin M: Insular involvement is associated with QT prolongation: ECG abnormalities in patients with acute stroke. Cerebrovasc Dis 2006;21:47-53.

196 Gunalp M, Atalar E, Coskun F, Yilmaz A, Aksoyek S, Aksu NM, Sivri B: Holter monitoring for $24 \mathrm{~h}$ in patients with thromboembolic stroke and sinus rhythm diagnosed in the emergency department. Adv Ther 2006;23:854-860.
197 Douen AG, Pageau N, Medic S: Serial electrocardiographic assessments significantly improve detection of atrial fibrillation 2.6fold in patients with acute stroke. Stroke 2008;39:480-482.

198 Liao J, Khalid Z, Scallan C, Morillo C, O’Donnell M: Noninvasive cardiac monitoring for detecting paroxysmal atrial fibrillation or flutter after acute ischemic stroke: a systematic review. Stroke 2007;38: 2935-2940

199 Jabaudon D, Sztajzel J, Sievert K, Landis T, Sztajzel R: Usefulness of ambulatory 7-day ECG monitoring for the detection of atrial fibrillation and flutter after acute stroke and transient ischemic attack. Stroke 2004; 35:1647-1651.

200 Lerakis S, Nicholson WJ: I: Use of echocardiography in the evaluation of patients with suspected cardioembolic stroke. Am J Med Sci 2005;329:310-316.

201 Kapral MK, Silver FL: Preventive health care, 1999 update. 2. Echocardiography for the detection of a cardiac source of embolus in patients with stroke. Canadian Task Force on Preventive Health Care. CMAJ 1999;161:989-996.

202 de Bruijn SF, Agema WR, Lammers GJ, van der Wall EE, Wolterbeek R, Holman ER, Bollen EL, Bax JJ: Transesophageal echocardiography is superior to transthoracic echocardiography in management of patients of any age with transient ischemic attack or stroke. Stroke 2006;37:2531-2534

203 Chiarella F, Santoro E, Domenicucci S, Maggioni A, Vecchio C: Predischarge twodimensional echocardiographic evaluation of left ventricular thrombosis after acute myocardial infarction in the GISSI- 3 study. Am J Cardiol 1998;81:822-827.

204 Zabalgoitia M, Halperin JL, Pearce LA, Blackshear JL, Asinger RW, Hart RG: Transesophageal echocardiographic correlates of clinical risk of thromboembolism in nonvalvular atrial fibrillation. Stroke Prevention in Atrial Fibrillation III Investigators. J Am Coll Cardiol 1998;31:16221626.

205 Kurth T, Moore S, Gaziano J, Kase C, Stampfer M, Berger K, Buring J: Healthy lifestyle and the risk of stroke in women. Arch Intern Med 2006;166:1403-1409.

206 Lewington S, Clarke R, Qizilbash N, Peto R, Collins R: Age-specific relevance of usual blood pressure to vascular mortality: a meta-analysis of individual data for one million adults in 61 prospective studies. Lancet 2002;360:1903-1913

207 Neal B, MacMahon S, Chapman N: Effects of ACE inhibitors, calcium antagonists, and other blood-pressure-lowering drugs: results of prospectively designed overviews of randomised trials. Blood Pressure Lowering Treatment Trialists' Collaboration. Lancet 2000;356:1955-1964.
208 Staessen J, Fagard R, Thijs L, Celis H, Arabidze G, Birkenhager W, Bulpitt C, de Leeuw P, Dollery C, Fletcher A, Forette F, Leonetti G, Nachev C, O’Brien E, Rosenfeld J, Rodicio J, Tuomilehto J, Zanchetti A: Randomised double-blind comparison of placebo and active treatment for older patients with isolated systolic hypertension. The systolic hypertension in Europe (SystEur) trial investigators. Lancet 1997;350: 757-764.

209 Gueyffier F, Bulpitt C, Boissel JP, Schron E, Ekbom T, Fagard R, Casiglia E, Kerlikowske $\mathrm{K}$, Coope J: Antihypertensive drugs in very old people: a subgroup meta-analysis of randomised controlled trials. INDANA Group. Lancet 1999;353:793-796.

210 * Mancia G, De Backer G, Dominiczak A, Cifkova R, Fagard R, Germano G, Grassi G, Heagerty AM, Kjeldsen SE, Laurent S, Narkiewicz K, Ruilope L, Rynkiewicz A, Schmieder RE, Struijker Boudier HA, Zanchetti A, Vahanian A, Camm J, De Caterina R, Dean V, Dickstein K, Filippatos G, Funck-Brentano C, Hellemans I, Kristensen SD, McGregor K, Sechtem U, Silber S, Tendera M, Widimsky P, Zamorano JL, Erdine S, Kiowski W, Agabiti-Rosei E, Ambrosioni E, Lindholm LH, Manolis A, Nilsson PM, Redon J, Struijker-Boudier HA, Viigimaa M, Adamopoulos S, Bertomeu V, Clement D, Farsang C, Gaita D, Lip G, Mallion JM, Manolis AJ, O’Brien E, Ponikowski P, Ruschitzka F, Tamargo J, van Zwieten P, Waeber B, Williams B; The task force for the management of arterial hypertension of the European Society of H, The task force for the management of arterial hypertension of the European Society of C: 2007 Guidelines for the management of arterial hypertension: The Task Force for the Management of Arterial Hypertension of the European Society of Hypertension (ESH) and of the European Society of Cardiology (ESC). Eur Heart J 2007;28:1462-1536.

211 * Mancia G: Optimal control of blood pressure in patients with diabetes reduces the incidence of macro- and microvascular events. J Hypertens Suppl 2007;25(suppl 1): S7-S12.

212 Black H, Elliott W, Grandits G, Grambsch P, Lucente T, White W, Neaton J, Grimm R, Hansson L, Lacourciere Y, Muller J, Sleight P, Weber M, Williams G, Wittes J, Zanchetti A, Anders R: Principal results of the controlled onset verapamil investigation of cardiovascular end points (convince) trial. JAMA 2003;289:2073-2082.

213 Dahlof B, Devereux RB, Kjeldsen SE, Julius S, Beevers G, Faire U, Fyhrquist F, Ibsen H, Kristiansson $\mathrm{K}$, Lederballe-Pedersen $\mathrm{O}$, Lindholm LH, Nieminen MS, Omvik P, Oparil S, Wedel H: Cardiovascular morbidity and mortality in the Losartan Intervention For Endpoint reduction in hypertension study (LIFE): a randomised trial against atenolol. Lancet 2002;359:995-1003.
ESO Executive Committee and ESO Writing Committee 
-214 Kizer J, Dahlof B, Kjeldsen S, Julius S, Beevers $G$, de Faire U, Fyhrquist F, Ibsen $H$, Kristianson $\mathrm{K}$, Lederballe-Pedersen $\mathrm{O}$, Lindholm L, Nieminen M, Omvik P, Oparil S, Wedel H, Wachtell K, Edelman J, Snapinn S, Harris K, Devereux R: Stroke reduction in hypertensive adults with cardiac hypertrophy randomized to losartan versus atenolol: the losartan intervention for endpoint reduction in hypertension study. Hypertension 2005;45:46-52.

-215 ALLHAT investigators: Major outcomes in moderately hypercholesterolemic, hypertensive patients randomized to pravastatin vs usual care: The Antihypertensive and Lipid-Lowering Treatment to Prevent Heart Attack Trial (ALLHAT-LLT). JAMA 2002; 288:2998-3007.

216 Ekbom T, Linjer E, Hedner T, Lanke J, De Faire U, Wester PO, Dahlof B, Schersten B: Cardiovascular events in elderly patients with isolated systolic hypertension. A subgroup analysis of treatment strategies in STOP-Hypertension-2. Blood Press 2004; 13:137-141.

-217 Turner RC, Cull CA, Frighi V, Holman RR: Glycemic control with diet, sulfonylurea, metformin, or insulin in patients with type 2 diabetes mellitus: progressive requirement for multiple therapies (UKPDS 49). UK Prospective Diabetes Study (UKPDS) Group. JAMA 1999;281:2005-2012.

-218 Colhoun HM, Betteridge DJ, Durrington PN, Hitman GA, Neil HA, Livingstone SJ, Thomason MJ, Mackness MI, CharltonMenys V, Fuller JH: Primary prevention of cardiovascular disease with atorvastatin in type 2 diabetes in the Collaborative Atorvastatin Diabetes Study (CARDS): multicentre randomised placebo-controlled trial. Lancet 2004;364:685-696.

219 Sever PS, Poulter NR, Dahlof B, Wedel H, Collins R, Beevers G, Caulfield M, Kjeldsen SE, Kristinsson A, McInnes GT, Mehlsen J, Nieminen M, O'Brien E, Ostergren J: Reduction in cardiovascular events with atorvastatin in 2,532 patients with type 2 diabetes: Anglo-Scandinavian Cardiac Outcomes Trial-lipid-lowering arm (ASCOTLLA). Diabetes Care 2005;28:1151-1157.

-220 * Kearney PM, Blackwell L, Collins R, Keech A, Simes J, Peto R, Armitage J, Baigent C: Efficacy of cholesterol-lowering therapy in 18,686 people with diabetes in 14 randomised trials of statins: a meta-analysis. Lancet 2008;371:117-125.

-221 * Amarenco P, Labreuche J, Lavallee P, Touboul P: Statins in stroke prevention and carotid atherosclerosis: systematic review and up-to-date meta-analysis. Stroke 2004; 35:2902-2909.

-222 Heart Protection Study Collaborative Group: MRC/BHF Heart Protection Study of cholesterol lowering with simvastatin in 20,536 high-risk individuals: a randomised placebo-controlled trial. Lancet 2002;360: $7-22$.
223 Wolf PA, D’Agostino RB, Kannel WB, Bonita $\mathrm{R}$, Belanger AJ: Cigarette smoking as a risk factor for stroke. The Framingham Study. JAMA 1988;259:1025-1029.

224 Abbott RD, Yin Y, Reed DM, Yano K: Risk of stroke in male cigarette smokers. N Engl J Med 1986;315:717-720.

225 Colditz GA, Bonita R, Stampfer MJ, Willett WC, Rosner B, Speizer FE, Hennekens CH: Cigarette smoking and risk of stroke in middle-aged women. N Engl J Med 1988; 318:937-941.

226 Kawachi I, Colditz GA, Stampfer MJ, Willett WC, Manson JE, Rosner B, Speizer FE, Hennekens $\mathrm{CH}$ : Smoking cessation and decreased risk of stroke in women. JAMA 1993;269:232-236.

227 Wannamethee SG, Shaper AG, Whincup $\mathrm{PH}$, Walker M: Smoking cessation and the risk of stroke in middle-aged men. JAMA 1995;274:155-160.

228 Iso H, Date C, Yamamoto A, Toyoshima H, Watanabe Y, Kikuchi S, Koizumi A, Wada Y, Kondo T, Inaba Y, Tamakoshi A: Smoking cessation and mortality from cardiovascular disease among japanese men and women: The JACC study. Am J Epidemiol 2005;161:170-179.

229 Qureshi A, Suri M, Kirmani J, Divani A: Cigarette smoking among spouses: another risk factor for stroke in women. Stroke 2005;36:74-76

230 Shinton R, Beevers G: Meta-analysis of relation between cigarette smoking and stroke. BMJ 1989;298:789-794.

231 Ong M, Glantz S: Cardiovascular health and economic effects of smoke-free workplaces. Am J Med 2004;117:32-38.

232 Reynolds K, Lewis B, Nolen JD, Kinney GL, Sathya B, He J: Alcohol consumption and risk of stroke: a meta-analysis. JAMA 2003; 289:579-588

233 Mukamal K, Ascherio A, Mittleman M, Conigrave K, Camargo C, Kawachi I, Stampfer M, Willett W, Rimm E: Alcohol and risk for ischemic stroke in men: the role of drinking patterns and usual beverage. Ann Intern Med 2005;142:11-19.

234 Bazzano LA, Gu D, Reynolds K, Wu X, Chen CS, Duan X, Chen J, Wildman RP, Klag MJ, He J: Alcohol consumption and risk for stroke among Chinese men. Ann Neurol 2007;62:569-578.

235 Lee C, Folsom A, Blair S: Physical activity and stroke risk: a meta-analysis. Stroke 2003;34:2475-2481.

236 Deplanque D, Masse I, Lefebvre C, Libersa C, Leys D, Bordet R: Prior tia, lipid-lowering drug use, and physical activity decrease ischemic stroke severity. Neurology 2006; 67:1403-1410.

237 Joshipura KJ, Ascherio A, Manson JE, Stampfer MJ, Rimm EB, Speizer FE, Hennekens $\mathrm{CH}$, Spiegelman D, Willett WC: Fruit and vegetable intake in relation to risk of ischemic stroke. JAMA 1999;282:1233-1239.
238 He K, Song Y, Daviglus M, Liu K, Van Horn L, Dyer A, Goldbourt U, Greenland P: Fish consumption and incidence of stroke: a meta-analysis of cohort studies. Stroke 2004;35:1538-1542.

239 Mellen PB, Walsh TF, Herrington DM: Whole grain intake and cardiovascular disease: a meta-analysis. Nutr Metab Cardiovasc Dis 2007;85:1495-1502.

240 Umesawa M, Iso H, Date C, Yamamoto A, Toyoshima H, Watanabe Y, Kikuchi S, Koizumi A, Kondo T, Inaba Y, Tanabe N, Tamakoshi A: Dietary intake of calcium in relation to mortality from cardiovascular disease: The JACC study. Stroke 2006;37: $20-26$.

-241 He K, Merchant A, Rimm E, Rosner B, Stampfer M, Willett W, Ascherio A: Dietary fat intake and risk of stroke in male US healthcare professionals: 14 year prospective cohort study. BMJ 2003;327:777782.

242 Howard B, Van Horn L, Hsia J, Manson J, Stefanick M, Wassertheil-Smoller S, Kuller L, LaCroix A, Langer R, Lasser N, Lewis C, Limacher M, Margolis K, Mysiw W, Ockene J, Parker L, Perri M, Phillips L, Prentice R, Robbins J, Rossouw J, Sarto G, Schatz I, Snetselaar L, Stevens V, Tinker L, Trevisan M, Vitolins M, Anderson G, Assaf A, Bassford T, Beresford S, Black H, Brunner R, Brzyski R, Caan B, Chlebowski R, Gass M, Granek I, Greenland P, Hays J, Heber D, Heiss G, Hendrix S, Hubbell F, Johnson K, Kotchen J: Low-fat dietary pattern and risk of cardiovascular disease: The women's health initiative randomized controlled dietary modification trial. JAMA 2006;295: 655-666.

243 Kurth T, Gaziano J, Berger K, Kase C, Rexrode K, Cook N, Buring J, Manson J: Body mass index and the risk of stroke in men. Arch Intern Med 2002;162:25572562.

244 Kurth T, Gaziano J, Rexrode K, Kase C, Cook N, Manson J, Buring J: Prospective study of body mass index and risk of stroke in apparently healthy women. Circulation 2005;111:1992-1998.

$245 \mathrm{Hu}$ G, Tuomilehto J, Silventoinen K, Sarti C, Mannisto S, Jousilahti P: Body mass index, waist circumference, and waist-hip ratio on the risk of total and type-specific stroke. Arch Intern Med 2007;167:14201427.

-246 Neter J, Stam B, Kok F, Grobbee D, Geleijnse J: Influence of weight reduction on blood pressure: a meta-analysis of randomized controlled trials. Hypertension 2003; 42:878-884.

247 Curioni C, Andre C, Veras R: Weight reduction for primary prevention of stroke in adults with overweight or obesity. Cochrane Database Syst Rev 2006: CD006062. 
-248 Marniemi J, Alanen E, Impivaara O, Seppanen R, Hakala P, Rajala T, Ronnemaa T: Dietary and serum vitamins and minerals as predictors of myocardial infarction and stroke in elderly subjects. Nutr Metab Cardiovasc Dis 2005; 15:188-197.

-249 Hsia J, Heiss G, Ren H, Allison M, Dolan N, Greenland P, Heckbert S, Johnson K, Manson J, Sidney S, Trevisan M: Calcium/vitamin D supplementation and cardiovascular events. Circulation 2007;115:846-854

-250 Tornwall M, Virtamo J, Korhonen P, Virtanen M, Albanes D, Huttunen J: Postintervention effect of alpha tocopherol and beta carotene on different strokes: a 6-year follow-up of the alpha tocopherol, beta carotene cancer prevention study. Stroke 2004; 35:1908-1913.

-251* Miller E, Pastor-Barriuso R, Dalal D, Riemersma R, Appel L, Guallar E: Metaanalysis: high-dosage vitamin E supplementation may increase all-cause mortality. Ann Intern Med 2005; 142:37-46.

-252 The Homocysteine Studies Collaboration: Homocysteine and risk of ischemic heart disease and stroke: a meta-analysis. JAMA 2002;288:2015-2022.

-253 Yang Q, Botto LD, Erickson JD, Berry RJ, Sambell C, Johansen H, Friedman JM: Improvement in stroke mortality in Canada and the United States, 1990 to 2002. Circulation 2006;113:1335-1343.

-254 Wang X, Qin X, Demirtas H, Li J, Mao G, Huo Y, Sun N, Liu L, Xu X: Efficacy of folic acid supplementation in stroke prevention: a meta-analysis. Lancet 2007;369:18761882.

-255 Grodstein F, Manson JE, Stampfer MJ: Postmenopausal hormone use and secondary prevention of coronary events in the nurses' health study. A prospective, observational study. Ann Intern Med 2001;135: $1-8$.

-256 Grady D, Herrington D, Bittner V, Blumenthal R, Davidson M, Hlatky M, Hsia J, Hulley S, Herd A, Khan S, Newby LK, Waters D, Vittinghoff E, Wenger N: Cardiovascular disease outcomes during 6.8 years of hormone therapy: Heart and Estrogen/progestin Replacement Study follow-up (HERS II). JAMA 2002;288:49-57.

257 * Gabriel S, Carmona L, Roque M, Sanchez G, Bonfill X: Hormone replacement therapy for preventing cardiovascular disease in post-menopausal women. Cochrane Database Syst Rev 2005:CD002229.

258 Brunner R, Gass M, Aragaki A, Hays J, Granek I, Woods N, Mason E, Brzyski R, Ockene J, Assaf A, LaCroix A, Matthews K, Wallace R: Effects of conjugated equine estrogen on health-related quality of life in postmenopausal women with hysterectomy: results from the women's health initiative randomized clinical trial. Arch Intern Med 2005;165:1976-1986.
259 Rossouw JE, Prentice RL, Manson JE, Wu L, Barad D, Barnabei VM, Ko M, LaCroix AZ, Margolis KL, Stefanick ML: Postmenopausal hormone therapy and risk of cardiovascular disease by age and years since menopause. JAMA 2007;297:1465-1477.

260 Peto R, Gray R, Collins R, Wheatley K, Hennekens C, Jamrozik K, Warlow C, Hafner B, Thompson E, Norton S, et al: Randomised trial of prophylactic daily aspirin in British male doctors. BMJ (Clin Res Ed) 1988;296:313-316.

261 Steering Committee of the Physicians' Health Study Research Group: Final report on the aspirin component of the ongoing Physicians' Health Study. N Engl J Med 1989;321:129-135.

-262 ETDRS Investigators: Aspirin effects on mortality and morbidity in patients with diabetes mellitus. Early Treatment Diabetic Retinopathy Study report 14. JAMA 1992; 268:1292-1300.

263 Hansson L, Zanchetti A, Carruthers SG, Dahlof B, Elmfeldt D, Julius S, Menard J, Rahn KH, Wedel H, Westerling S: Effects of intensive blood-pressure lowering and lowdose aspirin in patients with hypertension: principal results of the Hypertension Optimal Treatment (HOT) randomised trial. HOT Study Group. Lancet 1998;351:17551762.

264 de Gaetano G: Low-dose aspirin and vitamin $\mathrm{E}$ in people at cardiovascular risk: a randomised trial in general practice. Collaborative Group of the Primary Prevention Project. Lancet 2001;357:89-95.

-265 Iso H, Hennekens C, Stampfer M, Rexrode K, Colditz G, Speizer F, Willett W, Manson J: Prospective study of aspirin use and risk of stroke in women. Stroke 1999;30:17641771.

266 Bartolucci A, Howard G: Meta-analysis of data from the six primary prevention trials of cardiovascular events using aspirin. Am J Cardiol 2006;98:746-750.

267 * Berger J, Roncaglioni M, Avanzini F, Pangrazzi I, Tognoni G, Brown D: Aspirin for the primary prevention of cardiovascular events in women and men: A sex-specific meta-analysis of randomized controlled trials. JAMA 2006;295:306-313.

268 Ridker PM, Cook NR, Lee IM, Gordon D, Gaziano JM, Manson JE, Hennekens CH, Buring JE: A randomized trial of low-dose aspirin in the primary prevention of cardiovascular disease in women. N Engl J Med 2005;352:1293-1304.

269 * Bhatt D, Fox K, Hacke W, Berger P, Black H, Boden W, Cacoub P, Cohen E, Creager M, Easton J, Flather M, Haffner S, Hamm C, Hankey G, Johnston S, Mak K, Mas J, Montalescot G, Pearson T, Steg P, Steinhubl S, Weber M, Brennan D, Fabry-Ribaudo L, Booth J, Topol E: Clopidogrel and aspirin versus aspirin alone for the prevention of atherothrombotic events. N Engl J Med 2006;354:1706-1717.
270 Hobson R, 2nd, Krupski W, Weiss D: Influence of aspirin in the management of asymptomatic carotid artery stenosis. VA Cooperative Study Group on Asymptomatic Carotid Stenosis. J Vasc Surg 1993;17: 257-263.

271 Engelter S, Lyrer P: Antiplatelet therapy for preventing stroke and other vascular events after carotid endarterectomy. Cochrane Database Syst Rev 2003:CD001458.

$>272$ * Hart RG, Pearce LA, Aguilar MI: Metaanalysis: antithrombotic therapy to prevent stroke in patients who have nonvalvular atrial fibrillation. Ann Intern Med 2007; 146:857-867.

273 * Rash A, Downes T, Portner R, Yeo W, Morgan N, Channer K: A randomised controlled trial of warfarin versus aspirin for stroke prevention in octogenarians with atrial fibrillation (WASPO). Age Ageing 2007;36:151-156.

274 Mant J, Hobbs FD, Fletcher K, Roalfe A, Fitzmaurice D, Lip GY, Murray E: Warfarin versus aspirin for stroke prevention in an elderly community population with atrial fibrillation (the Birmingham Atrial Fibrillation Treatment of the Aged Study, BAFTA): a randomised controlled trial. Lancet 2007;370:493-503.

275 Connolly S, Pogue J, Hart R, Pfeffer M, Hohnloser S, Chrolavicius S, Pfeffer M, Hohnloser S, Yusuf S: Clopidogrel plus aspirin versus oral anticoagulation for atrial fibrillation in the atrial fibrillation clopidogrel trial with irbesartan for prevention of vascular events (ACTIVEW): a randomised controlled trial. Lancet 2006;367:19031912.

276 Cannegieter SC, Rosendaal FR, Wintzen AR, van der Meer FJ, Vandenbroucke JP, Briet E: Optimal oral anticoagulant therapy in patients with mechanical heart valves. $\mathrm{N}$ Engl J Med 1995;333:11-17.

277 * Chambers BR, Donnan GA: Carotid endarterectomy for asymptomatic carotid stenosis. Cochrane Database Syst Rev 2005: CD001923.

278 Executive Committee for the Asymptomatic Carotid Atherosclerosis Study: Endarterectomy for asymptomatic carotid artery stenosis. JAMA 1995;273:1421-1428.

279 * Halliday A, Mansfield A, Marro J, Peto C, Peto R, Potter J, Thomas D: Prevention of disabling and fatal strokes by successful carotid endarterectomy in patients without recent neurological symptoms: randomised controlled trial. Lancet 2004;363:14911502.

280 * North American Symptomatic Carotid Endarterectomy Trial Collaborators: Beneficial effect of carotid endarterectomy in symptomatic patients with high-grade carotid stenosis. N Engl J Med 1991;325:445453.

ESO Executive Committee and ESO Writing Committee 
-281 Baker WH, Howard VJ, Howard G, Toole JF: Effect of contralateral occlusion on long-term efficacy of endarterectomy in the asymptomatic carotid atherosclerosis study (ACAS). ACAS Investigators. Stroke 2000; 31:2330-2334.

-282 Straus SE, Majumdar SR, McAlister FA: New evidence for stroke prevention: scientific review. JAMA 2002;288:1388-1395.

283 The European Carotid Surgery Trialists Collaborative Group: Risk of stroke in the distribution of an asymptomatic carotid artery. Lancet 1995;345:209-212.

-284 Mayo Asymptomatic Carotid Endarterectomy Study Group: Results of a randomized controlled trial of carotid endarterectomy for asymptomatic carotid stenosis. Mayo Asymptomatic Carotid Endarterectomy Study Group. Mayo Clin Proc 1992;67:513518.

285 Derdeyn C: Carotid stenting for asymptomatic carotid stenosis: trial it. Stroke 2007;38:715-720.

286 Rashid P, Leonardi-Bee J, Bath P: Blood pressure reduction and secondary prevention of stroke and other vascular events: a systematic review. Stroke 2003;34:27412748.

-287 Group P: Post-stroke antihypertensive treatment study. A preliminary result. Chin Med J (Engl) 1995;108:710-717.

288 Yusuf S, Sleight P, Pogue J, Bosch J, Davies R, Dagenais G: Effects of an angiotensinconverting-enzyme inhibitor, ramipril, on cardiovascular events in high-risk patients. The Heart Outcomes Prevention Evaluation Study Investigators. N Engl J Med 2000;342:145-153.

289 Bosch J, Yusuf S, Pogue J, Sleight P, Lonn E, Rangoonwala B, Davies R, Ostergren J, Probstfield J: Use of ramipril in preventing stroke: double blind randomised trial. BMJ 2002;324:699-702.

290 PROGRESS collaborative group: Randomised trial of a perindopril-based bloodpressure-lowering regimen among 6,105 individuals with previous stroke or transient ischaemic attack. Lancet 2001;358: 1033-1041.

291 Chobanian A, Bakris G, Black H, Cushman W, Green L, Izzo J, Jones D, Materson B, Oparil S, Wright J, Roccella E: The seventh report of the joint national committee on prevention, detection, evaluation, and treatment of high blood pressure: The JNC 7 report. JAMA 2003;289:2560-2572.

-292 Schrader J, Luders S, Kulschewski A, Hammersen F, Plate K, Berger J, Zidek W, Dominiak P, Diener H: Morbidity and mortality after stroke: eprosartan compared with nitrendipine for secondary prevention: principal results of a prospective randomized controlled study (MOSES). Stroke 2005;36:1218-1226.
293 Wilcox R, Bousser MG, Betteridge DJ, Schernthaner G, Pirags V, Kupfer S, Dormandy J: Effects of pioglitazone in patients with type 2 diabetes with or without previous stroke: results from PROactive (PROspective pioglitAzone Clinical Trial In macroVascular Events 04). Stroke 2007;38: $865-873$.

$294{ }^{*}$ Amarenco P, Bogousslavsky J, Callahan A, Goldstein L, Hennerici M, Rudolph A, Sillesen H, Simunovic L, Szarek M, Welch K, Zivin J: High-dose atorvastatin after stroke or transient ischemic attack. N Engl J Med 2006;355:549-559.

295 * Blanco M, Nombela F, Castellanos M, Rodriguez-Yanez M, Garcia-Gil M, Leira R, Lizasoain I, Serena J, Vivancos J, Moro MA, Davalos A, Castillo J: Statin treatment withdrawal in ischemic stroke: a controlled randomized study. Neurology 2007;69: 904-910.

296 Vivekananthan D, Penn M, Sapp S, Hsu A, Topol E: Use of antioxidant vitamins for the prevention of cardiovascular disease: Metaanalysis of randomised trials. Lancet 2003; 361:2017-2023.

297 Eidelman R, Hollar D, Hebert P, Lamas G, Hennekens C: Randomized trials of vitamin $\mathrm{E}$ in the treatment and prevention of cardiovascular disease. Arch Intern Med 2004; 164:1552-1556.

298 * Bjelakovic G, Nikolova D, Gluud L, Simonetti R, Gluud C: Mortality in randomized trials of antioxidant supplements for primary and secondary prevention: Systematic review and meta-analysis. JAMA 2007;297:842-857.

299 Wald D, Law M, Morris J: Homocysteine and cardiovascular disease: Evidence on causality from a meta-analysis. BMJ 2002; 325:1202.

300 Toole J, Malinow M, Chambless L, Spence J, Pettigrew L, Howard V, Sides E, Wang C, Stampfer M: Lowering homocysteine in patients with ischemic stroke to prevent recurrent stroke, myocardial infarction, and death: The Vitamin Intervention for Stroke Prevention (VISP) randomized controlled trial. JAMA 2004;291:565-575.

301 Bonaa K, Njolstad I, Ueland P, Schirmer H, Tverdal A, Steigen T, Wang H, Nordrehaug J, Arnesen E, Rasmussen K: Homocysteine lowering and cardiovascular events after acute myocardial infarction. N Engl J Med 2006;354:1578-1588.

302 Bazzano L, Reynolds K, Holder K, He J: Effect of folic acid supplementation on risk of cardiovascular diseases: A meta-analysis of randomized controlled trials. JAMA 2006; 296:2720-2726.
303 VITATOPS Trial Study Group: The VITATOPS (Vitamins to Prevent Stroke) Trial: rationale and design of an international, large, simple, randomised trial of homocysteine-lowering multivitamin therapy in patients with recent transient ischaemic attack or stroke. Cerebrovasc Dis 2002;13: 120-126.

$304 *$ Bassetti CL: Sleep and stroke. Semin Neurol 2005;25:19-32.

305 Handke M, Harloff A, Olschewski M, Hetzel A, Geibel A: Patent foramen ovale and cryptogenic stroke in older patients. N Engl J Med 2007;357:2262-2268.

306 Overell JR, Bone I, Lees KR: Interatrial septal abnormalities and stroke: a meta-analysis of case-control studies. Neurology 2000; 55:1172-1179.

307 Di Tullio MR, Sacco RL, Sciacca RR, Jin Z, Homma S: Patent foramen ovale and the risk of ischemic stroke in a multiethnic population. J Am Coll Cardiol 2007;49: 797-802.

308 Meissner I, Khandheria BK, Heit JA, Petty GW, Sheps SG, Schwartz GL, Whisnant JP, Wiebers DO, Covalt JL, Petterson TM, Christianson TJ, Agmon Y: Patent foramen ovale: innocent or guilty? Evidence from a prospective population-based study. J Am Coll Cardiol 2006;47:440-445.

-309 Mas JL, Arquizan C, Lamy C, Zuber M, Cabanes L, Derumeaux G, Coste J: Recurrent cerebrovascular events associated with patent foramen ovale, atrial septal aneurysm, or both. N Engl J Med 2001;345:17401746.

310 Wahl A, Krumsdorf U, Meier B, Sievert H, Ostermayer S, Billinger K, Schwerzmann M, Becker U, Seiler C, Arnold M, Mattle HP, Windecker S: Transcatheter treatment of atrial septal aneurysm associated with patent foramen ovale for prevention of recurrent paradoxical embolism in high-risk patients. J Am Coll Cardiol 2005;45:377380 .

-311 Windecker S, Wahl A, Nedeltchev K, Arnold M, Schwerzmann M, Seiler C, Mattle HP, Meier B: Comparison of medical treatment with percutaneous closure of patent foramen ovale in patients with cryptogenic stroke. J Am Coll Cardiol 2004;44:750758 .

312 * Viscoli CM, Brass LM, Kernan WN, Sarrel PM, Suissa S, Horwitz RI: A clinical trial of estrogen-replacement therapy after ischemic stroke. N Engl J Med 2001;345: 1243-1249.

>313 * Antithrombotic Trialists' Collaboration: Collaborative meta-analysis of randomised trials of antiplatelet therapy for prevention of death, myocardial infarction, and stroke in high risk patients. BMJ 2002;324:71-86.

-314 Algra A, van Gijn J: Aspirin at any dose above $30 \mathrm{mg}$ offers only modest protection after cerebral ischaemia. J Neurol Neurosurg Psychiatry 1996;60:197-199. 
315 The Dutch TIA Trial Study Group: A comparison of two doses of aspirin $(30 \mathrm{mg}$ vs. $283 \mathrm{mg}$ a day) in patients after a transient ischemic attack or minor ischemic stroke. N Engl J Med 1991;325:1261-1266.

- 316 Farrell B, Godwin J, Richards S, Warlow C: The United Kingdom transient ischaemic attack (UK-TIA) aspirin trial: final results. J Neurol Neurosurg Psychiatry 1991;54: 1044-1054.

- 317 Campbell C, Smyth S, Montalescot G, Steinhubl S: Aspirin dose for the prevention of cardiovascular disease: a systematic review. JAMA 2007;297:2018-2024.

- $318{ }^{*}$ Chimowitz M, Lynn M, Howlett-Smith H, Stern B, Hertzberg V, Frankel M, Levine S, Chaturvedi S, Kasner S, Benesch C, Sila C, Jovin T, Romano J: Comparison of warfarin and aspirin for symptomatic intracranial arterial stenosis. N Engl J Med 2005;352: 1305-1316.

- 319 * CAPRIE Steering Committee: A randomised, blinded trial of clopidogrel versus aspirin in patients at risk of ischaemic events (CAPRIE). Lancet 1996;348:13291339.

-320* Diener HC, Cunha L, Forbes C, Sivenius J, Smets P, Lowenthal A: European Stroke Prevention Study. 2. Dipyridamole and acetylsalicylic acid in the secondary prevention of stroke. J Neurol Sci 1996;143:1-13.

$321{ }^{*}$ Costa J, Ferro JM, Matias-Guiu J, Alvarez-Sabin J, Torres F: Triflusal for preventing serious vascular events in people at high risk. Cochrane Database Syst Rev 2005: CD004296.

\322 * Halkes P, van Gijn J, Kappelle L, Koudstaal P, Algra A: Aspirin plus dipyridamole versus aspirin alone after cerebral ischaemia of arterial origin (ESPRIT): Randomised controlled trial. Lancet 2006;367: 1665-1673.

\$23 Chang YJ, Ryu SJ, Lee TH: Dose titration to reduce dipyridamole-related headache. Cerebrovasc Dis 2006;22:258-262.

- 324 Diener H, Davidai G: Dipyridamole and headache. Future Neurol 2007;2:279-283.

- 325 * Diener H, Bogousslavsky J, Brass L, Cimminiello C, Csiba L, Kaste M, Leys D, Matias-Guiu J, Rupprecht H: Aspirin and clopidogrel compared with clopidogrel alone after recent ischaemic stroke or transient ischaemic attack in high-risk patients (MATCH): randomised, double-blind, placebo-controlled trial. Lancet 2004;364: 331-337.

- 326 Yusuf S, Zhao F, Mehta S, Chrolavicius S, Tognoni G, Fox K, and the Clopidogrel in Unstable Angina to Prevent Recurrent Events Trial Investigators: Effects of clopidogrel in addition to aspirin in patients with acute coronary syndroms without STsegment elevation. N Engl J Med 2001;345: 494-502.
327 * Mohr JP, Thompson JL, Lazar RM, Levin B, Sacco RL, Furie KL, Kistler JP, Albers GW, Pettigrew LC, Adams HP Jr, Jackson CM, Pullicino P: A comparison of warfarin and aspirin for the prevention of recurrent ischemic stroke. N Engl J Med 2001;345: 1444-1451.

328 The Stroke Prevention in Reversible Ischemia Trial (SPIRIT) Study Group: A randomized trial of anticoagulants versus aspirin after cerebral ischemia of presumed arterial origin. Ann Neurol 1997;42:857865

329 * Algra A: Medium intensity oral anticoagulants versus aspirin after cerebral ischaemia of arterial origin (ESPRIT): a randomised controlled trial. Lancet Neurol 2007;6:115-124.

330 EAFT (European Atrial Fibrillation Trial) Study Group: Secondary prevention in non-rheumatic atrial fibrillation after transient ischaemic attack or minor stroke. Lancet 1993;342:1255-1262.

331 Visser CA, Kan G, Meltzer RS, Lie KI, Durrer D: Long-term follow-up of left ventricular thrombus after acute myocardial infarction. A two-dimensional echocardiographic study in 96 patients. Chest 1984;86: 532-536.

332 Flaker GC, Gruber M, Connolly SJ, Goldman S, Chaparro S, Vahanian A, Halinen MO, Horrow J, Halperin JL: Risks and benefits of combining aspirin with anticoagulant therapy in patients with atrial fibrillation: an exploratory analysis of stroke prevention using an oral thrombin inhibitor in atrial fibrillation (SPORTIF) trials. Am Heart J 2006;152:967-973.

333 Dressler FA, Craig WR, Castello R, Labovitz AJ: Mobile aortic atheroma and systemic emboli: efficacy of anticoagulation and influence of plaque morphology on recurrent stroke. J Am Coll Cardiol 1998;31: 134-138.

-334 Echiverri HC, Rubino FA, Gupta SR, Gujrati M: Fusiform aneurysm of the vertebrobasilar arterial system. Stroke 1989;20: 1741-1747.

335 Engelter ST, Brandt T, Debette S, Caso V, Lichy C, Pezzini A, Abboud S, Bersano A, Dittrich R, Grond-Ginsbach C, Hausser I, Kloss M, Grau AJ, Tatlisumak T, Leys D, Lyrer PA: Antiplatelets versus anticoagulation in cervical artery dissection. Stroke 2007;38:2605-2611.

336 * Rothwell PM, Eliasziw M, Gutnikov SA, Fox AJ, Taylor DW, Mayberg MR, Warlow $\mathrm{CP}$, Barnett HJ: Analysis of pooled data from the randomised controlled trials of endarterectomy for symptomatic carotid stenosis. Lancet 2003;361:107-116.

337 * European Carotid Surgery Trialists' Collaborative Group: Endarterectomy for moderate symptomatic carotid stenosis: Interim results from the MRC european carotid surgery trial. Lancet 1996;347:15911593.
$338{ }^{*}$ Cina C, Clase C, Haynes R: Carotid endarterectomy for symptomatic carotid stenosis. Cochrane Database Syst Rev 1999: CD001081.

339 * Rothwell P, Eliasziw M, Gutnikov S, Warlow C, Barnett HJ, for the Carotid Endarterectomy Trialists Collaboration: Endarterectomy for symptomatic carotid stenosis in relation to clinical subgroups and timing of surgery. Lancet 2004;363:915-924.

340 Bond R, AbuRahma A, Naylor A, Rothwell $\mathrm{P}$ : Patch angioplasty versus primary closure for carotid endarterectomy. Cochrane $\mathrm{Da}$ tabase Syst Rev 2004:CD000160.

- 341 Rothwell PM, Eliasziw M, Gutnikov SA, Warlow CP, Barnett HJ: Sex difference in the effect of time from symptoms to surgery on benefit from carotid endarterectomy for transient ischemic attack and nondisabling stroke. Stroke 2004;35:2855-2861.

342 Inzitari D, Eliasziw M, Sharpe BL, Fox AJ, Barnett HJ: Risk factors and outcome of patients with carotid artery stenosis presenting with lacunar stroke. North American Symptomatic Carotid Endarterectomy Trial Group. Neurology 2000;54:660-666.

343 Streifler JY, Eliasziw M, Benavente OR, Alamowitch S, Fox AJ, Hachinski VC, Barnett HJ: Prognostic importance of leukoaraiosis in patients with symptomatic internal carotid artery stenosis. Stroke 2002;33:16511655.

344 * Mas JL, Chatellier G, Beyssen B, Branchereau A, Moulin T, Becquemin J-P, Larrue $\mathrm{V}$, Lièvre $\mathrm{M}$, Leys $\mathrm{D}$, Bonneville J-F, Watelet J, Pruvo J-P, Albucher J-F, Viguier A, Piquet P, Garnier P, Viader F, Touzé E, Giroud $\mathrm{M}$, Hosseini $\mathrm{H}$, Pillet J-C, Favrole $\mathrm{P}$, Neau J-P, Ducrocq X, for the EVA-3S Investigators: Endarterectomy versus stenting in patients with symptomatic severe carotid stenosis. N Engl J Med 2006;355:16601671 .

-345 * Ringleb PA, Allenberg JR, Berger J, Brückmann H, Eckstein HH, Fraedrich G, Hartmann M, Hennerici M, Jansen O, Klein G, Kunze A, Marx P, Niederkorn K, Schmiedt W, Solymosi L, Stingele R, Zeumer H, Hacke W: 30 day results from the SPACE trial of stent-protected angioplasty versus carotid endarterectomy in symptomatic patients: a randomised non-inferiority trial. Lancet 2006;368:1239-1247.

346 Yadav JS, Sholey MH, Kuntz RE, Fayad P, Katzen BT, Mishkel GJ, Bajwa TK, Whitlow P, Strickman NE, Jaff MR, Popma JJ, Snead DB, Cutlip DE, Firth BG, Ouriel K; for the Stenting and Angioplasty with Protection in Patients at High Risk for Endarterectomy Investigators: Protected carotid-artery stenting versus endarterectomy in highrisk patients. N Engl J Med 2004;351:14931501.
ESO Executive Committee and ESO Writing Committee 
\$347 * Cavatas Group: Endovascular versus surgical treatment in patients with carotid stenosis in the Carotid and Vertebral Artery Transluminal Angioplasty Study (CAVATAS): a randomised trial. Lancet 2001;357: 1729-1737.

>348 Kastrup A, Groschel K: Carotid endarterectomy versus carotid stenting: an updated review of randomized trials and subgroup analyses. Acta Chir Belg 2007;107:119128.

\$349 The EC/IC Bypass Study Group: Failure of extracranial-intracranial arterial bypass to reduce the risk of ischemic stroke. Results of an international randomized trial. N Engl J Med 1985;313:1191-1200.

>350 Kasner SE, Chimowitz MI, Lynn MJ, Howlett-Smith H, Stern BJ, Hertzberg VS, Frankel MR, Levine SR, Chaturvedi S, Benesch CG, Sila CA, Jovin TG, Romano JG, Cloft HJ: Predictors of ischemic stroke in the territory of a symptomatic intracranial arterial stenosis. Circulation 2006;113: 555-563.

351 Jiang WJ, Xu XT, Du B, Dong KH, Jin M, Wang QH, Ma N: Long-term outcome of elective stenting for symptomatic intracranial vertebrobasilar stenosis. Neurology 2007;68:856-858.

>352 Jiang WJ, Xu XT, Du B, Dong KH, Jin M, Wang QH, Ma N: Comparison of elective stenting of severe vs moderate intracranial atherosclerotic stenosis. Neurology 2007; 68:420-426

-353 Marks MP, Wojak JC, Al-Ali F, Jayaraman M, Marcellus ML, Connors JJ, Do HM: Angioplasty for symptomatic intracranial stenosis: clinical outcome. Stroke 2006;37: 1016-1020.

-354 Fiorella D, Levy EI, Turk AS, Albuquerque FC, Niemann DB, Aagaard-Kienitz B, Hanel RA, Woo H, Rasmussen PA, Hopkins LN, Masaryk TJ, McDougall CG: US multicenter experience with the wingspan stent system for the treatment of intracranial atheromatous disease: periprocedural results. Stroke 2007;38:881-887.

-355* Bose A, Hartmann M, Henkes H, Liu HM, Teng MM, Szikora I, Berlis A, Reul J, Yu SC, Forsting M, Lui M, Lim W, Sit SP: A novel, self-expanding, nitinol stent in medically refractory intracranial atherosclerotic stenoses: the Wingspan study. Stroke 2007;38: 1531-1537.

356 * SSYLVIA Study investigators: Stenting of Symptomatic Atherosclerotic Lesions in the Vertebral or Intracranial Arteries (SSYLVIA): study results. Stroke 2004;35: 1388-1392.

-357 Lindstrom E, Boysen G, Christiansen L, Nansen B, Nielsen P: Reliability of Scandinavian neurological stroke scale. Cerebrovasc Dis 1991;1:103-107.
358 Sulter G, Elting JW, Langedijk M, Maurits NM, De Keyser J: Admitting acute ischemic stroke patients to a stroke care monitoring unit versus a conventional stroke unit: a randomized pilot study. Stroke 2003;34: 101-104.

359 Cavallini A, Micieli G, Marcheselli S, Quaglini S: Role of monitoring in management of acute ischemic stroke patients. Stroke 2003;34:2599-2603.

360 Ronning OM, Guldvog B: Should stroke victims routinely receive supplemental oxygen? A quasi-randomized controlled trial. Stroke 1999;30:2033-2037.

361 Bamford J, Dennis M, Sandercock P, Burn J, Warlow C: The frequency, causes and timing of death within 30 days of a first stroke: the Oxfordshire Community Stroke Project. J Neurol Neurosurg Psychiatry 1990;53:824-829.

362 Broderick JP, Phillips SJ, O'Fallon WM, Frye RL, Whisnant JP: Relationship of cardiac disease to stroke occurrence, recurrence, and mortality. Stroke 1992;23:1250 1256.

363 Barber M, Morton JJ, Macfarlane PW, Barlow N, Roditi G, Stott DJ: Elevated troponin levels are associated with sympathoadrenal activation in acute ischaemic stroke. Cerebrovasc Dis 2007;23:260-266.

364 Bhalla A, Sankaralingam S, Dundas R, Swaminathan R, Wolfe CD, Rudd AG: Influence of raised plasma osmolality on clinical outcome after acute stroke. Stroke 2000;31:2043-2048.

365 Gray CS, Hildreth AJ, Sandercock PA, O'Connell JE, Johnston DE, Cartlidge NE, Bamford JM, James OF, Alberti KG: Glucose-potassium-insulin infusions in the management of post-stroke hyperglycaemia: the UK Glucose Insulin in Stroke Trial (GIST-UK). Lancet Neurol 2007;6:397406.

366 Asplund K, Marke LA, Terent A, Gustafsson $\mathrm{C}$, Wester P: Costs and gains in stroke prevention: European perspective. Cerebrovasc Dis 1993;3(suppl):34-42.

367 Castillo J, Leira R, Garcia MM, Serena J, Blanco M, Davalos A: Blood pressure decrease during the acute phase of ischemic stroke is associated with brain injury and poor stroke outcome. Stroke 2004;35:520526.

368 Leonardi-Bee J, Bath PM, Phillips SJ, Sandercock PA: Blood pressure and clinical outcomes in the International Stroke Trial. Stroke 2002;33:1315-1320.

369 Blood pressure in Acute Stroke Collaboration (BASC): Interventions for deliberately altering blood pressure in acute stroke. Cochrane Database Syst Rev 2001:CD000039.

370 Nazir FS, Overell JR, Bolster A, Hilditch TE, Lees KR: Effect of perindopril on cerebral and renal perfusion on normotensives in mild early ischaemic stroke: a randomized controlled trial. Cerebrovasc Dis 2005; 19:77-83.
371 COSSACS investigators: COSSACS (Continue or Stop post-Stroke Antihypertensives Collaborative Study): rationale and design. J Hypertens 2005;23:455-458.

372 The ENOS Trial Investigators: Glyceryl trinitrate vs. control, and continuing vs. stopping temporarily prior antihypertensive therapy, in acute stroke: rationale and design of the Efficacy of Nitric Oxide in Stroke (ENOS) trial. Int J Stroke 2006;1: 245-249.

373 Grossman E, Messerli FH, Grodzicki T, Kowey P: Should a moratorium be placed on sublingual nifedipine capsules given for hypertensive emergencies and pseudoemergencies? JAMA 1996;276:1328-1331.

$>374$ Kiers L, Davis SM, Larkins R, Hopper J, Tress B, Rossiter SC, Carlin J, Ratnaike S: Stroke topography and outcome in relation to hyperglycaemia and diabetes. J Neurol Neurosurg Psychiatry 1992;55:263-270.

375 van Kooten F, Hoogerbrugge N, Naarding P, Koudstaal PJ: Hyperglycemia in the acute phase of stroke is not caused by stress. Stroke 1993;24:1129-1132.

-376 Baird TA, Parsons MW, Phanh T, Butcher KS, Desmond PM, Tress BM, Colman PG, Chambers BR, Davis SM: Persistent poststroke hyperglycemia is independently associated with infarct expansion and worse clinical outcome. Stroke 2003;34:22082214.

377 Baird TA, Parsons MW, Barber PA, Butcher KS, Desmond PM, Tress BM, Colman PG, Jerums G, Chambers BR, Davis SM: The influence of diabetes mellitus and hyperglycaemia on stroke incidence and outcome. J Clin Neurosci 2002;9:618-626.

378 Parsons MW, Barber PA, Desmond PM, Baird TA, Darby DG, Byrnes G, Tress BM, Davis SM: Acute hyperglycemia adversely affects stroke outcome: a magnetic resonance imaging and spectroscopy study. Ann Neurol 2002;52:20-28.

379 Huff JS: Stroke mimics and chameleons. Emerg Med Clin North Am 2002;20:583595.

380 Fukuda H, Kitani M, Takahashi K: Body temperature correlates with functional outcome and the lesion size of cerebral infarction. Acta Neurol Scand 1999;100:385390.

-381 Reith J, Jorgensen HS, Pedersen PM, Nakayama H, Raaschou HO, Jeppesen LL, Olsen TS: Body temperature in acute stroke: relation to stroke severity, infarct size, mortality, and outcome. Lancet 1996;347:422425.

382 Castillo J, Davalos A, Noya M: Aggravation of acute ischemic stroke by hyperthermia is related to an excitotoxic mechanism. Cerebrovasc Dis 1999;9:22-27.

383 Hajat C, Hajat S, Sharma P: Effects of poststroke pyrexia on stroke outcome: a metaanalysis of studies in patients. Stroke 2000; $31: 410-414$ 
384 Hacke W, Kaste M, Fieschi C, von Kummer R, Davalos A, Meier D, Larrue V, Bluhmki E, Davis S, Donnan G, Scheider D, DiezTejedor E, Trouilas P: Randomised doubleblind placebo-controlled trial of thrombolytic therapy with intravenous alteplase in acute ischaemic stroke (ECASS II). Lancet 1998;352:1245-1251.

- 385 Hacke W, Kaste M, Fieschi C, Toni D, Lesaffre E, von Kummer R, Boysen G, Bluhmki E, Höxter G, Mahagne MH, Hennerici M: Intravenous thrombolysis with recombinant tissue plasminogen activator for acute stroke. JAMA 1995;274:1017-1025.

386 * Wardlaw JM, Zoppo G, Yamaguchi T, Berge E: Thrombolysis for acute ischaemic stroke. Cochrane Database Syst Rev 2003: CD000213.

- 387 * Hacke W, Donnan G, Fieschi C, Kaste M, von Kummer R, Broderick JP, Brott T, Frankel M, Grotta JC, Haley EC Jr, Kwiatkowski T, Levine SR, Lewandowski C, Lu M, Lyden P, Marler JR, Patel S, Tilley BC, Albers G: Association of outcome with early stroke treatment: pooled analysis of ATLANTIS, ECASS, and NINDS rt-PA stroke trials. Lancet 2004;363:768-774.

- 388 Demchuk AM, Hill MD, Barber PA, Silver B, Patel SC, Levine SR: Importance of early ischemic computed tomography changes using ASPECTS in NINDS rtPA Stroke Study. Stroke 2005;36:2110-2115.

-389 Sylaja PN, Cote R, Buchan AM, Hill MD: Thrombolysis in patients older than 80 years with acute ischaemic stroke: Canadian Alteplase for Stroke Effectiveness Study. J Neurol Neurosurg Psychiatry 2006;77: 826-829.

- 390 van Oostenbrugge RJ, Hupperts RM, Lodder J: Thrombolysis for acute stroke with special emphasis on the very old: experience from a single Dutch centre. J Neurol Neurosurg Psychiatry 2006;77:375377.

- 391 Ringleb PA, Schwark C, Köhrmann M, Külkens S, Jüttler E, Hacke W, Schellinger PD: Thrombolytic therapy for acute ischaemic stroke in octogenarians: selection by magnetic resonance imaging improves safety but does not improve outcome. J Neurol Neurosurg Psychiatry 2007;78: 690-693.

- 392 Elkind MS, Prabhakaran S, Pittman J, Koroshetz W, Jacoby M, Johnston KC: Sex as a predictor of outcomes in patients treated with thrombolysis for acute stroke. Neurology 2007;68:842-848.

393 Hill MD, Buchan AM: Thrombolysis for acute ischemic stroke: results of the Canadian Alteplase for Stroke Effectiveness Study (CASES). CMAJ 2005; 172:13071312 .
394 Bateman BT, Schumacher HC, Boden-Albala B, Berman MF, Mohr JP, Sacco RL, Pile-Spellman J: Factors associated with inhospital mortality after administration of thrombolysis in acute ischemic stroke patients: an analysis of the nationwide inpatient sample 1999 to 2002. Stroke 2006;37: $440-446$.

$395 *$ Wahlgren N, Ahmed N, Davalos A, Ford GA, Grond M, Hacke W, Hennerici MG, Kaste M, Külkens S, Larrue V, Lees KR, Roine RO, Soinne L, Toni D, Vanhooren G: Thrombolysis with alteplase for acute ischaemic stroke in the Safe Implementation of Thrombolysis in Stroke-Monitoring Study (SITS-MOST): an observational study. Lancet 2007;369:275-282.

396 Katzan IL, Hammer MD, Furlan AJ, Hixson ED, Nadzam DM: Quality improvement and tissue-type plasminogen activator for acute ischemic stroke: a Cleveland update. Stroke 2003;34:799-800.

397 Graham GD: Tissue plasminogen activator for acute ischemic stroke in clinical practice: a meta-analysis of safety data. Stroke 2003;34:2847-2850.

398 Alexandrov AV, Molina CA, Grotta JC, Garami Z, Ford SR, Alvarez-Sabin J, Montaner J, Saqqur M, Demchuk AM, Moye LA, Hill $\mathrm{MD}$, Wojner AW: Ultrasound-enhanced systemic thrombolysis for acute ischemic stroke. N Engl J Med 2004;351:2170-2178.

399 Molina CA, Ribo M, Rubiera M, Montaner J, Santamarina E, Delgado-Mederos R, Arenillas JF, Huertas R, Purroy F, Delgado P, Alvarez-Sabin J: Microbubble administration accelerates clot lysis during continuous $2-\mathrm{MHz}$ ultrasound monitoring in stroke patients treated with intravenous tissue plasminogen activator. Stroke 2006;37: 425-429.

400 Köhrmann M, Jüttler E, Fiebach JB, Huttner HB, Siebert S, Schwark C, Ringleb PA, Schellinger PD, Hacke W: MRI versus CTbased thrombolysis treatment within and beyond the $3 \mathrm{~h}$ time window after stroke onset: a cohort study. Lancet Neurol 2006; 5:661-667.

401 Schellinger PD, Thomalla G, Fiehler J, Kohrmann M, Molina CA, Neumann-Haefelin T, Ribo M, Singer OC, Zaro-Weber O, Sobesky J: MRI-based and CT-based thrombolytic therapy in acute stroke within and beyond established time windows: an analysis of 1,210 patients. Stroke 2007;38:26402645.

-402 * Lansberg MG, Thijs VN, Bammer R, Kemp S, Wijman CA, Marks MP, Albers GW: Risk factors of symptomatic intracerebral hemorrhage after tPA therapy for acute stroke. Stroke 2007;38:2275-2278

-403 The Multicenter Acute Stroke Trial - Europe Study Group: Thrombolytic therapy with streptokinase in acute ischemic stroke. N Engl J Med 1996;335:145-150.
404 (MAST-I) Group: Randomised controlled trial of streptokinase, aspirin, and combination of both in treatment of acute ischaemic stroke. Multicentre Acute Stroke Trial-Italy. Lancet 1995;346:1509-1514.

$405 *$ Hacke W, Albers G, Al-Rawi Y, Bogousslavsky J, Davalos A, Eliasziw M, Fischer M, Furlan A, Kaste M, Lees KR, Soehngen $\mathrm{M}$, Warach S: The Desmoteplase in Acute Ischemic Stroke Trial (DIAS): a phase II MRI-based 9-hour window acute stroke thrombolysis trial with intravenous desmoteplase. Stroke 2005;36:66-73.

406 * Furlan AJ, Eyding D, Albers GW, Al-Rawi Y, Lees KR, Rowley HA, Sachara C, Soehngen $\mathrm{M}$, Warach S, Hacke W: Dose Escalation of Desmoteplase for Acute Ischemic Stroke (DEDAS): evidence of safety and efficacy 3 to $9 \mathrm{~h}$ after stroke onset. Stroke 2006;37:1227-1231.

-407 Ogawa A, Mori E, Minematsu K, Taki W, Takahashi A, Nemoto S, Miyamoto S, Sasaki M, Inoue T: Randomized trial of intraarterial infusion of urokinase within $6 \mathrm{~h}$ of middle cerebral artery stroke: the middle cerebral artery embolism local fibrinolytic intervention trial (MELT) Japan. Stroke 2007;38:2633-2639.

-408 Nedeltchev K, Fischer U, Arnold M, Ballinari P, Haefeli T, Kappeler L, Brekenfeld C, Remonda L, Schroth G, Mattle HP: Longterm effect of intra-arterial thrombolysis in stroke. Stroke 2006;37:3002-3007.

409 IMS investigators: The Interventional Management of Stroke (IMS) II Study. Stroke 2007;38:2127-2135.

410 Macleod MR, Davis SM, Mitchell PJ, Gerraty RP, Fitt G, Hankey GJ, Stewart-Wynne EG, Rosen D, McNeil JJ, Bladin CF, Chambers BR, Herkes GK, Young D, Donnan GA: Results of a multicentre, randomised controlled trial of intra-arterial urokinase in the treatment of acute posterior circulation ischaemic stroke. Cerebrovasc Dis 2005;20: 12-17.

-411 Brandt T, von Kummer R, Muller Kuppers M, Hacke W: Thrombolytic therapy of acute basilar artery occlusion. Variables affecting recanalization and outcome. Stroke 1996;27:875-881.

412 Hacke W, Zeumer H, Ferbert A, Brückmann H, DelZoppo G: Intraarterial thrombolytic therapy improves outcome in patients with acute vertebrobasilar occlusive disease. Stroke 1988;19:1216-1222.

413 * Lindsberg PJ, Mattle HP: Therapy of basilar artery occlusion: a systematic analysis comparing intra-arterial and intravenous thrombolysis. Stroke 2006;37:922-928.

414 * Smith WS, Sung G, Starkman S, Saver JL, Kidwell CS, Gobin YP, Lutsep HL, Nesbit GM, Grobelny T, Rymer MM, Silverman IE, Higashida RT, Budzik RF, Marks MP: Safety and efficacy of mechanical embolectomy in acute ischemic stroke: results of the MERCI trial. Stroke 2005;36:1432-1438.
ESO Executive Committee and ESO Writing Committee 
-415* International-Stroke-Trial-Collaborative-Group: The International Stroke Trial (IST): a randomised trial if aspirin, subcutaneous heparin, both, or neither among 19,435 patients with acute ischaemic stroke. Lancet 1997;349:1569-1581.

-416 * CAST-Collaborative-Group: CAST: randomised placebo-controlled trial of early aspirin use in 20,000 patients with acute ischeaemic stroke. Lancet 1997;349:16411649.

-417 Rödén-Jüllig A, Britton M, Malmkvist K, Leijd B: Aspirin in the prevention of progressing stroke: a randomized controlled study. J Intern Med 2003;254:584-590.

418 * AbESTT Investigators: Emergency administration of abciximab for treatment of patients with acute ischemic stroke: results of a randomized phase 2 trial. Stroke 2005; 36:880-890.

-419* Adams HP Jr, Effron MB, Torner J, Davalos A, Frayne J, Teal P, Leclerc J, Oemar B, Padgett L, Barnathan ES, Hacke W: Emergency administration of abciximab for treatment of patients with acute ischemic stroke: results of an international phase III trial. Abciximab in Emergency Treatment of Stroke Trial (AbESTT-II). Stroke 2008;39:87-99.

- 420 * Kay R, Wong KS, Yu YL, Chan YW, Tsoi TH, Ahuja AT, Chan FL, Fong KY, Law CB, Wong A, et al: Low-molecular-weight heparin for the treatment of acute ischemic stroke. N Engl J Med 1995;333:1588-1593.

- 421 * Wong KS, Chen C, Ng PW, Tsoi TH, Li HL, Fong WC, Yeung J, Wong CK, Yip KK, Gao H, Wong HB: Low-molecular-weight heparin compared with aspirin for the treatment of acute ischaemic stroke in Asian patients with large artery occlusive disease: a randomised study. Lancet Neurol 2007;6:407-413.

-422* Diener HC, Ringelstein EB, von Kummer $\mathrm{R}$, Langohr HD, Bewermeyer H, Landgraf H, Hennerici M, Welzel D, Grave M, Brom J, Weidinger G: Treatment of acute ischemic stroke with the low-molecular-weight heparin certoparin: results of the TOPAS trial. Therapy of Patients With Acute Stroke (TOPAS) Investigators. Stroke 2001;32:2229.

- 423 * Bath PM, Lindenstrom E, Boysen G, De Deyn P, Friis P, Leys D, Marttila R, Olsson J, O’Neill D, Orgogozo J, Ringelstein B, van der Sande J, Turpie AG: Tinzaparin in acute ischaemic stroke (TAIST): a randomised aspirin-controlled trial. Lancet 2001;358: 702-710.

- 424 * Berge E, Abdelnoor M, Nakstad PH, Sandset PM: Low molecular-weight heparin versus aspirin in patients with acute ischaemic stroke and atrial fibrillation: a double-blind randomised study. HAEST Study Group. Heparin in Acute Embolic Stroke Trial. Lancet 2000;355:1205-1210.
425 * The Publications Committee for the Trial of ORG 10172 in Acute Stroke Treatment (TOAST) Investigators: Low molecular weight heparinoid, ORG 10172 (danaparoid), and outcome after acute ischemic stroke: a randomized controlled trial. JAMA 1998;279:1265-1272.

426 * Gubitz G, Sandercock P, Counsell C: Anticoagulants for acute ischaemic stroke. Cochrane Database Syst Rev 2004: CD000024.

427 Camerlingo M, Salvi P, Belloni G, Gamba T, Cesana BM, Mamoli A: Intravenous heparin started within the first $3 \mathrm{~h}$ after onset of symptoms as a treatment for acute nonlacunar hemispheric cerebral infarctions. Stroke 2005;36:2415-2420.

428 Chamorro A, Busse O, Obach V, Toni D, Sandercock P, Reverter JC, Cervera A, Torres F, Davalos A: The rapid anticoagulation prevents ischemic damage study in acute stroke - final results from the writing committee. Cerebrovasc Dis 2005;19:402-404.

429 Chamorro A: Immediate anticoagulation for acute stroke in atrial fibrillation: yes. Stroke 2006;37:3052-3053.

430 Sandercock P: Immediate anticoagulation for acute stroke in atrial fibrillation: no. Stroke 2006;37:3054-3055.

431 * Paciaroni M, Agnelli G, Micheli S, Caso V: Efficacy and safety of anticoagulant treatment in acute cardioembolic stroke: a metaanalysis of randomized controlled trials Stroke 2007;38:423-430.

432 * Shuaib A, Lees KR, Lyden P, Grotta J, Davalos A, Davis SM, Diener HC, Ashwood T, Wasiewski WW, Emeribe U: NXY-059 for the treatment of acute ischemic stroke. N Engl J Med 2007;357:562-571.

$433{ }^{*}$ Muir KW, Lees KR, Ford I, Davis S: Magnesium for acute stroke (Intravenous Magnesium Efficacy in Stroke trial): randomised controlled trial. Lancet 2004;363: 439-445.

434 Amaro S, Soy D, Obach V, Cervera A, Planas AM, Chamorro A: A pilot study of dual treatment with recombinant tissue plasminogen activator and uric acid in acute ischemic stroke. Stroke 2007;38:21732175.

435 Davalos A, Castillo J, Alvarez-Sabin J, Secades JJ, Mercadal J, Lopez S, Cobo E, Warach S, Sherman D, Clark WM, Lozano $\mathrm{R}$ : Oral citicoline in acute ischemic stroke: an individual patient data pooling analysis of clinical trials. Stroke 2002;33:28502857.

-436 Hacke W, Schwab S, Horn M, Spranger M, De Georgia M, von Kummer R: 'Malignant' middle cerebral artery territory infarction: clinical course and prognostic signs. Arch Neurol 1996;53:309-315.
437 Qureshi AI, Suarez JI, Yahia AM, Mohammad Y, Uzun G, Suri MF, Zaidat OO, Ayata C, Ali Z, Wityk RJ: Timing of neurologic deterioration in massive middle cerebral artery infarction: a multicenter review. Crit Care Med 2003;31:272-277.

438 Unterberg AW, Kiening KL, Hartl R, Bardt T, Sarrafzadeh AS, Lanksch WR: Multimodal monitoring in patients with head injury: evaluation of the effects of treatment on cerebral oxygenation. J Trauma 1997;42: S32-S37.

439 Righetti E, Celani MG, Cantisani TA, Sterzi R, Boysen G, Ricci S: Glycerol for acute stroke: a Cochrane systematic review. J Neurol 2002;249:445-451.

440 Bereczki D, Liu M, do Prado GF, Fekete I: Mannitol for acute stroke. Cochrane Database Syst Rev 2001:CD001153.

441 Schwarz S, Georgiadis D, Aschoff A, Schwab S: Effects of hypertonic (10\%) saline in patients with raised intracranial pressure after stroke. Stroke 2002;33:136-140.

$442{ }^{*}$ Qizilbash N, Lewington SL, Lopez-Arrieta JM: Corticosteroids for acute ischaemic stroke. Cochrane Database Syst Rev 2002: CD000064.

-443 Schwab S, Schwarz S, Spranger M, Keller E, Bertram M, Hacke W: Moderate hypothermia in the treatment of patients with severe middle cerebral artery infarction. Stroke 1998;29:2461-2466.

-444 Steiner T, Ringleb P, Hacke W: Treatment options for large hemispheric stroke. Neurology 2001;57:S61-S68.

- 445 Els T, Oehm E, Voigt S, Klisch J, Hetzel A, Kassubek J: Safety and therapeutical benefit of hemicraniectomy combined with mild hypothermia in comparison with hemicraniectomy alone in patients with malignant ischemic stroke. Cerebrovasc Dis 2006;21:79-85.

446 * Vahedi K, Hofmeijer J, Jüttler E, Vicaut E, George B, Algra A, Amelink GJ, Schmiedeck P, Schwab S, Rothwell PM, Bousser MG, van der Worp HB, Hacke W: Early decompressive surgery in malignant infarction of the middle cerebral artery: a pooled analysis of three randomised controlled trials. Lancet Neurol 2007;6:215-222.

447 Jüttler E, Schwab S, Schmiedek P, Unterberg A, Hennerici M, Woitzik J, Witte S, Jenetzky E, Hacke W: Decompressive Surgery for the Treatment of Malignant Infarction of the Middle Cerebral Artery (DESTINY): a randomized, controlled trial. Stroke 2007; 38:2518-2525

448 Gupta R, Connolly ES, Mayer S, Elkind MS: Hemicraniectomy for massive middle cerebral artery territory infarction: a systematic review. Stroke 2004;35:539-543.

- 449 Weimar C, Roth MP, Zillessen G, Glahn J, Wimmer ML, Busse O, Haberl RL, Diener HC: Complications following acute ischemic stroke. Eur Neurol 2002;48:133-140. 
-450 Horner J, Massey EW, Riski JE, Lathrop $\mathrm{DL}$, Chase $\mathrm{KN}$ : Aspiration following stroke: clinical correlates and outcome. Neurology 1988;38:1359-1362.

-451 Prass K, Meisel C, Höflich C, Braun J, Halle E, Wolf T, Ruscher K, Victorov IV, Priller J, Dirnagl U, Volk HD, Meisel A: Stroke-induced immunodeficiency promotes spontaneous bacterial infections and is mediated by sympathetic activation reversal by poststroke T helper cell type 1-like immunostimulation. J Exp Med 2003;198:725736.

452 Chamorro A, Amaro S, Vargas M, Obach V, Cervera A, Torres F, Planas AM: Interleukin 10, monocytes and increased risk of early infection in ischaemic stroke. J Neurol Neurosurg Psychiatry 2006;77:1279-1281.

-453 Chamorro A, Horcajada JP, Obach V, Vargas M, Revilla M, Torres F, Cervera A, Planas AM, Mensa J: The Early Systemic Prophylaxis of Infection After Stroke study: a randomized clinical trial. Stroke 2005;36: 1495-1500.

$454{ }^{*}$ Mazzone C, Chiodo GF, Sandercock P, Miccio M, Salvi R: Physical methods for preventing deep vein thrombosis in stroke. Cochrane Database Syst Rev 2004: CD001922.

-455 Kamphuisen PW, Agnelli G, Sebastianelli M: Prevention of venous thromboembolism after acute ischemic stroke. J Thromb Haemost 2005;3:1187-1194.

- 456 * Diener HC, Ringelstein EB, von Kummer R, Landgraf H, Koppenhagen K, Harenberg J, Rektor I, Csanyi A, Schneider D, Klingelhofer J, Brom J, Weidinger G: Prophylaxis of thrombotic and embolic events in acute ischemic stroke with the low-molecularweight heparin certoparin: results of the PROTECT Trial. Stroke 2006;37:139-144.

-457 * Sherman DG, Albers GW, Bladin C, Fieschi C, Gabbai AA, Kase CS, O'Riordan W, Pineo GF: The efficacy and safety of enoxaparin versus unfractionated heparin for the prevention of venous thromboembolism after acute ischaemic stroke (PREVAIL Study): an open-label randomised comparison. Lancet 2007;369:1347-1355.

-458 Reddy M, Gill SS, Rochon PA: Preventing pressure ulcers: a systematic review. JAMA 2006;296:974-984.

-459 Forster A, Young J: Incidence and consequences of falls due to stroke: a systematic inquiry. BMJ 1995;311:83-86.

460 Mackintosh SF, Goldie P, Hill K: Falls incidence and factors associated with falling in older, community-dwelling, chronic stroke survivors ( $>1$ year after stroke) and matched controls. Aging Clin Exp Res 2005;17:7481.

461 Mackintosh SF, Hill KD, Dodd KJ, Goldie PA, Culham EG: Balance score and a history of falls in hospital predict recurrent falls in the 6 months following stroke rehabilitation. Arch Phys Med Rehabil 2006;87: 1583-1589.
462 Lamb SE, Ferrucci L, Volapto S, Fried LP, Guralnik JM: Risk factors for falling in home-dwelling older women with stroke: the Women's Health and Aging Study. Stroke 2003;34:494-501.

463 Aizen E, Shugaev I, Lenger R: Risk factors and characteristics of falls during inpatient rehabilitation of elderly patients. Arch Gerontol Geriatr 2007;44:1-12.

464 Teasell R, McRae M, Foley N, Bhardwaj A: The incidence and consequences of falls in stroke patients during inpatient rehabilitation: factors associated with high risk. Arch Phys Med Rehabil 2002;83:329-333.

465 Vassallo M, Vignaraja R, Sharma JC, Hallam H, Binns K, Briggs R, Ross I, Allen S: The effect of changing practice on fall prevention in a rehabilitative hospital: the Hospital Injury Prevention Study. J Am Geriatr Soc 2004:52:335-339.

466 Oliver D, Connelly JB, Victor CR, Shaw FE, Whitehead A, Genc Y, Vanoli A, Martin FC, Gosney MA: Strategies to prevent falls and fractures in hospitals and care homes and effect of cognitive impairment: systematic review and meta-analyses. BMJ 2007;334: 82.

467 Ramnemark A, Nyberg L, Borssen B, Olsson T, Gustafson Y: Fractures after stroke. Osteoporos Int 1998;8:92-95.

468 Ramnemark A, Nilsson M, Borssen B, Gustafson Y: Stroke, a major and increasing risk factor for femoral neck fracture. Stroke 2000;31:1572-1577.

469 * Pang MY, Eng JJ, Dawson AS, Gylfadottir S: The use of aerobic exercise training in improving aerobic capacity in individuals with stroke: a meta-analysis. Clin Rehabil 2006;20:97-111.

470 Sato Y, Iwamoto J, Kanoko T, Satoh K: Lowdose vitamin $\mathrm{D}$ prevents muscular atrophy and reduces falls and hip fractures in women after stroke: a randomized controlled trial. Cerebrovasc Dis 2005;20:187-192.

471 Sato Y, Asoh T, Kaji M, Oizumi K: Beneficial effect of intermittent cyclical etidronate therapy in hemiplegic patients following an acute stroke. J Bone Miner Res 2000; 15:2487-2494.

472 Parker MJ, Gillespie LD, Gillespie WJ: Hip protectors for preventing hip fractures in the elderly. Cochrane Database Syst Rev 2001:CD001255.

473 Gerberding JL: Hospital-onset infections: a patient safety issue. Ann Intern Med 2002; 137:665-670.

474 Thomas L, Cross S, Barrett J, French B, Leathley M, Sutton C, Watkins C: Treatment of urinary incontinence after stroke in adults. Cochrane Database Syst Rev 2008:CD004462.

475 Jorgensen L, Engstad T, Jacobsen BK: Selfreported urinary incontinence in noninstitutionalized long-term stroke survivors: A population-based study. Arch Phys Med Rehabil 2005;86:416-420.
476 Thomas LH, Barrett J, Cross S, French B, Leathley M, Sutton C, Watkins C: Prevention and treatment of urinary incontinence after stroke in adults. Cochrane Database Syst Rev 2005:CD004462.

477 Meijer R, Ihnenfeldt DS, de Groot IJ, van Limbeek J, Vermeulen M, de Haan RJ: Prognostic factors for ambulation and activities of daily living in the subacute phase after stroke. A systematic review of the literature. Clin Rehabil 2003;17:119-129.

478 Dumoulin C, Korner-Bitensky N, Tannenbaum C: Urinary incontinence after stroke: does rehabilitation make a difference? A systematic review of the effectiveness of behavioral therapy. Top Stroke Rehabil 2005; 12:66-76.

479 Martino R, Foley N, Bhogal S, Diamant N, Speechley M, Teasell R: Dysphagia after stroke: incidence, diagnosis, and pulmonary complications. Stroke 2005;36:27562763.

480 Mann G, Hankey GJ, Cameron D: Swallowing function after stroke: prognosis and prognostic factors at 6 months. Stroke 1999; 30:744-748

-481 Dennis MS, Lewis SC, Warlow C: Routine oral nutritional supplementation for stroke patients in hospital (FOOD): a multicentre randomised controlled trial. Lancet 2005; 365:755-763.

482 Axelsson K, Asplund K, Norberg A, Alafuzoff I: Nutritional status in patients with acute stroke. Acta Med Scand 1988;224: 217-224.

-483 Axelsson K, Asplund K, Norberg A, Eriksson S: Eating problems and nutritional status during hospital stay of patients with severe stroke. J Am Diet Assoc 1989;89: 1092-1096.

484 Finestone HM, Greene-Finestone LS, Wilson ES, Teasell RW: Malnutrition in stroke patients on the rehabilitation service and at follow-up: prevalence and predictors. Arch Phys Med Rehabil 1995;76:310-316.

485 Finestone HM, Greene-Finestone LS, Wilson ES, Teasell RW: Prolonged length of stay and reduced functional improvement rate in malnourished stroke rehabilitation patients. Arch Phys Med Rehabil 1996;77: 340-345.

486 Dávalos A, Ricart W, Gonzalez-Huix F, Soler S, Marrugat J, Molins A, Suner R, Genis D: Effect of malnutrition after acute stroke on clinical outcome. Stroke 1996;27:10281032 .

487 Food trial collaboration: Poor nutritional status on admission predicts poor outcomes after stroke: observational data from the FOOD trial. Stroke 2003;34:14501456 .

488 * Dennis MS, Lewis SC, Warlow C: Effect of timing and method of enteral tube feeding for dysphagic stroke patients (FOOD): a multicentre randomised controlled trial. Lancet 2005;365:764-772.
ESO Executive Committee and ESO Writing Committee 
-489 Norton B, Homer-Ward M, Donnelly MT, Long RG, Holmes GK: A randomised prospective comparison of percutaneous endoscopic gastrostomy and nasogastric tube feeding after acute dysphagic stroke. BMJ 1996;312:13-16.

490 Hamidon BB, Abdullah SA, Zawawi MF, Sukumar N, Aminuddin A, Raymond AA: A prospective comparison of percutaneous endoscopic gastrostomy and nasogastric tube feeding in patients with acute dysphagic stroke. Med J Malaysia 2006;61:5966.

-491 Callahan CM, Haag KM, Weinberger M, Tierney WM, Buchanan NN, Stump TE, Nisi R: Outcomes of percutaneous endoscopic gastrostomy among older adults in a community setting. J Am Geriatr Soc 2000; 48:1048-1054.

492 Rickman J: Percutaneous endoscopic gastrostomy: psychological effects. Br J Nurs 1998;7:723-729.

493 WHO: International Classification of Functioning Disability and Health. Geneva, World Health Organisation, 2001.

494 Langhorne P, Dennis MS: Stroke Units, an Evidence Based Approach. London, BMJ Publishing Group, 1998.

-495 Lincoln NB, Husbands S, Trescoli C, Drummond AE, Gladman JR, Berman P: Fiveyear follow-up of a randomised controlled trial of a stroke rehabilitation unit. BMJ 2000;320:549.

-496 Indredavik B, Slordahl SA, Bakke F, Rokseth R, Haheim LL: Stroke unit treatment. Long-term effects. Stroke 1997;28:18611866.

497 Early Supported Discharge Trialists: Services for reducing duration of hospital care for acute stroke patients. Cochrane Database Syst Rev 2005:CD000443.

498 Langhorne P, Taylor G, Murray G, Dennis M, Anderson C, Bautz-Holter E, Dey P, Indredavik B, Mayo N, Power M, Rodgers H, Ronning OM, Rudd A, Suwanwela N, Widen-Holmqvist L, Wolfe C: Early supported discharge services for stroke patients: a meta-analysis of individual patients' data. Lancet 2005;365:501-506.

499 Ronning OM, Guldvog B: Outcome of subacute stroke rehabilitation: a randomized controlled trial. Stroke 1998;29:779-784.

500 * Legg L, Langhorne P: Rehabilitation therapy services for stroke patients living at home: systematic review of randomised trials. Lancet 2004;363:352-356.

-501 Baron JC, Cohen LG, Cramer SC, Dobkin $\mathrm{BH}$, Johansen-Berg H, Loubinoux I, Marshall RS, Ward NS: Neuroimaging in stroke recovery: a position paper from the First International Workshop on Neuroimaging and Stroke Recovery. Cerebrovasc Dis 2004;18:260-267.
502 Barbay S, Plautz E, Friel K, Frost F, Stowe A, Dancause N, Wang H, Nudo R: Delayed rehabilitative training following a small ischaemic infarct in non-human primate primary cortex. Soc Neurosci Abstr 2001;27: 931-934.

503 Biernaskie J, Chernenko G, Corbett D: Efficacy of rehabilitative experience declines with time after focal ischemic brain injury. J Neurosci 2004;24:1245-1254.

504 Paolucci S, Antonucci G, Grasso MG, Morelli D, Troisi E, Coiro P, Bragoni M: Early versus delayed inpatient stroke rehabilitation: a matched comparison conducted in Italy. Arch Phys Med Rehabil 2000;81:695700.

505 Salter K, Jutai J, Hartley M, Foley N, Bhogal $\mathrm{S}$, Bayona N, Teasell R: Impact of early vs delayed admission to rehabilitation on functional outcomes in persons with stroke. J Rehabil Med 2006;38:113-117.

506 Langhorne P, Stott DJ, Robertson L, MacDonald J, Jones L, McAlpine C, Dick F, Taylor GS, Murray G: Medical complications after stroke: a multicenter study. Stroke 2000;31:1223-1229.

507 Diserens K, Michel P, Bogousslavsky J: Early mobilisation after stroke: review of the literature. Cerebrovasc Dis 2006;22:183-190.

508 Bernhardt J, Dewey H, Thrift A, Donnan G: Inactive and alone: physical activity within the first 14 days of acute stroke unit care. Stroke 2004;35:1005-1009.

509 * Aziz N, Leonardi-Bee J, Walker M, Phillips M, Gladman J, Legg L: Therapy based rehabilitation services for patients living at home more than one year after stroke. Cochrane Database Syst Rev 2008:CD005952.

510 * Kwakkel G, van Peppen R, Wagenaar RC, Wood Dauphinee S, Richards C, Ashburn A, Miller K, Lincoln N, Partridge C, Wellwood I, Langhorne P: Effects of augmented exercise therapy time after stroke: a metaanalysis. Stroke 2004;35:2529-2539.

511 * Langhorne P, Wagenaar R, Partridge C: Physiotherapy after stroke: more is better? Physiother Res Int 1996;1:75-88.

512 * van der Lee JH, Snels IA, Beckerman H, Lankhorst GJ, Wagenaar RC, Bouter LM: Exercise therapy for arm function in stroke patients: a systematic review of randomized controlled trials. Clin Rehabil 2001;15:2031.

513 Evans A, Perez I, Harraf F, Melbourn A, Steadman J, Donaldson N, Kalra L: Can differences in management processes explain different outcomes between stroke unit and stroke-team care? Lancet 2001;358:15861592.

514 Kalra L, Dale P, Crome P: Improving stroke rehabilitation. A controlled study. Stroke 1993;24:1462-1467.

515 * Stroke Unit Trialists' Collaboration: How do stroke units improve patient outcomes? A collaborative systematic review of the randomized trials. Stroke Unit Trialists Collaboration. Stroke 1997;28:2139-2144.
516 * van Peppen RP, Kwakkel G, Wood-Dauphinee S, Hendriks HJ, Van der Wees PJ, Dekker J: The impact of physical therapy on functional outcomes after stroke: what's the evidence? Clin Rehabil 2004;18:833862 .

517 * Pollock A, Baer G, Langhorne P, Pomeroy V: Physiotherapy treatment approaches for the recovery of postural control and lower limb function following stroke: a systematic review. Clin Rehabil 2007;21:395-410.

518 * Pomeroy VM, King LM, Pollock A, BailyHallam A, Langhorne P: Electrostimulation for promoting recovery of movement or functional ability after stroke. Systematic review and meta-analysis. Stroke 2006; 37:2441-2442.

519 * Moseley AM, Stark A, Cameron ID, Pollock A: Treadmill training and body weight support for walking after stroke. Cochrane Database Syst Rev 2005:CD002840.

520 Mehrholz J, Werner C, Kugler J, Pohl M: Electromechanical-assisted training for walking after stroke. Cochrane Database Syst Rev 2007:CD006185.

521 de Wit DC, Buurke JH, Nijlant JM, Ijzerman MJ, Hermens HJ: The effect of an ankle-foot orthosis on walking ability in chronic stroke patients: a randomized controlled trial. Clin Rehabil 2004;18:550557.

522 Gordon NF, Gulanick M, Costa F, Fletcher G, Franklin BA, Roth EJ, Shephard T: Physical activity and exercise recommendations for stroke survivors: an American Heart Association scientific statement from the Council on Clinical Cardiology, Subcommittee on Exercise, Cardiac Rehabilitation, and Prevention; the Council on Cardiovascular Nursing; the Council on Nutrition, Physical Activity, and Metabolism, and the Stroke Council. Stroke 2004;35:12301240.

-523 Wolf SL, Winstein CJ, Miller JP, Taub E, Uswatte G, Morris D, Giuliani C, Light KE, Nichols-Larsen D: Effect of constraint-induced movement therapy on upper extremity function 3 to 9 months after stroke: the EXCITE randomized clinical trial. JAMA 2006;296:2095-2104.

$524{ }^{*}$ Legg LA, Drummond AE, Langhorne P: Occupational therapy for patients with problems in activities of daily living after stroke. Cochrane Database Syst Rev 2006: CD003585.

525 * Walker M, Leonardi-Bee J, Bath P, Langhorne P, Dewey M, Corr S, Drummond A, Gilbertson L, Gladman J, Jongbloed L, Logan $\mathrm{P}$, Parker C: Individual patient data meta-analysis of randomised controlled trials of community occupational therapy for stroke patients. Stroke 2004;35:22262232 . 
-526 Sackley C, Wade DT, Mant D, Atkinson JC, Yudkin P, Cardoso K, Levin S, Lee VB, Reel $\mathrm{K}$ : Cluster randomized pilot controlled trial of an occupational therapy intervention for residents with stroke in UK care homes. Stroke 2006;37:2336-2341.

527 Bath PM, Bath-Hextall FJ, Smithard DG: Interventions for dysphagia in acute stroke. Cochrane Database Syst Rev 2000: CD000323.

- 528 DePippo KL, Holas MA, Reding MJ, Mandel FS, Lesser ML: Dysphagia therapy following stroke: a controlled trial. Neurology 1994:44:1655-1660.

-529 Engelter ST, Gostynski M, Papa S, Frei M, Born C, Ajdacic-Gross V, Gutzwiller F, Lyrer PA: Epidemiology of aphasia attributable to first ischemic stroke: incidence, severity, fluency, etiology, and thrombolysis. Stroke 2006;37:1379-1384

530 * Sellars C, Hughes T, Langhorne P: Speech and language therapy for dysarthria due to non-progressive brain damage. Cochrane Database Syst Rev 2005:CD002088.

$531{ }^{*}$ Greener J, Enderby P, Whurr R: Speech and language therapy for aphasia following stroke. Cochrane Database Syst Rev 2000: CD000425.

532 Robey RR: The efficacy of treatment for aphasic persons: a meta-analysis. Brain Lang 1994;47:582-608.

533 Robey RR: A meta-analysis of clinical outcomes in the treatment of aphasia. J Speech Lang Hear Res 1998;41:172-187.

-534 Pulvermuller F, Neininger B, Elbert T, Mohr B, Rockstroh B, Koebbel P, Taub E: Constraint-induced therapy of chronic aphasia after stroke. Stroke 2001;32:16211626.

- 535 Bhogal SK, Teasell R, Speechley M: Intensity of aphasia therapy, impact on recovery. Stroke 2003;34:987-993.

-536 * Stroke Liaison Workers Collaboration: Meta-analysis of stroke liaison workers for patients and carers: results by intervention characteristic. Cerebrovasc Dis 2006;21: 120.

- 537 O’Mahony PG, Rodgers H, Thomson RG, Dobson R, James OF: Satisfaction with information and advice received by stroke patients. Clin Rehabil 1997;11:68-72.

538 * Forster A, Young J, Langhorne P: Medical day hospital care for the elderly versus alternative forms of care. Cochrane Database Syst Rev 2000:CD001730.

-539 Kalra L, Evans A, Perez I, Melbourn A, Patel A, Knapp M, Donaldson N: Training carers of stroke patients: randomised controlled trial. BMJ 2004;328:1099.

540 Johansson BB: Brain plasticity and stroke rehabilitation. The Willis lecture. Stroke 2000;31:223-230.

541 Nair RD, Lincoln NB: Cognitive rehabilitation for memory deficits following stroke. Cochrane Database Syst Rev 2007: CD002293.
542 Lincoln NB, Majid MJ, Weyman N: Cognitive rehabilitation for attention deficits following stroke. Cochrane Database Syst Rev 2000:CD002842.

543 Bowen A, Lincoln NB: Cognitive rehabilitation for spatial neglect following stroke. Cochrane Database Syst Rev 2007: CD003586.

544 Cicerone KD, Dahlberg C, Malec JF, Langenbahn DM, Felicetti T, Kneipp S, Ellmo W, Kalmar K, Giacino JT, Harley JP, Laatsch L, Morse PA, Catanese J: Evidence-based cognitive rehabilitation: updated review of the literature from 1998 through 2002. Arch Phys Med Rehabil 2005;86:16811692.

545 Marinkovic S, Badlani G: Voiding and sexual dysfunction after cerebrovascular accidents. J Urol 2001;165:359-370.

546 Sjogren K, Fugl-Meyer AR: Adjustment to life after stroke with special reference to sexual intercourse and leisure. J Psychosom Res 1982;26:409-417.

547 Muller JE: Triggering of cardiac events by sexual activity: findings from a case-crossover analysis. Am J Cardiol 2000;86:14F$18 \mathrm{~F}$.

548 McLean DE: Medical complications experienced by a cohort of stroke survivors during inpatient, tertiary-level stroke rehabilitation. Arch Phys Med Rehabil 2004;85: 466-469.

549 Paolucci S, Antonucci G, Pratesi L, Traballesi M, Lubich S, Grasso MG: Functional outcome in stroke inpatient rehabilitation: predicting no, low and high response patients. Cerebrovasc Dis 1998;8:228-234.

550 Hackett ML, Anderson CS: Predictors of depression after stroke: a systematic review of observational studies. Stroke 2005;36: 2296-2301.

551 Paolucci S, Gandolfo C, Provinciali L, Torta $\mathrm{R}$, Toso V: The Italian multicenter observational study on post-stroke depression (DESTRO). J Neurol 2006;253:556-562.

552 Linden T, Blomstrand C, Skoog I: Depressive disorders after 20 months in elderly stroke patients: a case-control study. Stroke 2007;38:1860-1863.

553 Thomas SA, Lincoln NB: Factors relating to depression after stroke. Br J Clin Psychol 2006;45:49-61.

554 Kauhanen M, Korpelainen JT, Hiltunen P, Brusin E, Mononen H, Maatta R, Nieminen P, Sotaniemi KA, Myllyla VV: Poststroke depression correlates with cognitive impairment and neurological deficits. Stroke 1999;30:1875-1880.

-555*van de Meent H, Geurts AC, Van Limbeek J: Pharmacologic treatment of poststroke depression: a systematic review of the literature. Top Stroke Rehabil 2003;10:7992.

556 * Hackett ML, Anderson CS, House AO: Management of depression after stroke: a systematic review of pharmacological therapies. Stroke 2005;36:1098-1103.
557 * Bhogal SK, Teasell R, Foley N, Speechley M: Heterocyclics and selective serotonin reuptake inhibitors in the treatment and prevention of poststroke depression. J Am Geriatr Soc 2005;53:1051-1057.

558 * Anderson CS, Hackett ML, House AO: Interventions for preventing depression after stroke. Cochrane Database Syst Rev 2004:CD003689.

$559{ }^{*}$ House AO, Hackett ML, Anderson CS, Horrocks JA: Pharmaceutical interventions for emotionalism after stroke. Cochrane Database Syst Rev 2004:CD003690.

560 Lindgren I, Jonsson AC, Norrving B, Lindgren A: Shoulder pain after stroke: a prospective population-based study. Stroke 2007;38:343-348.

561 Vuagnat $\mathrm{H}$, Chantraine A: Shoulder pain in hemiplegia revisited: contribution of functional electrical stimulation and other therapies. J Rehabil Med 2003;35:49-54; quiz 56.

562 * Price CI, Pandyan AD: Electrical stimulation for preventing and treating post-stroke shoulder pain: a systematic Cochrane review. Clin Rehabil 2001;15:5-19.

563 Ada L, Foongchomcheay A, Canning C: Supportive devices for preventing and treating subluxation of the shoulder after stroke. Cochrane Database Syst Rev 2005: CD003863.

564 * Wiffen P, Collins S, McQuay H, Carroll D, Jadad A, Moore A: Anticonvulsant drugs for acute and chronic pain. Cochrane Database Syst Rev 2005:CD001133.

565 * Satkunam LE: Rehabilitation medicine. 3. Management of adult spasticity. CMAJ 2003;169:1173-1179.

566 Lannin NA, Herbert RD: Is hand splinting effective for adults following stroke? A systematic review and methodologic critique of published research. Clin Rehabil 2003; 17:807-816.

567 Brashear A, Gordon MF, Elovic E, Kassicieh VD, Marciniak C, Do M, Lee CH, Jenkins S, Turkel C: Intramuscular injection of botulinum toxin for the treatment of wrist and finger spasticity after a stroke. $\mathrm{N}$ Engl J Med 2002;347:395-400.

568 van Kuijk AA, Geurts AC, Bevaart BJ, van Limbeek J: Treatment of upper extremity spasticity in stroke patients by focal neuronal or neuromuscular blockade: a systematic review of the literature. J Rehabil Med 2002;34:51-61.

569 Pittock SJ, Moore AP, Hardiman O, Ehler E, Kovac M, Bojakowski J, Al Khawaja I, Brozman M, Kanovsky P, Skorometz A, Slawek J, Reichel G, Stenner A, Timerbaeva S, Stelmasiak Z, Zifko UA, Bhakta B, Coxon E: A double-blind randomised placebocontrolled evaluation of three doses of botulinum toxin type A (Dysport) in the treatment of spastic equinovarus deformity after stroke. Cerebrovasc Dis 2003;15:289300 .
ESO Executive Committee and ESO Writing Committee 
570 Meythaler JM, Guin-Renfroe S, Johnson A, Brunner RM: Prospective assessment of tizanidine for spasticity due to acquired brain injury. Arch Phys Med Rehabil 2001; 82:1155-1163.

571 Shah S, Vanclay F, Cooper B: Efficiency, effectiveness, and duration of stroke rehabilitation. Stroke 1990;21:241-246.

-572 Wyller TB, Sodring KM, Sveen U, Ljunggren AE, Bautz-Holter E: Are there gender differences in functional outcome after stroke? Clin Rehabil 1997;11:171-179.

573 Chae J, Zorowitz RD, Johnston MV: Functional outcome of hemorrhagic and nonhemorrhagic stroke patients after in-patient rehabilitation. Am J Phys Med Rehabil 1996;75:177-182.

574 Falconer JA, Naughton BJ, Strasser DC, Sinacore JM: Stroke inpatient rehabilitation: a comparison across age groups. J Am Geriatr Soc 1994;42:39-44.
575 Katz N, Hartman-Maeir A, Ring H, Soroker N: Functional disability and rehabilitation outcome in right hemisphere damaged patients with and without unilateral spatial neglect. Arch Phys Med Rehabil 1999;80: 379-384.

576 Ween JE, Alexander MP, D’Esposito M, Roberts M: Factors predictive of stroke outcome in a rehabilitation setting. Neurology 1996;47:388-392.

577 Gladman JR, Sackley CM: The scope for rehabilitation in severely disabled stroke patients. Disabil Rehabil 1998;20:391-394.

578 Rodgers H: The scope for rehabilitation in severely disabled stroke patients. Disabil Rehabil 2000;22:199-200; discussion, 205.

579 van Peppen RP, Hendriks HJ, van Meeteren NL, Helders PJ, Kwakkel G: The development of a clinical practice stroke guideline for physiotherapists in The Netherlands: a systematic review of available evidence. Disabil Rehabil 2007;29:767-783.
580 Kalra L, Eade J: Role of stroke rehabilitation units in managing severe disability after stroke. Stroke 1995;26:2031-2034.

581 Schmidt J, Drew-Cates J, Dombovy M: Severe disability after stroke: outcome after inpatient rehabilitation. Neurorehab Neural Repair 1999;13:199-203.

582 Brainin M, Barnes M, Baron JC, Gilhus NE, Hughes R, Selmaj K, Waldemar G: Guidance for the preparation of neurological management guidelines by EFNS scientific task forces - revised recommendations 2004. Eur J Neurol 2004;11:577-581.

583 Hankey GJ, Warlow CP: Treatment and secondary prevention of stroke: evidence, costs, and effects on individuals and populations. Lancet 1999;354:1457-1463.

584 Ringleb PA, Hacke W: Stent and surgery for symptomatic carotid stenosis. SPACE study results (in German). Nervenarzt 2007;78: 1130-1137. 